UNIVERSIDADE DE SÃO PAULO

ESCOLA DE ENFERMAGEM

RAMON ANTÔNIO OLIVEIRA

FATORES DE RISCO PARA INFECÇÃO DO SÍTIO CIRÚRGICO EM TRANSPLANTE DE FÍGADO: COORTE HISTÓRICA

SÃO PAULO

2016 


\section{RAMON ANTÔNIO OLIVEIRA}

\section{FATORES DE RISCO PARA INFECÇÃO DO SÍTIO CIRÚRGICO EM TRANSPLANTE DE FÍGADO: COORTE HISTÓRICA}

Dissertação apresentada ao Programa de Pós-graduação em Enfermagem na Saúde do Adulto da Escola de Enfermagem da Universidade de São Paulo para obtenção do título de Mestre em Ciências.

Orientadora: Prof. ${ }^{\text {a }}$ Dr. ${ }^{\text {a }}$ Vanessa de Brito Poveda.

Área de Concentração: Enfermagem na Saúde do Adulto.

São Paulo

2016 
AUTORIZO A REPRODUÇÃO E DIVULGAÇÃO TOTAL OU PARCIAL DESTE TRABALHO, POR QUALQUER MEIO CONVENCIONAL OU ELETRÔNICO, PARA FINS DE ESTUDO E PESQUISA, DESDE QUE CITADA A FONTE.

Assinatura:

Data:

\section{Catalogação na Publicação (CIP) \\ Biblioteca "Wanda de Aguiar Horta" \\ Escola de Enfermagem da Universidade de São Paulo}

Oliveira, Ramon Antônio

Fatores de risco para infecção do sítio cirúrgico em transplante de fígado: Coorte Histórica / Ramon Antônio Oliveira. São Paulo, 2016.

$121 \mathrm{p}$.

Dissertação (Mestrado) - Escola de Enfermagem da Universidade de São Paulo.

Orientador: Prof. ${ }^{\text {a }}$ Dr. ${ }^{\text {a }}$ Vanessa de Brito Poveda

Área de concentração: Enfermagem na Saúde do Adulto

1. Infecção da ferida operatória. 2. Transplante de fígado. 3. Enfermagem. I. Título. 
Nome: Ramon Antônio Oliveira

Título: Fatores de risco para infecção do sítio cirúrgico em transplante de fígado: coorte histórica.

Aprovado em:

Banca Examinadora

Prof. ${ }^{\underline{a}}$ Dr..$^{-}$: Instituição:

Julgamento: Assinatura:

Prof. ${ }^{\mathrm{a}} \mathrm{Dr} . \underline{\mathrm{a}}$ : Instituição:

Julgamento: Assinatura:

Prof. ${ }^{\underline{a}}$ Dr. ${ }^{-}$: Instituição: Julgamento: Assinatura: 


\section{DEDICATÓRIA}

Aos meus pais Fátima e Antônio Carlos de Oliveira (in memoriam), sem vocês não teria chegado até aqui.

Ao João Noronha, meu companheiro, pelo apoio e por acreditar nesse sonho.

Aos meus irmãos Claucio e Lilian, vocês são parte de tudo isso, meu exemplo de luta, persistência e carinho.

Ao meu sobrinho Pietro, por existir em nossas vidas e torná-las ricas em significado.

Aos meus cunhados Roseane Rodrigues e Geraldo Machado, pelo apoio.

Aos queridos amigos Maiara e Lucas, pelo carinho. 


\section{AGRADECIMENTOS}

\section{A Deus.}

À Prof.. Dr.. Vanessa de Brito Poveda, por me receber no grupo de Pesquisas, mais tarde aceitar me orientar, pelos ensinamentos e por todo o cuidado na condução deste estudo; nos momentos de maior angústia, você foi o apoio necessário para continuar.

À Prof. ${ }^{a}$ Dr. ${ }^{\text {a }}$ Ruth Natália Teresa Turrini, por me receber no grupo de Pesquisas, compor a banca do Exame de Qualificação e pelas importantes contribuições feitas ao longo da realização deste trabalho.

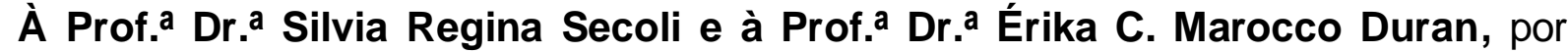
participarem do Exame de Qualificação e pelas valiosas observações feitas ao projeto.

À querida amiga que o Mestrado me trouxe, Juliana Chaves Coelho, por muitos momentos de intenso aprendizado compartilhados, por me ouvir nos diversos momentos de angústia e por participar da construção desta pesquisa.

À Prof. ${ }^{a}$ Dr. ${ }^{a}$ Heloísa Garcia Claro e MSc. Rosana Ribeiro Tarifa, por participarem do primeiro passo para a concretização deste sonho.

À Prof.'- Dr.. Sônia Paiva, pela amizade, pelo respeito e por cuidar da amizade construída desde a Graduação em Poços de Caldas.

À querida amiga Ivanyse Pereira (Ivy), pelo exemplo no exercício da Enfermagem, pela convivência enriquecedora e por compartilhar sonhos.

Aos membros da banca de defesa, pela disponibilidade e pela valorosa contribuição para esta investigação.

Aos pacientes transplantados, ao hospital e equipe médica, por autorizarem o acesso aos prontuários para a elaboração desta investigação.

À enfermeira Dalila Faria, à secretária Letícia Araújo e aos colaboradores do Serviço de Arquivo Médico e Estatístico, pela preciosa colaboração na etapa de coleta de dados.

À Escola de Enfermagem da Universidade de São Paulo.

À Fundação CAPES, pela concessão de bolsa para a realização do curso de Mestrado. 
"All our dreams can come true, if we have the courage to pursue them" Walt E. Disney 
OLIVEIRA RA. Fatores de risco para infecção do sítio cirúrgico em transplante de fígado: coorte histórica [Dissertação]. São Paulo: Escola de Enfermagem, Universidade de São Paulo; 2016.

\section{RESUMO}

Introdução: As infecções do sítio cirúrgico (ISC) estão entre as principais complicações em pacientes submetidos ao transplante de fígado, com incidências que variam de $10,4 \%$ a $23,6 \%$. Ademais, recente revisão da literatura aponta lacunas entre os fatores de risco para esta população específica. Objetivo: Analisar a incidência e os fatores de risco para o desenvolvimento de ISC entre pacientes adultos submetidos ao transplante de fígado. Método: Coorte histórica, realizada por meio de consulta a prontuários de pacientes adultos submetidos ao transplante de fígado entre os anos de 2009 e 2015, em um hospital filantrópico do interior do Estado de São Paulo. O projeto foi aprovado pelo Comitê de Ética em Pesquisa da Escola de Enfermagem da Universidade de São Paulo. Para análise dos dados utilizou-se medidas de tendência central e de variabilidade, os testes $X^{2}$ de Pearson, teste exato de Fisher, Mann-Whitney e Wilcoxon-Mann-Whitney. Após análise bivariada, as variáveis foram incluídas em um modelo de regressão Classification and Regression Tree. Resultados: Foram investigados os prontuários de 156 pacientes submetidos ao transplante de fígado, dos quais $26,9 \%$ desenvolveram ISC. Verificou-se que elevado tempo cirúrgico ( $>487$ minutos) associado a diferenças de índice de massa corporal entre doador e receptor $\left(>1,3 \mathrm{~kg} / \mathrm{m}^{2}\right)$ aumentaram a chance de ISC em aproximadamente 5,5 vezes (OR 5,5; IC 95\% 2,511,8); e glicemia capilar (>175 mg/dl) nas primeiras 96 horas de pós-operatório elevou a chance de ISC em aproximadamente três vezes (OR 2,97; IC 95\% 1,43$6,17)$. Os principais micro-organismos isolados em sítios de coleta diretamente relacionados à ISC foram Staphylococcus sp., P. aeruginosa, Klebsiella sp., A. baumanii e $C$. albicans. Conclusão: Encontrou-se elevada incidência de ISC entre a população estudada. Os fatores de risco encontrados para esta categoria de pacientes diferem dos amplamente apontados pela literatura científica em outras categorias ou especialidades cirúrgicas.

Palavras-chave: Infecção da ferida operatória. Transplante de fígado. Enfermagem perioperatória. 
OLIVEIRA RA. Risk factors for surgical site infections in liver transplantation: historical cohort [Thesis]. São Paulo (SP), Brasil: Escola de Enfermagem, Universidade de São Paulo; 2016.

\begin{abstract}
Introduction: Surgical site infections (SSI) are one of the main liver transplantation complications with incidence varying between $10.4 \%$ to $23.6 \%$. Recent literature review shows gaps between risk factors within this specific population. Objective: To analyze the incidence and the risk factors in the development of SSI among adults submitted to liver transplantation. Methods: Historical cohort done through records of adults submitted to liver transplant between 2009 and 2015 in a philanthropic hospital in the countryside of Sao Paulo state. The Research Ethics Committee of School of Nursing of University of Sao Paulo approved the project. Data was analyzed by central tendency and variability measures, Pearson $X^{2}$-test, Fisher exact test, Mann Whitney test and Wilcoxon-Man Whitney test. After the bivariate analyzes, the variables were included in the Classification and Regression Tree model. Results: The records of 156 patients submitted to liver transplant were investigated, of which $26.9 \%$ developed SSI. Prolonged operative time (>487 minutes) associated with Body Mass Index differences between donator/receptor $\left(>1.3 \mathrm{~kg} / \mathrm{m}^{2}\right)$ increased the chance of SSI in approximately 5.5 times (OR 5,5; CI 95\% 2,5 - 11,8); and in the first 96 postoperative hours capillary glycemia $(>175 \mathrm{mg} / \mathrm{dl})$ increased the chance of SSI in approximately three times (OR 2.97; $\mathrm{Cl} 95 \% 1.43-6.17)$. The main microorganisms isolated in collection sites related to SSI were Staphylococcus sp., $P$. aeruginosa, Klebsiella sp., A. baumanii and C. albicans. Conclusion: There is high incidence of SSI among the studied population and the identified risk factors for this patients' category are highly diverse from the ones indicated by scientific literature in other categories or surgical specialties.
\end{abstract}

Keywords: Surgical wound infection. Liver transplantation. Perioperative nursing. 


\section{LISTA DE ILUSTRAÇÕES}

Figura 1 - Árvore de classificação e regressão, identificação dos participantes que desenvolveram ISC de acordo com a inter-relação entre tempo cirúrgico e diferença

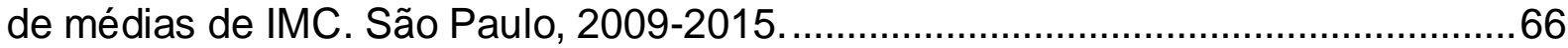

Gráfico 1 - Média dos valores de glicemia capilar entre receptores de transplante de fígado em 14 dias de pós-operatório. São Paulo, 2009-2014. 


\section{LISTA DE QUADROS}

Quadro 1- Predição de mortalidade em três meses de acordo com o escore MELD. São Paulo, 2016. .21 


\section{LISTA DE TABELAS}

Tabela 1- Distribuição de pacientes submetidos ao transplante de fígado de acordo com hábitos de vida, características clínicas, cirúrgicas e ocorrência de ISC. São Paulo, 2009-2015.

Tabela 2 - Distribuição de doadores de fígado falecidos de acordo com características clínicas, causa mortis e inter-relação de variáveis de doadores/receptores do transplante de acordo com a ocorrência de ISC. São Paulo, 2009-2015.

Tabela 3- Distribuição dos pacientes submetidos ao transplante de fígado de acordo com o ano de realização do transplante, estado físico, origem, preparo, dispositivos instalados no pré-operatório e ocorrência de ISC. São Paulo, 2009-2015. .52

Tabela 4- Distribuição de pacientes submetidos ao transplante de fígado de acordo com características do transoperatório e ocorrência de ISC. São Paulo, 2009-2015.

Tabela 5- Distribuição de pacientes submetidos ao transplante de fígado de acordo com características clínicas e assistenciais do pós-operatório e ocorrência de ISC. São Paulo, 2009-2015.

Tabela 6- Distribuição de pacientes submetidos ao transplante de fígado que desenvolveram ISC de acordo com critérios diagnósticos, presença de registro do diagnóstico médico e sítios de coleta de material para cultura. São Paulo, 20092015.

Tabela 7- Distribuição de pacientes submetidos ao transplante de fígado de acordo com medicamentos antimicrobianos administrados no pós-operatório e ocorrência de ISC. São Paulo, 2009-2015.

Tabela 8- Distribuição de pacientes submetidos ao transplante de fígado que desenvolveram ISC de acordo os micro-organismos isolados, coloração de Gram, espécie e sítio de coleta. São Paulo, 2009-2015.

Tabela 9 - Perfil de sensibilidade e resistência de micro-organismos isolados entre pacientes submetidos ao transplante de fígado que apresentaram ISC, por sítio de coleta e grupos de antimicrobianos. São Paulo, 2009-2015. 


\section{LISTA DE SIGLAS}

Anvisa Agência Nacional de Vigilância Sanitária

ASA

Classificação do estado físico de acordo com a American Society of Anesthesiology

CART Classification and Regression Tree

CDC

Centers for Disease Control and Prevention

CEP

Comitê de Ética em Pesquisa

$\mathrm{CHC}$

Carcinoma hepatocelular

CVC

Cateter vascular central

CVP

Cateter vascular periférico

DATASUS Departamento de Informática do SUS

DM

Diabetes mellitus

ECDC

European Centre for Disease Prevention and Control

EUA

Estados Unidos da América

GISC

Grupo acometido por ISC

HAS

Hipertensão arterial sistêmica

$\mathrm{IH}$

Infecção hospitalar

IMC

Índice de massa corporal

IRAS

Infecção relacionada à assistência à saúde

ISC

Infecção do sítio cirúrgico

MELD

Model of End-stage Liver Disease

MS

Ministério da Saúde

NHSN

National Healthcare Safety Network

NISC

Grupo não acometido por ISC

NNIS

National Nosocomial Infection Study

NNIS System

National Nosocomial Infection Surveillance System

PAI

Pressão arterial invasiva

PVPI

Polivinilpirrolidona

$\mathrm{RNI}$

Razão normalizada internacional

SAME

Serviço de Arquivo Médico e Estatístico

SENIC

Study on the Efficacy of Nosocomial Infection Control

SNG

Sonda nasogástrica 
SPSS

SUS

SVD

TCLE

UTI

VHC

Statistical Package for the Social Sciences

Sistema Único de Saúde

Sonda vesical de demora

Termo de Consentimento Livre e Esclarecido

Unidade de terapia intensiva

Vírus da hepatite $\mathrm{C}$ 


\section{LISTA DE SÍMBOLOS}

$\begin{array}{ll}{ }^{\circ} \mathrm{C} & \text { Graus Celsius } \\ \mathrm{kg} & \text { Quilograma } \\ \mathrm{m}^{2} & \text { Metro quadrado } \\ x^{2} & \text { Qui-quadrado } \\ \min & \text { Minuto(s) }\end{array}$




\section{SUMÁRIO}

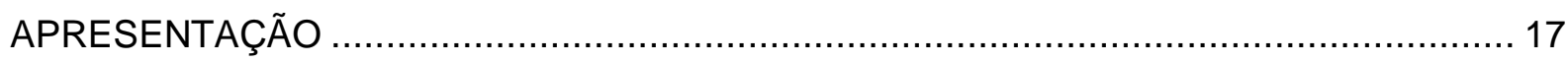

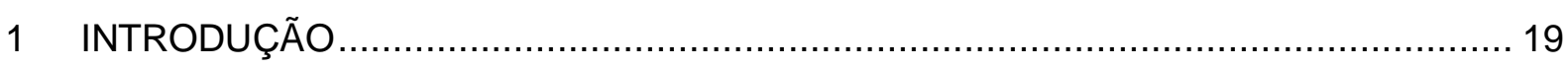

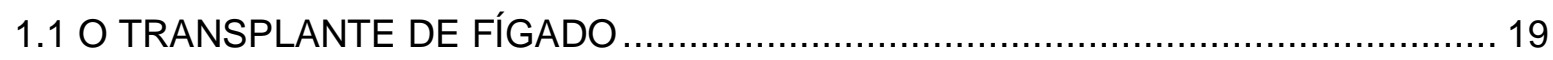

1.2 HISTÓRICO E SITUAÇÃO ATUAL DAS INFECÇÕES RELACIONADAS À ASSISTÊNCIA À SAÚDE NO BRASIL E NO MUNDO ……...................................... 23

1.3 AS INFECÇÕES DE SÍTIO CIRÚRGICO E O PACIENTE SUBMETIDO AO

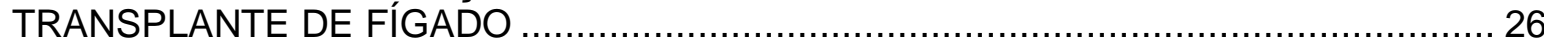

2 OBJETIVOS

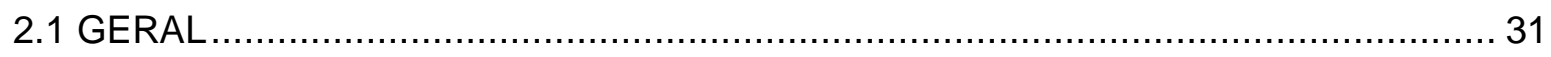

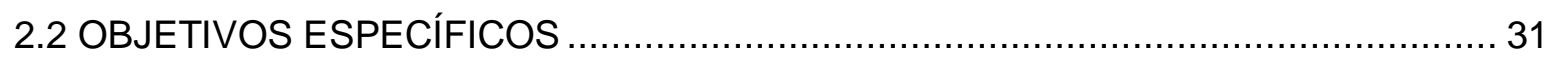

$3 \quad$ MÉTODO

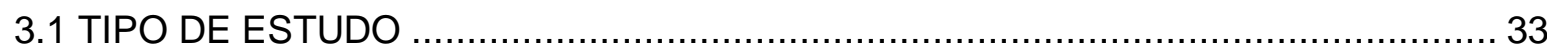

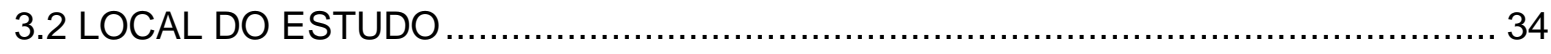

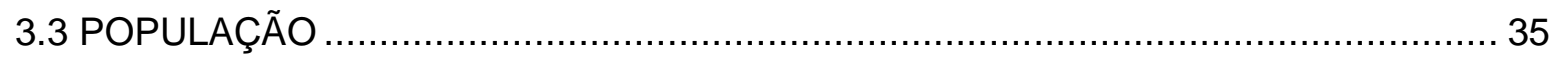

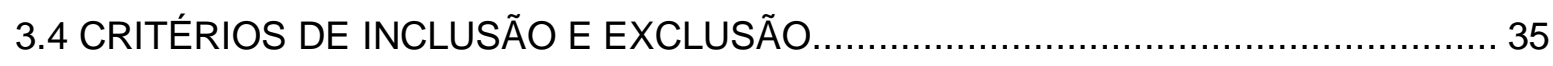

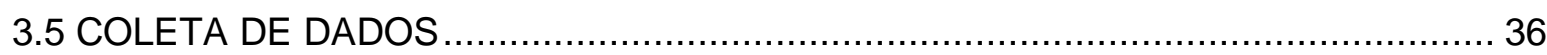

3.6 CONSTRUÇÃO E AVALIAÇÃO DO INSTRUMENTO DE COLETA DE DADOS POR

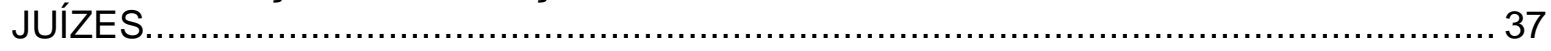

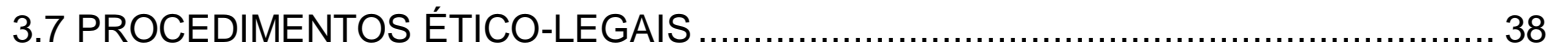

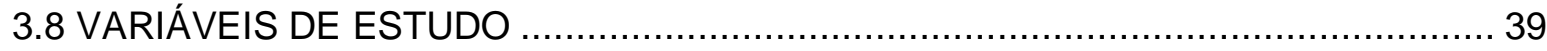

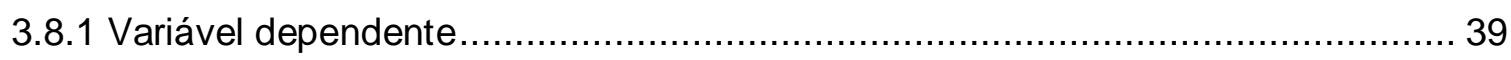

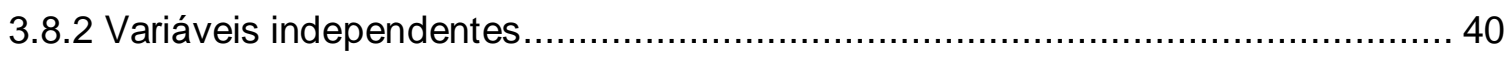

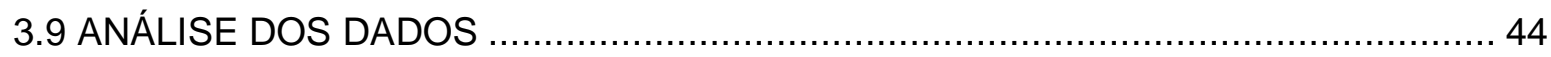

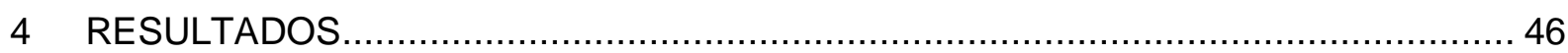

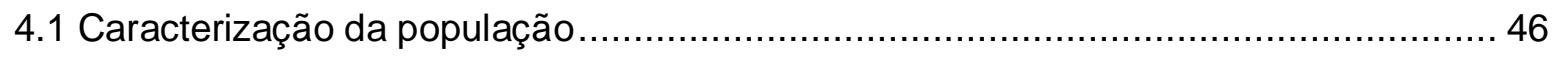

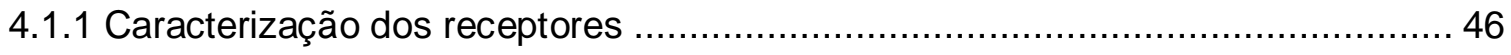

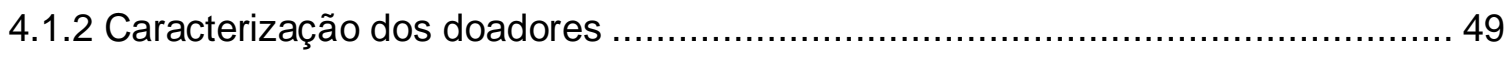

4.2 Caracterização do procedimento anestésico-cirúrgico …...................................... 50

4.3 CARACTERÍSTICAS RELACIONADAS ÀS INFECÇÕES DO SíTIO CIRÚRGICO .... 58

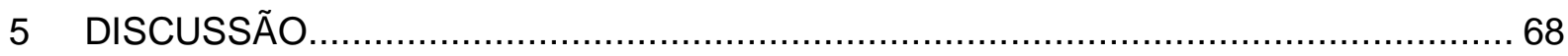

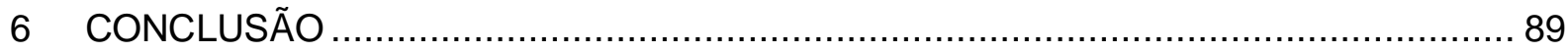

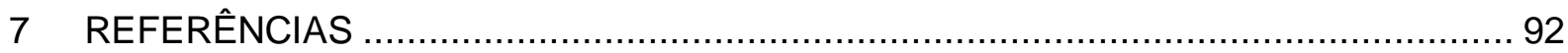

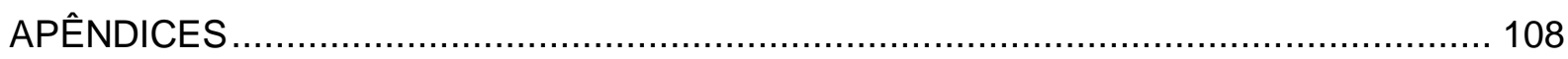

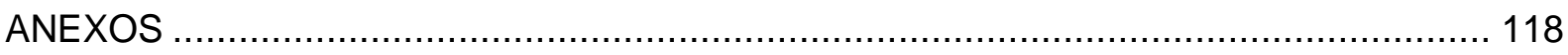


Apresentação 


\section{APRESENTAÇÃO}

Esta investigação é reflexo da observação e inquietação do autor sobre a temática da infecção do sítio cirúrgico (ISC). Sua atuação profissional como enfermeiro assistencial em um centro cirúrgico onde são realizados transplantes, na cidade de São Paulo, influenciou na escolha do objeto de pesquisa.

A temática das ISC tem sido estudada mundialmente, por tratar-se da complicação mais frequente entre os pacientes submetidos a procedimentos cirúrgicos. Entretanto, os fatores de risco para ISC entre pacientes submetidos ao transplante de fígado têm sido pouco explorados. Infere-se que esses sujeitos apresentam diferentes fatores de risco, os quais podem estar associados a maior possibilidade de adoecimento ${ }^{(1-3)}$.

Trata-se de uma questão pouco explorada e os fatores de risco para o desenvolvimento de ISC entre essa população específica ainda não estão completamente compreendidos ${ }^{(4,5)}$. Ademais, em recente revisão integrativa da literatura que buscou elencar os fatores de risco para o desenvolvimento de ISC entre pacientes submetidos ao transplante de fígado, não foram localizadas investigações de autoria de profissionais da área da enfermagem ${ }^{(6)}$.

Diante do exposto, elaborou-se a seguinte questão: os fatores de risco para o desenvolvimento de ISC entre pacientes adultos submetidos ao transplante de fígado são semelhantes àqueles amplamente investigados?

A presente investigação buscou apurar os fatores predisponentes à ISC entre pacientes adultos submetidos ao transplante de fígado. Os resultados encontrados poderão fornecer subsídios que auxiliem o profissional enfermeiro e a equipe de saúde na tomada de decisões durante a assistência perioperatória e a composição de saberes que fortaleçam o planejamento de ações preventivas. 
1. Introdução 


\section{INTRODUÇÃO}

\subsection{O TRANSPLANTE DE FÍGADO}

A história dos transplantes de órgãos entre seres humanos data de 1880, quando foi realizado o primeiro transplante de córnea. Em 1936, um cirurgião russo realizou o primeiro transplante de rim, o qual resultou na morte do receptor 48 horas após o ato anestésico-cirúrgico. Apenas no ano de 1954, foi realizado o primeiro transplante de rim bem-sucedido, entre gêmeos, nos EUA ${ }^{(7)}$.

Em 1963, nos EUA e na Europa foram realizadas as primeiras tentativas de transplante de fígado. No entanto, em razão dos resultados insatisfatórios das técnicas disponíveis, foram necessários mais quatro anos de desenvolvimento antes do primeiro procedimento bem-sucedido, que ocorreu em 1967. Neste caso, a paciente, uma menina de um ano e meio de idade, sobreviveu por 13 meses e faleceu com o diagnóstico de carcinoma hepatocelular $(\mathrm{CHC})$, para o qual havia sido tratada por meio do transplante ${ }^{(7,8)}$.

Diversos outros avanços foram fundamentais para o desenvolvimento do transplante de fígado; entre eles, a forma de preservação do órgão, com a utilização, a partir de 1976, de uma solução com composição eletrolítica semelhante à encontrada no espaço intracelular para preservação do órgão; e o uso da ciclosporina em doses menores que as utilizadas no transplante de rim em $1980^{(7,8)}$.

Em 1983, o Ministério da Saúde dos EUA realizou uma reunião entre especialistas de diversas áreas objetivando criar um consenso sobre indicações, contraindicações, recursos mínimos para criação de serviços de transplante de fígado, necessidades institucionais e definição dos potenciais candidatos ao transplante. Esse consenso foi publicado em 1984 e tornou o transplante de fígado um procedimento terapêutico, e não mais experimental ${ }^{(8,9)}$.

Atualmente, o transplante de fígado é o procedimento mais complexo da cirurgia moderna, pois nenhum outro interfere em tantas funções orgânicas. Para a obtenção dos objetivos esperados, é necessário a completa sincronia entre a equipe 


\section{Ramon Antônio Oliveira}

multidisciplinar e uma infraestrutura adequada que permita à equipe a realização do procedimento cirúrgico de grande porte e o acompanhamento de pacientes gravemente debilitados pela doença ${ }^{(8)}$.

O transplante de fígado é utilizado para o tratamento da doença hepática terminal potencialmente fatal, para a qual não se dispõe de nenhuma outra forma de intervenção ou quando a qualidade de vida é inaceitável ${ }^{(10)}$. O procedimento do transplante envolve a hepatectomia e a substituição por um órgão saudável na mesma localização anatômica. A remoção do fígado doente cria espaço para o novo órgão e permite a reconstrução anatômica da vasculatura hepática e do trato biliar o mais próximo possível do normal ${ }^{(10,11)}$.

As indicações gerais para o transplante de fígado envolvem a doença hepática crônica e irreversível, insuficiência hepática fulminante, doenças hepáticas metabólicas e algumas neoplasias hepáticas. Exemplos de distúrbios que são indicações para transplante de fígado incluem doenças hepatocelulares, como as hepatites virais, doença hepática induzida por medicamentos ou por álcool, doença de Wilson, doenças colestáticas como a cirrose biliar primária, colangite esclerosante e atresia $\operatorname{biliar}^{(9,11)}$.

O paciente que é considerado candidato ao transplante de fígado, frequentemente, apresenta numerosos problemas sistêmicos, que influenciam os cuidados perioperatórios. Por conseguinte, busca-se realizar o transplante antes que a doença evolua até complicações como a hemorragia gastrointestinal grave e/ou encefalopatia com agravamento para o estado de coma hepático ${ }^{(8,11)}$.

Portanto, o paciente deve ser submetido a uma avaliação completa da reserva hepática e de seu estado de saúde. Parte dessa avaliação inclui a classificação do grau de necessidade clínica, por meio do Model of End-stage Liver Disease (MELD), que estratifica o nível da doença dos que aguardam o transplante de fígado, constituindo um indicador de mortalidade em curto prazo para pacientes com doença hepática terminal ${ }^{(8,11)}$.

Os escores para avaliação prognóstica do paciente portador de doença hepática iniciaram-se na década de 1960. O primeiro escore Child-Pugh utilizava cinco parâmetros, como o valor sérico da albumina e bilirrubina, ascite, encefalopatia e estado nutricional. Esse escore foi revisto mais de uma vez, pois apresentava 


\section{Ramon Antônio Oliveira}

parâmetros de avaliação subjetivos, como estado nutricional, ascite e encefalopatia $^{(12,13)}$.

Em 1999, o escore MELD surgiu, nos EUA, como uma resposta à problemática da alocação de órgãos utilizando um critério clínico objetivo para classificação dos pacientes. O escore deriva de uma fórmula que incorpora os níveis de bilirrubina, o tempo de protrombina expresso pela razão normalizada internacional (RNI), creatinina e causa da doença hepática ${ }^{(12,13)}$.

O modelo, inicialmente, foi expresso por: MELD $=3,8^{\star} \log _{\mathrm{e}}($ bilirrubina[mg/dl] $)+$ $11,2^{*} \log _{\mathrm{e}}(\mathrm{RNI})+9,6^{*} \log _{\mathrm{e}}($ creatinina $[\mathrm{mg} / \mathrm{dl}])+6,4^{*}$ (etiologia: 0 se colestática ou alcoólica, 1 caso contrário) ${ }^{(13)}$.

Investigações posteriores demonstraram que a incorporação dos níveis séricos de sódio ( $\mathrm{Na}$ ) aumenta a acurácia do modelo para a predição de óbitos entre pacientes que aguardam transplante. O modelo de MELD-Na é expresso por:

"MELD-Na"= MELD + 1,59 $(135-\mathrm{Na})^{(14)}$.

O modelo foi validado como um preditor de sobrevida em grupos de pacientes portadores de doença hepática. Os resultados do escore MELD traduzem a possibilidade da mortalidade estimada em três meses (Quadro 1).

Quadro 1- Predição de mortalidade em três meses de acordo com o escore MELD. São Paulo, 2016.

\begin{tabular}{|c|c|}
\hline Escore MELD & Percentual de mortalidade em 3 meses \\
\hline$<9$ & $1,9 \%$ \\
\hline $10-19$ & $6,0 \%$ \\
\hline $20-29$ & $19,6 \%$ \\
\hline $30-39$ & $52,6 \%$ \\
\hline 40 ou mais & $71,3 \%$ \\
\hline
\end{tabular}

Fonte: Wiesner RH, McDiarmid SV, Kamath PS, Edwards EB, Malinchoc M, Kremers WK, et al. MELD and PELD: application of survival models to liver allocation. Liver Transpl. $2001 ; 7(7): 567-80 .^{(15)}$

Os receptores de transplantes devem passar por um rigoroso processo de seleção e preparação, que inclui aconselhamento e educação, para ajudá-los em escolhas críticas para melhora da saúde ${ }^{(11,16)}$.

O transplante de fígado é uma modalidade terapêutica na qual é possível a reversão do quadro terminal de um paciente portador de doença hepática. A maioria 
dos doentes apresenta uma longa história de tratamento em unidades de terapia intensiva (UTI). Os candidatos ao transplante têm baixa qualidade de vida e vivem na perspectiva iminente da morte; portanto, a inclusão na lista de espera para o transplante traduz-se em esperança de sobrevivência ${ }^{(10,17)}$.

Contudo, o transplante de fígado pode ser acompanhado de complicações relacionadas ao elevado tempo cirúrgico, à terapia imunossupressora e às dificuldades técnicas encontradas na reconstrução dos vasos sanguíneos e do trato biliar. No pós-operatório, observam-se complicações como hemorragia, infecção, rejeição do enxerto, obstrução da anastomose biliar, estenose e trombose vasculares. Além disso, os problemas sistêmicos de longa duração resultantes da doença hepática primária podem impactar a evolução perioperatória ${ }^{(11,18)}$.

Dessa forma, ressalta-se que o objetivo do transplante de fígado perpassa não apenas a questão de proporcionar a sobrevivência de um paciente com doença hepática, mas de permitir que a evolução do processo de transplante leve ao êxito do próprio transplante ${ }^{(10)}$.

Os EUA são o país com o maior número de transplantes de fígado no mundo, com 5.134 procedimentos. O Brasil encontra-se em segundo lugar, com 1.712 procedimentos no ano de 2013 e taxa de sobrevida nos primeiros cinco anos de $70 \%$, de acordo com os dados do Registro Brasileiro de Transplantes ${ }^{(19)}$.

Com mais de 190 milhões de habitantes, o Brasil está diminuindo progressivamente a fila de espera por transplante de córneas e atendendo $40 \%$ da fila de espera por transplante de rim e $30 \%$ dos pacientes que necessitam de transplante de fígado ${ }^{(19)}$.

Dentre os Estados brasileiros, São Paulo teve o maior número de transplantes realizados no ano de 2013, com 1.914 procedimentos; destes, 648 foram transplantes de fígado ${ }^{(19)}$. 


\subsection{HISTÓRICO E SITUAÇÃO ATUAL DAS INFECÇÕES RELACIONADAS À ASSISTÊNCIA À SAÚDE NO BRASIL E NO MUNDO}

É premente que se faça uma revisão histórica sobre a temática das infecções relacionadas à assistência à saúde (IRAS), em virtude da complexidade que envolve essa matéria.

Durante a Idade Média, suspeitava-se que alguma coisa sólida pudesse transmitir moléstias entre os indivíduos. No período do Renascimento (1300-1650), com o surgimento da imprensa, pode-se destacar o livro De Contagione, escrito por Francastorius, que descreveu as doenças endêmicas da Itália ${ }^{(20)}$.

O século XIX trouxe avanços importantes para o controle das infecções hospitalares. Em 1847, Ignaz Phillip Semmelweis publicou um trabalho que confirmou a hipótese da transmissão de doença durante a assistência hospitalar. Ele demonstrou que a incidência da infecção puerperal era maior nas parturientes assistidas por médicos do que naquelas assistidas por parteiras ${ }^{(21-23)}$.

Em 1854, Florence Nightingale liderava um grupo de 38 enfermeiras que foram chamadas para o Hospital de Base de Scutari, Constantinopla, responsabilizando-se por 1.500 pacientes, quando do conflito entre a Rússia e forças aliadas da Inglaterra, França e Turquia. O hospital apresentava condições precárias para a assistência, não havia roupas de cama suficientes para os leitos, sanitários, bacia, sabão, e a taxa de mortalidade chegava a $42 \%{ }^{(22)}$.

A partir de 1860, houve avanços em decorrência dos trabalhos de Joseph Lister, que propôs uma técnica para evitar a contaminação de incisões cirúrgicas, e de Louis Pasteur, indicando a desinfecção das salas operatórias pulverizando-as com ácido fênico para reduzir as propriedades sépticas da atmosfera ${ }^{(21,22)}$.

Em 1863, Florence Nightingale descreveu cuidados com o paciente e com o meio ambiente, buscando reduzir as possibilidades de infecção hospitalar (IH). Além disso, implantou outras inovações, como o registro dos óbitos hospitalares, com vistas a avaliar a qualidade do serviço ${ }^{(22,23)}$.

Posteriormente, a partir dos estudos de Pasteur, iniciou-se a desinfecção do instrumental cirúrgico com o uso de ácido carbólico; além disso, em 1883, Pasteur e 


\section{Ramon Antônio Oliveira}

o criador da autoclave, Charles Chamberland, demonstraram a maior eficácia da esterilização do instrumental cirúrgico pelo calor ${ }^{(22,23)}$.

Destacam-se ainda como importantes contribuições para a prevenção das infecções, no final do século XIX e início do século XX, a invenção da luva cirúrgica, por Willian S. Halsted; a utilização de máscara em procedimento cirúrgico, por J. von Mickulicz-Radecki; a criação de instrumentos cirúrgicos, por Jules Émile Péan, evitando a introdução dos dedos na cavidade abdominal. Os cirurgiões habituaramse a evitar diálogos nas salas operatórias, iniciando assim a era da prevenção das infecções ${ }^{(24)}$.

No século $X X$, houve o advento dos antimicrobianos, revolucionando 0 tratamento das infecções. Com isso, houve o aumento dos custos hospitalares, uma vez que as infecções caracterizam-se como um dos principais problemas relacionados à assistência à saúde ${ }^{(24)}$.

Após epidemias bacterianas nos EUA, na década de 1950, iniciaram-se ações para o controle de infecções. Essas ações só foram institucionalizadas quando houve a responsabilização legal de hospitais pelos danos causados aos pacientes em decorrência de $\mathrm{IH}^{(22-24)}$.

Em resposta a esse fenômeno, o Centers for Disease Control and Prevention (CDC) criou o National Nosocomial Infection Study (NNIS), que mais tarde tornou-se o National Nosocomial Infection Surveillance System (NNISS System), que estimou a incidência de $\mathrm{IH}$, estudou a tendência das taxas, avaliou a resistência microbiana e desenvolveu um método para monitorar os casos de $\mathrm{IH}^{(2)}$.

Dentre as ações desenvolvidas pelo CDC para o controle das $\mathrm{IH}$, destaca-se o projeto Study on the Efficacy of Nosocomial Infection Control (SENIC), desenvolvido em 1976, que avaliou a efetividade da vigilância epidemiológica e dos programas de controle de $\mathrm{IH}$ em atividade nos EUA ${ }^{(2)}$.

Por fim, em 2009, o National Healthcare Safety Network (NHSN), órgão vinculado ao CDC, alterou a denominação "infecção hospitalar" para "infecção relacionada à assistência à saúde", pois este termo abrange não somente aquelas infecções adquiridas nos serviços hospitalares, mas também aquelas relacionadas à assistência prestada nos ambulatórios, clínicas e consultórios, incluindo as infecções adquiridas por profissionais que prestam assistência à saúde ${ }^{(2)}$. 


\section{Ramon Antônio Oliveira}

Entretanto, a evolução do sistema de saúde, das práticas assistenciais e da resistência microbiana nas duas últimas décadas traz novos desafios para o controle das IRAS ${ }^{(25)}$.

A Organização Mundial da Saúde reconhece o fenômeno das IRAS como um problema de saúde pública que necessita ser manejado por gestores regionais e locais e propõe que sejam elaboradas ações estratégicas com vistas a sua redução ${ }^{(25)}$.

Atualmente, as IRAS são um dos principais problemas advindos da internação hospitalar e resultam em aumento do tempo de internação e incremento nos custos relacionados à assistência devido ao maior uso de antimicrobianos, por exemplo. Elas têm impacto direto na vida dos pacientes, pois interrompem o trabalho, geram consequências psicológicas motivadas pela permanência em isolamentos, a separação do convívio familiar e outros distúrbios relacionados ao sofrimento enfrentado pelo paciente ${ }^{(25)}$.

Para o enfrentamento das IRAS, propõe-se "a máxima redução de doença infecciosa causada por um agente específico em uma área geográfica definida como resultados de esforços deliberados; ações continuadas para a prevenção do reestabelecimento da doença são necessárias"(26).

Entretanto, para o êxito das ações, diversas etapas precisam ser percorridas, desde a promoção da adesão a práticas baseadas em evidências até incentivos financeiros em estratégias que demonstrem sucesso e pesquisas capazes de preencher as lacunas no conhecimento atual, norteando os esforços de prevenção e mensurando os progressos a partir da coleta e análise dos dados ${ }^{(26)}$.

Padoveze e Fortaleza(27) afirmam que, em países em desenvolvimento, as taxas de IRAS podem ser maiores que as encontradas em países desenvolvidos. No entanto, a única investigação realizada pelo Ministério da Saúde, conduzida por Prade e cols. ${ }^{(28)}$, denominada "Estudo brasileiro da magnitude das infecções hospitalares em hospital terciário", foi realizada em 1994, avaliou 8.624 pacientes internados por mais de 24 horas, com tempo médio de permanência de 11,8 dias e taxa de IRAS de $15,5 \%$. Os maiores índices ocorreram em hospitais públicos $(18,4 \%)$; os menores, nos privados sem fins lucrativos (10\%). Os dados apontaram 
diferentes frequências de IRAS entre as regiões do país, a saber: Região Sudeste $(16,4 \%)$, Nordeste $(13,1 \%)$, Norte (11,5\%), Sul (9\%) e Centro-Oeste $(7,2 \%)$.

Ainda hoje, inexistem no Brasil pesquisas que apontem os efeitos ocasionados pelas IRAS, sendo a problemática frequentemente subestimada, aliada a dificuldades orçamentárias para aquisição de materiais e para a contratação de profissionais especializados. Esses aspectos tornam-se adversidades impactantes no sistema de saúde brasileiro ${ }^{(27)}$.

\subsection{AS INFECÇÕES DE SÍTIO CIRÚRGICO E O PACIENTE SUBMETIDO AO TRANSPLANTE DE FÍGADO}

O conceito de ISC estabelecido pela Agência Nacional de Vigilância Sanitária (ANVISA) em $2013^{(3)}$ menciona que esse tipo de infecção ocorre nos primeiros 30 dias de pós-operatório para cirurgias em que não foram implantadas próteses e até um ano para aquelas em que houve o implante.

Para o European Centre for Disease Prevention and Control (ECDC) $)^{(1)}$, as ISC são aquelas que ocorrem nos primeiros 30 dias após a realização do procedimento cirúrgico, para aqueles pacientes em que não foram implantadas próteses; para aqueles em que houve o implante, a vigilância deve ser estendida por mais de 30 dias.

Uma vez que o procedimento de transplante de fígado não envolve o implante de próteses, recomenda-se que o período de vigilância para detecção de ISC seja de 30 dias, a contar como primeiro dia aquele da realização da cirurgia ${ }^{(2)}$.

$\mathrm{Na}$ presente investigação, optou-se por adotar a recomendação mundialmente aceita proposta pelo CDC, por tratar-se da mais atual definição disponível, descrita no capítulo de métodos no item variável dependente ${ }^{(2)}$.

O desenvolvimento de ISC pode decorrer de fontes endógenas e exógenas. Dentre as endógenas, destaca-se a microbiota cutânea, das mucosas e do trato gastrointestinal do paciente. Com relação às fontes exógenas, pode-se citar a quebra da técnica asséptica, fatores relacionados à esterilização de instrumentais, campos e aventais cirúrgicos. Há que se considerar problemas relacionados ao 


\section{Ramon Antônio Oliveira}

ambiente físico da sala operatória, como a ausência de filtros adequados nos equipamentos de ar condicionado ou o descumprimento de normas cuja aplicação pode reduzir a contaminação ambiental. Além destes, deve-se considerar como fatores de risco a obesidade, extremos de idade, diabetes mellitus (DM), desnutrição, tabagismo, uso de medicamentos imunossupressores, uso inadequado de antibióticos, falta de controle da temperatura corporal no transoperatório e controle inadequado da glicemia nos trans e pós-operatório, acrescidos ao elevado tempo cirúrgico e à maciça transfusão de hemocomponentes ${ }^{(29-33)}$.

A problemática das ISC pode ser constatada no estudo realizado por Magill e cols. ${ }^{(34)}$, que compreendeu 183 hospitais com no mínimo 150 leitos, prestadores de assistência de alta complexidade nos EUA. Foram coletados dados de pacientes pediátricos e adultos, detectando-se que, dentre os tipos mais comuns de IRAS, estão as ISC, com $21,8 \%$ da taxa global de infecção.

As ISC são complicações relevantes que contribuem para o aumento da morbimortalidade de pacientes no período pós-operatório, além de causarem prejuízos físicos e emocionais, como o afastamento do convívio social e familiar e o distanciamento do trabalho, devido ao prolongamento da internação hospitalar, bem como reflexos econômicos pelo maior uso de antimicrobianos e elevação dos custos com o tratamento ${ }^{(33,35-37)}$.

As infecções estão entre as complicações presentes no transplante de fígado, sobressaindo-se no período pós-operatório como importantes causas de morbimortalidade. Evidencia-se que a taxa de mortalidade relacionada a infecções é de aproximadamente $50 \%$ quando acompanhada de choque séptico ${ }^{(38-40)}$.

Ressalta-se também que é uma difícil tarefa o estabelecimento do diagnóstico entre o grupo de pacientes transplantados, pois geralmente não há sinais e sintomas relacionados à infecção e, quando estes existem, são discretos. Além disso, mesmo pequenas infecções em pacientes imunossuprimidos podem levar a desfechos catastróficos $^{(41)}$.

Investigação envolvendo 1.222 pacientes submetidos ao transplante de fígado verificou incidência de $10,4 \%$ de ISC, $76 \%$ das quais foram detectadas nas primeiras quatro semanas após o transplante ${ }^{(42)}$. 


\section{Ramon Antônio Oliveira}

Estudo que incluiu 75 pacientes submetidos ao transplante de fígado verificou que participantes com escores MELD mais altos apresentaram maior frequência de infecções, maior tempo de internação em unidade de terapia intensiva, acréscimo no tempo de uso de ventilação mecânica e maiores taxas de mortalidade. Além disso, a ISC esteve presente em $14,3 \%$ dos pacientes ${ }^{(43)}$.

Dados semelhantes foram encontrados em uma investigação retrospectiva que analisou prontuários de 370 pacientes submetidos ao transplante de fígado e identificou que $18 \%$ deles tiveram ISC $^{(4)}$. Já em estudo que envolveu 109 participantes submetidos ao transplante de fígado, verificou-se que $56 \%$ tiveram pelo menos um episódio de infecção, sendo a ISC a mais frequente (16\%); destaca-se que, em $46 \%$ dos casos, as infecções nessa população evoluíram para insuficiência renal, em $40 \%$ para falência múltipla de órgãos, em 10\% para insuficiência respiratória e em $4 \%$ para choque séptico ${ }^{(44)}$.

Em um estudo nacional, verificou-se que, entre 543 pacientes submetidos ao transplante de fígado, retransplante e transplante de rim simultâneo ao de fígado, a incidência de ISC foi de $23,6 \%$, e observou-se tempo médio para detecção de ISC de 11 dias $^{(45)}$.

Em recente revisão integrativa da literatura(6), concluiu-se que, embora os fatores de risco para o desenvolvimento de ISC sejam amplamente investigados pela literatura científica, existem lacunas entre os preditores de ISC em pacientes submetidos ao transplante de fígado. Ademais, a revisão apontou fatores de risco diferentes dos que se manifestam entre pacientes submetidos a procedimentos cirúrgicos em outras especialidades. Os fatores de risco elencados são: IMC maior que $35 \mathrm{~kg} / \mathrm{m}^{2}$, baixos níveis de albumina sérica e necessidade de ventilação mecânica no pré-operatório. No transoperatório, escore MELD maior que 35, transfusão maciça de unidades de concentrado de hemácias, prolongado tempo cirúrgico, níveis glicêmicos maiores que 200 mg/dl, uso de drogas vasopressoras e débito de líquido ascítico maior que $1.000 \mathrm{ml}$. Também foram levantados fatores de risco oriundos da inter-relação entre doador/receptor, como diferença entre idade de doador/receptor maior que 10 anos, incompatibilidade de sexo de doador/receptor e receptores de enxerto "pequeno para o tamanho". 
Deste modo, o estudo proposto tem por hipótese: os fatores de risco para o desenvolvimento de ISC entre pacientes adultos submetidos ao transplante de fígado são diferentes daqueles amplamente apontados pela literatura científica.

Diante do exposto, entende-se que a elucidação dos fatores de risco para o desenvolvimento de ISC entre pacientes adultos submetidos ao transplante de fígado é condição essencial para que ações que visam à prevenção e detecção desse agravo sejam tomadas. $O$ desenvolvimento de investigações que apontem variáveis preditoras de ISC específicas entre essa categoria de pacientes poderá contribuir para melhor conhecer as particularidades desse grupo específico de pacientes e planejar, especialmente, a assistência de enfermagem com vistas à melhoria da sua qualidade, dos resultados e da minimização dos efeitos deletérios causados pelas ISC. Assim, a presente investigação tem como objetivo analisar a incidência e os fatores de risco para o desenvolvimento de ISC entre pacientes adultos submetidos ao transplante de fígado. 
2.Objetivos 


\section{OBJETIVOS}

\subsection{GERAL}

Analisar a incidência e os fatores de risco para o desenvolvimento de infecção do sítio cirúrgico entre pacientes adultos submetidos ao transplante de fígado.

\subsection{OBJETIVOS ESPECÍFICOS}

- Analisar a relação entre a ocorrência de infecção do sítio cirúrgico em pacientes submetidos ao transplante de fígado e as variáveis relacionadas ao paciente e ao transoperatório.

- Investigar a relação entre as características de doadores e receptores de transplante de fígado quanto a incompatibilidade de sexo, diferenças de idade e disparidade entre índice de massa corporal e a ocorrência de ISC.

- Descrever os micro-organismos frequentes entre os pacientes acometidos por ISC.

- Verificar a associação entre a infecção do sítio cirúrgico e a mortalidade em 30 dias após o transplante de fígado. 


\section{Método}




\section{MÉTODO}

\subsection{TIPO DE ESTUDO}

Trata-se de uma coorte histórica realizada por meio da consulta a prontuários de pacientes submetidos ao transplante de fígado de 2009 a 2015.

A análise quantitativa dos dados envolve um conjunto de procedimentos sistemáticos utilizados para adquirir informações, utilizando o raciocínio dedutivo para gerar predições que serão testadas ${ }^{(46)}$. A isso, soma-se o princípio básico da epidemiologia clínica, ou seja, promover métodos de observação e interpretação de dados que conduzam a conclusões válidas ${ }^{(47)}$.

Os estudos observacionais são indicados quando não é possível ou se considera antiético manipular as variáveis investigadas. Dessa forma, esses tipos de estudo podem oferecer informações para a proposição de intervenções e indicar quais sujeitos podem beneficiar-se delas ${ }^{(46)}$.

Nos estudos de coorte, coleta-se dados em mais de um ponto temporal, o que permite estabelecer causalidade. Esse método é aplicado de modo clássico para determinar a ocorrência de um evento específico em um grupo de indivíduos inicialmente livres do fenômeno em estudo, para avaliar efeitos colaterais de medicamentos e para investigar fatores de risco para o desenvolvimento de doenças $^{(46-49)}$. Quanto à coleta de dados, as coortes devem ser observadas pelo período suficiente na história natural do fenômeno em questão para que o risco se expresse $^{(47)}$.

Quanto à definição de estudos retrospectivos, sabe-se que são aqueles em que, inicialmente, a coorte é constituída e, após esse procedimento, efetua-se o seguimento, inferindo-se que o fenômeno observado no presente está relacionado a eventos ocorridos no passado ${ }^{(46,47)}$. Portanto, o investigador retroage no tempo e busca os sujeitos expostos e não expostos em busca do desfecho de interesse ${ }^{(50)}$. 


\section{Ramon Antônio Oliveira}

\subsection{LOCAL DO ESTUDO}

O estudo ocorreu em um hospital geral terciário, privado, filantrópico, prestador de serviços ao Sistema Único de Saúde (SUS), situado no interior do Estado de São Paulo, destinado ao ensino, pesquisa e assistência, credenciado pelo MS para realização de transplantes de córnea, esclera e fígado. Possui 209 leitos em unidades de internação, 21 leitos em unidade de terapia intensiva para adultos, seis leitos em unidade de terapia intensiva neonatal e 10 salas operatórias no centro cirúrgico ${ }^{(51)}$.

O hospital conta com equipe multidisciplinar composta por assistentes sociais, enfermeiros, fisioterapeutas, fonoaudiólogos, médicos e psicólogos. O centro cirúrgico dispõe de uma equipe de enfermagem composta por três enfermeiros e 32 técnicos em enfermagem. Na unidade de terapia intensiva existem 20 enfermeiros e 87 técnicos em enfermagem, divididos entre os diferentes plantões.

O centro cirúrgico atende as especialidades de bucomaxilofacial, cirurgia de cabeça e pescoço, cirurgia geral, cirurgia oncológica, cirurgia pediátrica, cirurgia plástica e reparadora, cirurgia torácica, cirurgia vascular, cirurgia ortopédica e traumatológica, urologia, otorrinolaringologia, proctologia e transplantes.

Quanto ao transplante de fígado, há uma equipe habilitada pelo MS, composta por três cirurgiões, um hepatologista clínico e uma enfermeira. De acordo com o Departamento de Informática do SUS (DATASUS), no hospital em estudo, entre os anos de 2009 e 2015 foram realizados 176 transplantes de fígado cujo enxerto era proveniente de doadores falecidos ${ }^{(51)}$.

Para a realização do transplante de fígado são ocupadas duas salas operatórias, na primeira das quais é realizado o transplante propriamente dito; cabe destacar que seu uso não é exclusivo para esse procedimento. A segunda sala operatória é destinada à realização do procedimento de preparo do órgão que será transplantado, também conhecido como back table ${ }^{(52)}$.

No transoperatório, para prevenção de hemorragias, em todos os procedimentos foi utilizado um sistema de eletrocirurgia, que emprega plasma de argônio e permite rápida hemostasia e redução do trauma tecidual ${ }^{(53)}$. 


\section{Ramon Antônio Oliveira}

Também no transoperatório, os pacientes foram submetidos a procedimento de prevenção da hipotermia acidental, com uso do sistema de aquecimento por ar forçado, por meio do emprego de mantas para os membros superiores e inferiores. Soma-se a isso a administração de soluções aquecidas por via intravenosa.

No pós-operatório, os pacientes são encaminhados à UTI e, posteriormente, à enfermaria cirúrgica, onde permanecem em isolamento como medida profilática (rotina da instituição) para o controle de infecções, em ambas as unidades.

\subsection{POPULAÇÃO}

A população foi composta por prontuários de sujeitos adultos, de ambos os sexos, que foram submetidos ao transplante de fígado com enxertos provenientes de doadores falecidos, no período de 1. de janeiro de 2009 a 31 de dezembro de 2015. Justifica-se a opção por incluir prontuários de sujeitos a partir do ano de 2009 porque este corresponde ao credenciamento do serviço para a realização de transplantes de fígado; portanto, observados os critérios de inclusão e exclusão, todos os sujeitos submetidos ao procedimento no hospital em estudo integraram a presente investigação.

Entende-se por população a agregação total de casos em que se tem interesse, ou seja, todas as pessoas em um cenário definido que atendam a determinadas características que são comumente explicitadas pelo pesquisador, como os critérios de inclusão e exclusão ${ }^{(46,47)}$.

\subsection{CRITÉRIOS DE INCLUSÃO E EXCLUSÃO}

Foram incluídos os prontuários de pacientes maiores de 18 anos, submetidos ao transplante de fígado proveniente de doador falecido, no período de $1 . \stackrel{\circ}{\text { de janeiro }}$ de 2009 a 31 dezembro de 2015, que sobreviveram às primeiras 72 horas após o transplante, cujos prontuários estavam disponíveis no Serviço de Arquivo Médico e Estatístico (SAME) da instituição escolhida para condução do estudo. 


\section{Ramon Antônio Oliveira}

A exclusão dos sujeitos do estudo que não sobreviveram às primeiras 72 horas após o transplante justifica-se pela menor exposição aos fatores de risco elencados nos objetivos específicos e endossados por investigações anteriores ${ }^{(45,}$ 54).

Foram excluídos os prontuários de pacientes submetidos a procedimento cirúrgico, com ou sem implante de próteses, nos 30 dias anteriores à realização do transplante e pacientes submetidos ao retransplante no período de 30 dias após o primeiro.

\subsection{COLETA DE DADOS}

Ao se iniciar a coleta de dados, obteve-se uma relação dos pacientes transplantados, por meio de relatório emitido pela coordenação de transplantes de fígado do hospital escolhido para condução do estudo. Esse documento era composto pela data da realização do transplante de fígado, nome do paciente, idade, número do prontuário, origem do órgão (se doador falecido ou não) e norteou a busca pelos prontuários.

Dos 176 prontuários de sujeitos submetidos ao transplante de fígado no período de investigação proposto, foram excluídos: um por não ter sido encontrado pelo SAME após três tentativas; um em que o paciente era menor de 18 anos de idade; quatro prontuários de pacientes submetidos ao retransplante de fígado no período inferior a 30 dias da realização do primeiro; e 14 prontuários de pacientes que faleceram nas primeiras 72 horas após o transplante.

Assim, dos 176 prontuários solicitados ao SAME, 156 atenderam aos critérios de inclusão e exclusão estabelecidos para o desenvolvimento desta investigação.

A coleta de dados foi executada pelo pesquisador no período de $1 . \stackrel{\circ}{\text { de }}$ março a 26 de abril de 2016. No local escolhido para a realização do estudo, o prontuário era composto por duas partes: na primeira, constam os dados relativos à assistência prestada no ambulatório de referência; na segunda, os registros referentes ao período de internação hospitalar. 
Assim, a coleta deu-se em duas etapas. Na primeira, foram extraídos dados dos prontuários físicos que estavam arquivados no ambulatório de referência em transplantes de fígado, com ênfase nos dados sociodemográficos e histórico de saúde e os dados referentes ao doador, como idade, sexo, comorbidades e causa mortis. Para isso, foram utilizadas as fichas de admissão médica e de enfermagem, bem como a ficha de inscrição no sistema estadual de transplantes e a ficha de informações do doador de múltiplos órgãos.

$\mathrm{Na}$ segunda etapa, foram coletados os dados dos prontuários físicos, arquivados no SAME. Para tal, foram utilizados relatórios de enfermagem dos períodos pré, trans e pós-operatório, ficha de acompanhamento de sinais vitais e parâmetros clínicos em UTI, ficha de evolução de enfermagem, ficha de evolução clínica, ficha de evolução da equipe multidisciplinar, relatório de descrição do ato cirúrgico, ficha anestésica e prescrições médicas.

A coleta de dados compreendeu os períodos pré-operatório, transoperatório e até 0 30. dia de pós-operatório, tendo em vista o conceito de ISC adotado para a condução desta investigação ${ }^{(2)}$.

\subsection{CONSTRUÇÃo E AVALIAÇÃO DO INSTRUMENTO DE COLETA DE DADOS POR JUÍZES}

Para atingir o objetivo proposto nesta investigação, foi construído um instrumento de coleta de dados (Apêndice A), composto por sete domínios: dados de identificação; dados sociodemográficos e histórico de saúde; dados do préoperatório; dados do transoperatório; dados do pós-operatório; informações sobre a incisão cirúrgica; dados sobre o doador. Para detecção das ISC foi elaborado um domínio fundamentado no estudos de Ribeiro ${ }^{(55)}$, Poveda ${ }^{(56)}$ e nas diretrizes estabelecidas pelo $\mathrm{CDC}^{(2)}$.

O instrumento elaborado foi submetido à avaliação de três juízes; destes, dois eram envolvidos na assistência perioperatória a essa categoria de pacientes e um enfermeiro, pesquisador, com diversas investigações publicadas na área de enfermagem perioperatória. 


\section{Ramon Antônio Oliveira}

Os juízes apresentaram concordância maior que $90 \%$ sobre os itens compreendidos pelo instrumento. Foram apresentadas algumas sugestões quanto à inclusão de itens para o alcance do objetivo da pesquisa, as quais foram acatadas pelo pesquisador.

Após a aprovação da instituição em que foi desenvolvida a pesquisa e do Comitê de Ética em Pesquisa (CEP), foi realizado um teste piloto utilizando 10 prontuários, que não foram incluídos na coleta de dados para verificação da adequação do instrumento ante a mensuração das variáveis pretendidas.

\subsection{PROCEDIMENTOS ÉTICO-LEGAIS}

Para a realização deste estudo, foram respeitadas as Diretrizes e Normas Regulamentadoras de Pesquisas envolvendo seres humanos, emanadas da Resolução n..$^{466}$ de 2012 do Conselho Nacional de Saúde ${ }^{(57)}$. O projeto foi aprovado pelo CEP da Escola de Enfermagem da Universidade de São Paulo sob o Parecer n. 1.400.112 e CAAE n. 50960815.1.0000.5392 (Anexo A), após a autorização do hospital selecionado para a presente investigação.

Seguindo as recomendações do CEP, a assinatura do Termo de Consentimento Livre e Esclarecido (TCLE) foi obtida no momento do retorno ambulatorial dos pacientes cujos prontuários foram consultados. Utilizou-se esse momento para explicitação dos objetivos da pesquisa e posterior obtenção do consentimento em participação da pesquisa, por meio da permissão para o acesso ao prontuário, mediante a assinatura do TCLE (Apêndice B).

Para aqueles em que não foi possível o encontro no serviço de saúde, o pesquisador encaminhou o TCLE em duas vias em um envelope resposta previamente preenchido e selado para o endereço do paciente.

Os dados relacionados ao doador foram obtidos a partir do prontuário do receptor. Sabe-se que a identidade do doador, em virtude dos procedimentos de manutenção do sigilo e confidencialidade, não está disponível nos prontuários dos receptores $^{(58)}$. 
Ramon Antônio Oliveira

\subsection{VARIÁVEIS DE ESTUDO}

A descrição e análise das ISC entre os pacientes submetidos ao transplante de fígado foram realizadas por meio das seguintes variáveis:

\subsubsection{Variável dependente}

- Infecção de sítio cirúrgico: são consideradas aquelas que acometem a incisão cirúrgica, tecidos, órgãos e cavidades manipulados durante o procedimento cirúrgico; podem ser identificadas 30 a 90 dias após a data de realização da cirurgia. O período de vigilância de 90 dias é aplicado para os procedimentos em que houve o implante de próteses ${ }^{(2)}$.

\section{ISC incisional superficial:}

A infecção ocorre nos 30 primeiros dias do procedimento cirúrgico, a contar do dia da realização da cirurgia. Envolve apenas a pele e o tecido subcutâneo adjacente à incisão. $O$ paciente apresenta pelo menos um dos sinais e sintomas a seguir:

a) Drenagem purulenta da incisão superficial.

b) Organismos isolados de uma cultura obtida assepticamente a partir de incisão superficial ou do tecido subcutâneo.

c) A incisão superficial é deliberadamente aberta pelo cirurgião e a cultura é positiva ou não foi obtida, na vigência de pelo menos um dos seguintes sinais ou sintomas: dor ou sensibilidade, edema local, hiperemia ou calor, exceto se a cultura for negativa.

d) Diagnóstico de ISC incisional superficial pelo médico assistente ou profissional designado ${ }^{(2)}$. 


\section{ISC incisional profunda:}

A infecção ocorre dentro de 30 a 90 dias, a depender do procedimento cirúrgico, a contar do dia da realização da cirurgia. Envolve tecidos moles adjacentes à incisão. $O$ paciente apresenta pelo menos um dos seguintes sinais e sintomas:

a) Drenagem purulenta proveniente da incisão profunda.

b) Deiscência parcial ou total da parede abdominal ou abertura ou aspiração da ferida pelo cirurgião.

c) Febre (temperatura axilar $>38^{\circ} \mathrm{C}$ ), dor ou aumento da sensibilidade local, exceto se a cultura for negativa.

d) Presença de abscesso ou outra evidência de que a infecção envolva os planos profundos da ferida, identificada em reoperação, exame histocitopatológico ou exame de imagem ${ }^{(2)}$.

\section{ISC em órgão ou cavidade:}

A infecção ocorre de 30 a 90 dias após o procedimento operatório, considerando-se o dia 1 aquele da realização do procedimento. Envolve qualquer órgão ou cavidade que tenha sido aberto ou manipulado durante a cirurgia. $\mathrm{O}$ paciente apresenta pelo menos um dos seguintes sinais e sintomas:

a) Drenagem purulenta de um dreno localizado dentro do órgão ou cavidade.

b) Cultura positiva de secreção, fluido ou tecido obtido assepticamente.

c) Abscesso ou evidência de infecção envolvendo os planos profundos da ferida, identificada em reoperação, exame histocitopatológico ou exame de imagem ${ }^{(2)}$.

\subsubsection{Variáveis independentes}

\section{Variáveis demográficas:}




\section{Ramon Antônio Oliveira}

- Idade do receptor: expressa em anos.

- Sexo do receptor: masculino ou feminino.

\section{Variáveis clínicas:}

- Status de tabagismo: sim ou não.

- Histórico de uso de tabaco: sim ou não.

- Quantificação do uso do tabaco: em maços por dia.

- Etilismo prévio ao transplante: sim ou não.

- Uso de bebida alcoólica: tipo e frequência (quantas vezes por semana).

- Quantificação do tempo de abstinência: em meses.

- Diagnóstico de indicação do transplante: cirrose hepática alcoólica; colangite esclerosante primária; cirrose hepática pelo vírus da hepatite B (VHB); cirrose hepática pelo vírus da hepatite $\mathrm{C}$ (VHC); cirrose biliar primária; cirrose hepática criptogênica; paramiloidose familiar; cirrose hepática por VHB e VHC; cirrose hepática por hepatite autoimune; carcinoma hepatocelular; doença hepática alcoólica não gordurosa (DHGNA); hepatite aguda fulminante; cirrose hepática por vírus da hepatite D; metástase hepática de carcinoma neuroendócrino; doença de Wilson; síndrome de Budd-Chiari; hemocromatose e cirrose hepática.

- Doenças de base: sim ou não e quais; DM; hipertensão arterial sistêmica (HAS); cardiopatia; obesidade; insuficiência renal crônica não dialítica e dialítica; hipotireoidismo; asma.

- Histórico de transplante de órgãos: fígado; pâncreas; intestino; rim; pulmão; coração; não submetido a transplantes.

- Tempo de espera na fila pelo transplante: expresso em anos e meses.

- Escore MELD sem correção quando indicado o transplante.

- Tratamento hemodialítico em decorrência da doença hepática: sim ou não.

- Data da internação para o transplante: expresso em dia, mês e ano.

- Escore MELD basal corrigido quando realizado o transplante.

- Índice de massa corporal (IMC): calculado a partir da expressão matemática IMC $=$ peso $(\mathrm{kg}) / \mathrm{altura}(\mathrm{m})^{2}$, expresso em $\mathrm{kg} / \mathrm{m}^{2}$. 


\section{Ramon Antônio Oliveira}

- Tempo de permanência hospitalar: calculado pela subtração da data de internação e a data de alta hospitalar ou da data correspondente ao $30 . \frac{0}{\text { dia de }}$ pós-operatório, expresso em dias.

- Ocorrência de óbito: sim ou não e data do óbito.

- Diagnóstico atribuído ao óbito: questão aberta.

- Uso de dispositivos invasivos: cateter venoso periférico; cateter venoso central e localização; sonda vesical de demora; cateter nasogástrico; cateter nasoentérico; cateter de oxigênio tipo óculos; via aérea artificial; cateter de pressão arterial invasiva; cateter central para hemodiálise.

- Classificação do estado físico de acordo com a American Society of Anesthesiology (ASA): expresso em ASA I, ASA II, ASA III, ASA IV e ASA V.

- Tempo de internação em UTI no pós-operatório: expresso em dias.

- Valores de glicemia capilar máximos e mínimos no pós-operatório: expressos em $\mathrm{mg} / \mathrm{dl}$.

- Análise do perfil de sensibilidade entre os classificados como portadores de ISC.

- Tempo de internação em unidade de internação cirúrgica: expresso em dias.

\section{Variáveis cirúrgicas:}

- Banho com solução antisséptica prévio ao transplante: sim ou não.

- Solução antisséptica utilizada no banho: clorexidina degermante ou polivinilpirrolidona (PVPI) degermante.

- Antissepsia da pele.

- Tricotomia da pele: sim ou não.

- Utilizado o tricotomizador elétrico: sim ou não.

- Procedência: enfermaria ou UTI.

- Data da realização do transplante: expresso em dia, mês e ano.

- Uso de antibiótico profilático: ampicilina; ampicilina+sulbactam; anfotericina; cefazolina; cefepima; ceftiaxona; cefuroxima; clindamicina; fluconazol; imipenem; levofloxacino; meropenem; metronidazol; piperaciclina; tazobactam; tazocin; teicoplanina; tienan; vancomicina.

- Horário da antibioticoprofilaxia: expresso em horas e minutos. 


\section{Ramon Antônio Oliveira}

- Horário de manutenção da antibioticoprofilaxia: expresso em horas e minutos ou não realizado.

- Horário de incisão da pele: expresso em horas e minutos.

- Tempo cirúrgico: obtido por meio da subtração do horário de incisão da pele e do horário da sutura da pele, expresso em minutos.

- Tempo de isquemia fria: tempo referente à retirada do órgão do doador até a anastomose vascular e biliar do receptor, expresso em minutos.

- Número de concentrado de hemácias utilizado no transoperatório: expresso em número absoluto.

- Volume de débito do líquido ascítico: expresso em ml.

- Uso de drogas vasopressoras no transoperatório: sim ou não.

- Dispositivos instalados no centro cirúrgico: cateter venoso periférico; cateter venoso central e localização; cateter de Swan-Ganz; cateter para monitorização de pressão arterial invasiva e localização; sonda vesical de demora.

- Ocorrência de reaborgem cirúrgica: sim ou não.

\section{Variáveis relacionadas à terapêutica:}

- Medicamentos utilizados para imunossupressão: prednisona; hidrocortisona; micofenolato de mofetila; ciclosporina; tacrolimo; micofenolato; metilprednisolona.

- Antibioticoterapia: piperaciclina+tazobactam; ampicilina; cefotaxima; clindamicina; anfotericina; vancomicina; cefepima; ceftriaxona; imipenem+cislastatina (tienam); ceftazidima; teicoplanina; fluconazol; meropenem; ciprofloxacino; ampicilina+sulbactam; polimixina B; cefuroxima; cefazolina; garamicina; linezulida.

\section{Variáveis relacionadas ao doador:}

- Idade do doador: expressa em anos.

- Sexo do doador: masculino ou feminino.

- IMC do doador: expresso em kg/m².

- Comorbidades: DM; HAS; injúria renal crônica dialítica; asma brônquica; tumor cerebral. 
- Causa mortis.

\subsection{ANÁLISE DOS DADOS}

Para análise dos dados foi construído um banco de dados no software Microsoft Excel for Mac 2011® e, posteriormente, os dados foram exportados para o software Statistical Package for the Social Sciences (SPSS) para o Windows $\AA$ versão 22.0.

Os resultados foram analisados com auxílio de um profissional estatístico, segundo os objetivos e metodologia proposta, com os testes descritos a seguir:

- As variáveis dicotômicas foram avaliadas por meio do teste $\mathrm{x} 2$ de Pearson ou teste de Fisher.

- As variáveis contínuas foram avaliadas por meio do teste t de Student ou MannWhitney.

- Para variáveis contínuas cuja distribuição era diferente da normal foi utilizado o teste de Wilcoxon-Mann-Whitney.

- Para análise de sobrevida foi utilizado o teste Log-rank (Mantel Cox).

- Após a análise bivariada, as variáveis reconhecidas pela literatura como fatores de risco para ISC foram incluídas na construção de um modelo de regressão CART (Classification and Regression Tree); para seleção das variáveis, utilizouse o critério de homogeneização de grupos, índice Gini e validação cruzada utilizada para diminuir o erro de classificação interna.

- O nível de significância adotado foi $\alpha=0,05$. 


\section{Resultados}




\section{RESULTADOS}

A população do estudo foi composta por 156 prontuários de pacientes, com idade igual ou superior a 18 anos, submetidos a transplante de fígado, no período de janeiro de 2009 a dezembro de 2015, em um hospital filantrópico do interior do Estado de São Paulo.

Os resultados serão apresentados em categorias, a saber: caracterização da população, caracterização do procedimento anestésico-cirúrgico e aspectos relacionados às ISC.

\subsection{Caracterização da população}

\subsubsection{Caracterização dos receptores}

Dos 156 receptores de transplante de fígado investigados, 114 (73,1\%) não desenvolveram ISC e $42(26,9 \%)$ a apresentaram; assim, a incidência de ISC no período investigado foi de $26,9 \%$.

Entre os pacientes incluídos, $1(0,6 \%)$ havia sido submetido ao transplante de rim e $1(0,6 \%)$ ao de fígado, ambos há mais de 100 dias e não acometidos por ISC durante o período de acompanhamento desta investigação.

Na população em estudo, 11 (7,1\%) pacientes foram censurados no 30.0 dia de pós-operatório. Desses, 6 (54,5\%) pacientes haviam desenvolvido ISC; no entanto, não houve associação estatística significante entre a censura no 30. e a ocorrência de ISC $(p=0,070)$.

Verificou-se que 123 (78,9\%) participantes eram do sexo masculino e 33 $(21,1 \%)$ do feminino, dentre os quais $48(30,8 \%)$ apresentavam DM e $40(25,6 \%)$ HAS. Quanto aos hábitos de vida, a maioria negou tabagismo (104; 66,7\%) e etilismo (98; 62,8\%) (Tabela 1). 
Entre o grupo que desenvolveu ISC (GISC) houve predomínio de sujeitos do sexo masculino (35; 83,3\%), na faixa etária dos 51 aos 60 anos, não tabagistas ou etilistas ou portadores de HAS e DM (Tabela 1).

A idade média do GISC foi de 54,9 anos ( $\pm 9,7$ anos), similar à idade média de 54,6 anos ( $\pm 10,6$ anos) dos pacientes não acometidos por ISC (NISC). Com relação ao IMC, a média no GISC foi de $28,2 \mathrm{~kg} / \mathrm{m}^{2}\left( \pm 5,3 \mathrm{~kg} / \mathrm{m}^{2}\right)$ e, entre o NISC, de 26,9 $\mathrm{kg} / \mathrm{m}^{2}\left( \pm 4,4 \mathrm{~kg} / \mathrm{m}^{2}\right)$ (Tabela 1$)$.

Os diagnósticos de indicação do transplante mais frequentes na população estudada foram cirrose hepática pelo VHC + CHC $(29 ; 18,2 \%)$, seguido pela cirrose hepática causada pelo VHC $(24 ; 15,4 \%)$. Verifica-se que, em relação ao GISC, a cirrose hepática alcoólica e a cirrose hepática pelo VHC destacaram-se como as principais causas de indicação do transplante; já entre os pacientes NISC, houve predomínio de cirrose hepática pelo VHC associado a $\mathrm{CHC}$, seguido pela cirrose hepática criptogênica (Tabela 1).

Combinações diagnósticas de indicação do transplante de menor frequência perfizeram sete casos entre o NISC. Assim, foram categorizados como outros diagnósticos: cirrose hepática causada por doença hepática gordurosa não alcoólica associada ao vírus da hepatite D; metástase de tumor neuroendócrino; doença de Wilson; colangite esclerosante primária; síndrome de Budd-Chiari; $\mathrm{CHC}$; tumor primário de fígado. Entre o GISC, um caso classificado como "outros diagnósticos" corresponde a cirrose hepática causada por doença hepática gordurosa não alcoólica (Tabela 1). 
Tabela 1- Distribuição de pacientes submetidos ao transplante de fígado de acordo com hábitos de vida, características clínicas, cirúrgicas e ocorrência de ISC. São Paulo, 20092015.

$\begin{array}{cccc}\text { Variáveis } & \begin{array}{c}\text { GISC } \\ (n=42)\end{array} & \begin{array}{c}\text { NISC } \\ (n=114)\end{array} & p\end{array}$

\section{Características dos receptores}

Idade, anos, média $( \pm \mathrm{DP})$

Peso, kg, média $( \pm D P)$

$\mathrm{IMC}, \mathrm{kg} / \mathrm{m}^{2}$, média $( \pm \mathrm{DP})$

Sexo masculino, $\mathrm{n}(\%)$

Sexo feminino, $\mathrm{n}(\%)$

Histórico de uso de tabaco, n (\%)

Histórico de uso de álcool, $\mathrm{n}(\%)$

Diabetes mellitus, $\mathrm{n}(\%)$

Hipertensão arterial sistêmica, n (\%)

$\begin{array}{ccc}54,9( \pm 9,7) & 54,6( \pm 10,6) & 0,912^{\star} \\ 80,5( \pm 17,8) & 77,6( \pm 15,9) & 0,460^{\star} \\ 28,2( \pm 5,3) & 26,9( \pm 4,4) & 0,238^{\star} \\ 35(28,5) & 88(71,5) & 0,405^{\star *} \\ 7(21,2) & 26(78,8) & 0,247^{\star *} \\ 17(31,5) & 37(68,5) & 0,770^{\star *} \\ 16(26,2) & 45(73,8) & 0,111^{\star *} \\ 17(35,4) & 31(64,6) & 0,924^{\star *} \\ 11(27,5) & 29(72,5) & \end{array}$

Diagnósticos de indicação do transplante

$\mathrm{CH}$ alcoólica, $\mathrm{n}(\%)$

$\mathrm{CH}$ pelo $\mathrm{VHC}, \mathrm{n}(\%)$

$\mathrm{CH}$ pelo $\mathrm{VHC}+\mathrm{CHC}, \mathrm{n}(\%)$

$\mathrm{CH}$ criptogênica, $\mathrm{n}(\%)$

$\mathrm{CH}$ alcoólica + VHC, $\mathrm{n}(\%)$

$10(43,5)$

$13(56,5)$

$\mathrm{n} / \mathrm{a}$

$8(33,3)$

$16(66,7)$

$\mathrm{n} / \mathrm{a}$

$6(20,7)$

$23(79,3)$

$\mathrm{n} / \mathrm{a}$

$5(21,7)$

$18(78,3)$

$\mathrm{n} / \mathrm{a}$

$3(37,5)$

$5(62,5)$

$\mathrm{n} / \mathrm{a}$

DHGNA, n (\%)

$3(27,3)$

$8(72,7)$

$\mathrm{n} / \mathrm{a}$

$\mathrm{CH}$ por hepatite autoimune, $\mathrm{n}(\%)$

$2(50,0)$

$2(50,0)$

$\mathrm{n} / \mathrm{a}$

$\mathrm{CH}$ alcoólica $+\mathrm{VHC}+\mathrm{CHC}, \mathrm{n}(\%)$

$2(25,0)$

$6(75,0)$

$n / a$

$\mathrm{CH}$ pelo $\mathrm{VHB}, \mathrm{n}(\%)$

$1(33,3)$

$2(66,7)$

$\mathrm{n} / \mathrm{a}$

$\mathrm{CH}$ pelo $\mathrm{VHB}+\mathrm{VHC}, \mathrm{n}(\%)$

$1(12,5)$

$7(87,5)$

$\mathrm{n} / \mathrm{a}$

$\mathrm{CH}$ alcoólica $+\mathrm{CHC}, \mathrm{n}(\%)$

$5(100,0)$

$\mathrm{n} / \mathrm{a}$

Hepatite aguda fulminante, $\mathrm{n}(\%)$

$\mathrm{CH}$ pelo $\mathrm{VHB}+\mathrm{VHC}, \mathrm{n}(\%)$

$1(100,0)$

$\mathrm{n} / \mathrm{a}$

Outros diagnósticos, $\mathrm{n}(\%)$

* Teste de Wilcoxon-Mann-Whitney; ${ }^{*}$ X2 de Pearson; n/a: não se aplica

$\mathrm{CH}$ : cirrose hepática; $\mathrm{CHC}$ : carcinoma hepatocelular; DHGNA: doença hepática gordurosa não alcoólica; VHB: vírus da hepatite B; VHC: vírus da hepatite C. 


\subsubsection{Caracterização dos doadores}

Foram obtidos os dados de 155 doadores; não foi possível recuperar os dados de apenas um $(0,64 \%)$ doador da população estudada devido à ausência da ficha de informações de doador de múltiplos órgãos.

Os dados dos doadores foram analisados segundo a ocorrência de ISC nos receptores. Observou-se que a média de idade, peso e IMC no GISC foi menor que a apresentada pelo grupo NISC; no entanto, não houve correlação estatística significante entre as variáveis analisadas e a ocorrência de ISC (Tabela 2).

A maioria, 90 (57,7\%) doadores, era do sexo masculino e não apresentava HAS $(98 ; 62,8 \%)$ ou DM $(154 ; 98,7 \%)$.

As causas externas estiveram relacionadas a $74(48,7 \%)$ causas mortis entre os doadores, seguidas pelas doenças cerebrovasculares em 55 (42,3\%) casos e doenças do sistema nervoso entre 14 (8,3\%) pacientes.

Não houve diferença estatística significativa entre os grupos quando comparadas as causas de óbitos dos doadores e a ocorrência de ISC (Tabela 2).

A interação das variáveis idade, sexo e diferenças entre as médias de IMC entre doador e receptor foi motivo de investigação. Assim, estudou-se a incompatibilidade de sexo entre doadores do sexo masculino e receptores do sexo feminino e as disparidades entre idades dos doadores e receptores, categorizadas em diferenças maiores ou menores que 10 anos; entretanto, foi constatada ausência de significância estatística (Tabela 2).

Foi calculada a diferença entre os valores de IMC dos doadores em relação aos receptores e a média por grupo com ou sem ISC. Assim, a diferença média para o GISC foi $6,5 \mathrm{~kg} / \mathrm{m}^{2}\left( \pm 6,0 \mathrm{~kg} / \mathrm{m}^{2}\right)$ e, para o grupo NISC, $4,2 \mathrm{~kg} / \mathrm{m}^{2}\left( \pm 3,7 \mathrm{~kg} / \mathrm{m}^{2}\right)$. Houve correlação estatisticamente significante entre as diferenças do IMC dos doadores em relação aos receptores e a ocorrência de ISC $(p=0,006)$ (Tabela 2). 
Tabela 2 - Distribuição de doadores de fígado falecidos de acordo com características clínicas, causa mortis e inter-relação de variáveis de doadores/receptores do transplante de acordo com a ocorrência de ISC. São Paulo, 2009-2015.

\section{Variáveis}

\section{Características dos doadores}

Idade, anos, média $( \pm D P)$

Peso, kg, média $( \pm D P)$

IMC, $\mathrm{kg} / \mathrm{m}^{2}$, média $( \pm \mathrm{DP})$

Sexo masculino, $\mathrm{n}(\%)$

Diabetes mellitus, $\mathrm{n}(\%)$

Hipertensão arterial sistêmica, n (\%)

\section{Causa mortis}

Causas externas, $\mathrm{n}(\%)^{1}$

Doenças cerebrovasculares, $\mathrm{n}(\%)$

Doenças do sistema nervoso, $\mathrm{n}(\%)$
GISC (n=42) NISC $(n=114) \quad p$

$\begin{array}{ccc}34,4( \pm 14,2) & 38,1( \pm 12,5) & 0,159^{*} \\ 72,3( \pm 12,3) & 73,0( \pm 13,8) & 0,181^{*} \\ 24,8( \pm 3,5) & 25,4( \pm 4,0) & 0,353^{*} \\ 28(31,1) & 62(68,9) & 0,186^{\star *} \\ - & 1(100,0) & 1,000^{* *} \\ 12(21,1) & 45(78,9) & 0,261^{* *}\end{array}$

$\begin{array}{ccc}23(28,7) & 57(71,3) & 0,632^{\star *} \\ 16(26,2) & 45(73,8) & 0,845^{\star *} \\ 3(21,4) & 11(78,6) & 0,760^{\star \star \star}\end{array}$

Inter-relação entre variáveis de doadores e receptores

Diferenças entre médias de IMC $D^{\ddagger}$ versus $R^{\dagger}$, média ( $\pm D P$ )

Doador masculino/receptor feminino, $\mathrm{n}(\%)$

$6,5( \pm 6,0)$

$4,2( \pm 3,7)$

$0,006^{*}$

Diferenças maiores que 10 anos, $\mathrm{n}(\%)$

$37(26,6) \quad 101(73,4) \quad 0,778^{* * *}$

$30(28,8) \quad 74(71,2) \quad 0,484^{\star *}$

* Teste de Wilcoxon-Mann-Whitney; ${ }^{* *} \mathrm{X} 2$ de Pearson; ${ }^{* * *}$ Teste exato de Fisher

'D: Doador; 'R: Receptor;

\subsection{Caracterização do procedimento anestésico-cirúrgico}

Foram realizados 156 (100\%) transplantes de fígado com enxertos provenientes de doadores falecidos. Entre os anos de 2012 e 2015, observou-se tendência de crescimento no número de procedimentos realizados no hospital em estudo (Tabela 3).

Os anos com maior número de casos de transplantes foram 2015, com 39 (25\%) casos; 2014, com 34 (21,8\%); 2010, com 27 (17,3\%); 2013, com 24 (15,4\%); e 2012 , com $18(11,5 \%)$.

Quanto ao número de casos de ISC, considerando o número de transplantes realizados no período, observa-se que os anos de 2015, 2011 e 2009 apresentaram maiores frequências relativas de casos de ISC, a saber: $41 \%, 37,5 \%$ e $33,3 \%$, 


\section{Ramon Antônio Oliveira}

respectivamente. Além disso, verificou-se que não houve associação estatística significativa entre o ano de realização do transplante e a ocorrência de ISC (Tabela $3)$.

Com relação ao tempo de espera para a realização do transplante, verifica-se discreta diferença entre os grupos. Para os participantes GISC, a média foi de 208,2 $( \pm 252,0)$ dias de espera, enquanto para o NISC foi de $188,3( \pm 293,8)$ dias $(p=0,639)$.

No período pré-operatório, a maioria dos pacientes, dos dois grupos, esteve internada em enfermaria cirúrgica, sendo 39 (92,9\%) do GISC e 106 (93\%) NISC. O tempo médio de internação hospitalar prévio ao transplante entre os que desenvolveram ISC variou de zero a 30 dias, média 2,6 dias ( $\pm 5,1$ dias). Entre os que não apresentaram ISC, esteve entre zero e 89 dias, média 2,49 ( $\pm 9,5$ dias). Cabe ressaltar que apenas um sujeito do grupo NISC esteve internado por 89 dias.

Com relação à avaliação geral do estado físico e comorbidades imediatamente antes do procedimento cirúrgico, expresso pelo escore ASA, a maioria dos pacientes em ambos os grupos foi classificada como ASA IV, ou seja, portadores de doença sistêmica grave (Tabela 3).

Em relação ao uso de dispositivos invasivos, no GISC, 20 (47,6\%) pacientes foram admitidos na sala operatória apenas com cateter venoso periférico. O mesmo pode ser verificado no grupo NISC, em que 51 (44,7\%) participantes foram admitidos com cateter venoso periférico e 53 (46,5\%) sem nenhum dispositivo invasivo (Tabela $3)$.

O banho pré-operatório foi relatado no prontuário de 123 (78,8\%) pacientes, dos quais 35 (83,3\%) pertenciam ao GISC e 88 (77,2\%) ao NISC. Foram encontrados relatos especificando a solução antisséptica utilizada para o procedimento em 115 (94,4\%) prontuários. O gluconato de clorexidina foi utilizado pela maioria dos pacientes (99; 80,5\%) e PVPI degermante por 16 (13,0\%) participantes. Além disso, 7 (16,7\%) pacientes GISC não foram submetidos ao banho pré-operatório e não foi observada associação estatística significante com a ocorrência de ISC (Tabela 3).

A tricotomia da pele foi relatada no prontuário de 120 pacientes, sendo 30 $(71,4 \%)$ pacientes GISC e 90 (78,9\%) pacientes NISC. A técnica empregada para a 
remoção dos pelos não foi informada em 85 (54,5\%) prontuários. O uso de lâmina para barbear foi identificado em 34 (21,8\%) prontuários; destes, 6 (14,3\%) pacientes eram GISC e 28 (24,6\%) NISC (Tabela 3).

O tempo médio entre a tricotomia e a incisão da pele no GISC foi de 317,2 minutos ( $\pm 243,2$ minutos) e menor para o grupo NISC, 297,1 ( $\pm 123,2$ minutos) (Tabela 3).

Tabela 3- Distribuição dos pacientes submetidos ao transplante de fígado de acordo com o ano de realização do transplante, estado físico, origem, preparo, dispositivos instalados no pré-operatório e ocorrência de ISC. São Paulo, 20092015.

\begin{tabular}{|c|c|c|c|}
\hline Variáveis & $\operatorname{GISC}(n=42)$ & NISC (n=114) & $\mathbf{p}$ \\
\hline \multicolumn{4}{|l|}{ Ano de realização do transplante } \\
\hline 2009, n (\%) & $2(33,3)$ & $4(66,7)$ & \\
\hline 2010, n (\%) & $7(25,9)$ & $20(74,1)$ & \\
\hline 2011, n (\%) & $3(37,5)$ & $5(62,5)$ & \\
\hline 2012, n (\%) & $2(11,1)$ & $16(88,9)$ & $0,125^{\star \star}$ \\
\hline $2013, \mathrm{n}(\%)$ & $7(29,2)$ & $17(70,8)$ & \\
\hline $2014, \mathrm{n}(\%)$ & $5(14,7)$ & $29(85,3)$ & \\
\hline 2015, n (\%) & $16(41,0)$ & $23(59,0)$ & \\
\hline $\begin{array}{l}\text { Tempo de espera para realização do } \\
\text { transplante, dias (média } \pm D P \text { ) }\end{array}$ & $\begin{array}{c}190,8 \\
( \pm 225,4)\end{array}$ & $188,3( \pm 293,8)$ & $0,639^{\star \star *}$ \\
\hline \multicolumn{4}{|l|}{ Estado físico } \\
\hline ASA III, n (\%) & $9(37,5)$ & $15(62,5)$ & \\
\hline ASA IV, n (\%) & $31(25,2)$ & $92(74,8)$ & $0,405^{\star *}$ \\
\hline ASA V, n (\%) & $2(22,2)$ & $7(77,8)$ & \\
\hline \multicolumn{4}{|l|}{ Origem e preparo pré-operatório } \\
\hline UTI, n (\%) & $3(27,3)$ & $8(72,7)$ & $1,000^{\star *}$ \\
\hline Banho, n (\%) & $35(28,5)$ & $88(71,5)$ & $0,626^{\star}$ \\
\hline Não realizado banho, n (\%) & $7(21,2)$ & $26(78,8)$ & $0,405^{\star}$ \\
\hline Tricotomia, n (\%) & $30(25,0)$ & $90(75,0)$ & $0,323^{*}$ \\
\hline $\begin{array}{l}\text { Intervalo entre a tricotomia e incisão da pele, } \\
\text { minutos (média } \pm D P \text { ) }\end{array}$ & $\begin{array}{c}317,2 \\
( \pm 243,2)\end{array}$ & $297,1( \pm 123,2)$ & $0,845^{\star * \star}$ \\
\hline \multicolumn{4}{|l|}{ Dispositivos invasivos no pré-operatório } \\
\hline CVP, n (\%) & $19(27,9)$ & $49(72,1)$ & $0,801^{*}$ \\
\hline CVC, n (\%) & - & $1(100,0)$ & $1,000^{* *}$ \\
\hline CVP+CVC+SNE+SVD, n (\%) & $1(50,0)$ & $1(50,0)$ & $0,467^{\star \star}$ \\
\hline CVC+SVD+SNE, n (\%) & - & $1(100,0)$ & $1,000^{* *}$ \\
\hline CVC+SVD+VM, n (\%) & - & $1(100,0)$ & $1,000^{\star *}$ \\
\hline
\end{tabular}




\section{Ramon Antônio Oliveira}

O escore MELD na indicação do transplante, ou seja, na inscrição do paciente na lista estadual de transplantes, apresentou média de $18,1( \pm 7,1)$ para o GISC e $16,8( \pm 6,5)$ entre o NISC. A média do escore MELD na realização do transplante foi de $18,5( \pm 7,8)$ para o GISC e $18,9( \pm 7,7)$ para o NISC (Tabela 4).

A média de tempo de isquemia fria do enxerto entre os pacientes GISC foi maior, ou seja, 422,5 ( $\pm 89,5)$ minutos; no NISC, 402,4 $( \pm 95,1)$ minutos. A média do tempo de anestesia foi de $588,1( \pm 78,3)$ minutos e $564,5( \pm 83,3)$ minutos entre os participantes GISC e NISC, respectivamente. A média do tempo cirúrgico entre o GISC foi de $504,1( \pm 125,1)$ minutos e, no NISC, $457,1( \pm 90,1)$ minutos. O tempo de anestesia $(p=0,025)$ e $o$ tempo de cirurgia $(p=0,038)$ apresentaram correlação estatisticamente significante para a ocorrência de ISC (Tabela 4).

Unidades de concentrado de hemácias foram administradas no transoperatório a $37(83,3 \%)$ pacientes GISC e a $89(78,1 \%)$ NISC. A média de unidades de concentrado de hemácias recebidas no transoperatório foi de 3,2 $( \pm 2,1)$ unidades pelos pacientes GISC e de 3,0 $( \pm 1,6)$ unidades entre participantes NISC. Além disso, não foi observada significância estatística $(p=0,858)$ (Tabela 4).

Antibióticos profiláticos foram administrados aos 156 (100\%) pacientes. Os principais medicamentos utilizados para a realização desse procedimento foram os das classes das penicilinas e cefalosporinas de segunda e terceira gerações por via intravenosa. A ampicilina foi utilizada em 35 (83,3\%) pacientes GISC e 87 (76,3\%) NISC. As cefalosporinas foram utilizadas em 38 (90,5\%) pacientes GISC e 82 (71,9\%) pacientes NISC (Tabela 4).

O intervalo entre a administração da antibioticoprofilaxia e a incisão da pele não foi calculado, tendo em vista a omissão da informação em 97 (62,2\%) prontuários. O mesmo fato foi observado para a reaplicação (repique) do antibiótico profilático, pois os dados não foram informados em 154 (98,7\%) prontuários.

Dos 156 pacientes submetidos ao transplante, $111(71,1 \%)$ receberam drogas vasopressoras no transoperatório, sendo 32 (76,2\%) no GISC e 79 (69,3\%) no NISC (Tabela 4).

Quanto à instalação de dispositivos invasivos no transoperatório, não foram observadas diferenças entre os grupos, pois 152 (97,4\%) pacientes receberam cateter venoso periférico; $153(98,1 \%)$, cateter venoso central na veia jugular interna 
ou veia subclávia; 153 (98,1\%), cateter para mensuração de pressão arterial invasiva na artéria radial; 150 (96,1\%) pacientes foram submetidos a cateterização vesical de demora; e 153 (98,1\%) foram submetidos a sondagem nasogástrica (Tabela 4). Cabe ressaltar que os pacientes que não receberam esses procedimentos no transoperatório já o haviam realizado na unidade de origem.

O débito de líquido ascítico no transoperatório foi mensurado entre 131 $(84,0 \%)$ sujeitos, resultando na média de 2.663,3 $( \pm 3.784,3) \mathrm{ml}$. Observou-se débito maior que $1.000 \mathrm{ml}$ entre 15 (35,7\%) pacientes GISC e entre 40 (35,1\%) participantes GISC, não havendo, assim, diferença estatística significante ( $p=0,903)$ (Tabela 4).

Tabela 4- Distribuição de pacientes submetidos ao transplante de fígado de acordo com características do transoperatório e ocorrência de ISC. São Paulo, 2009-2015.

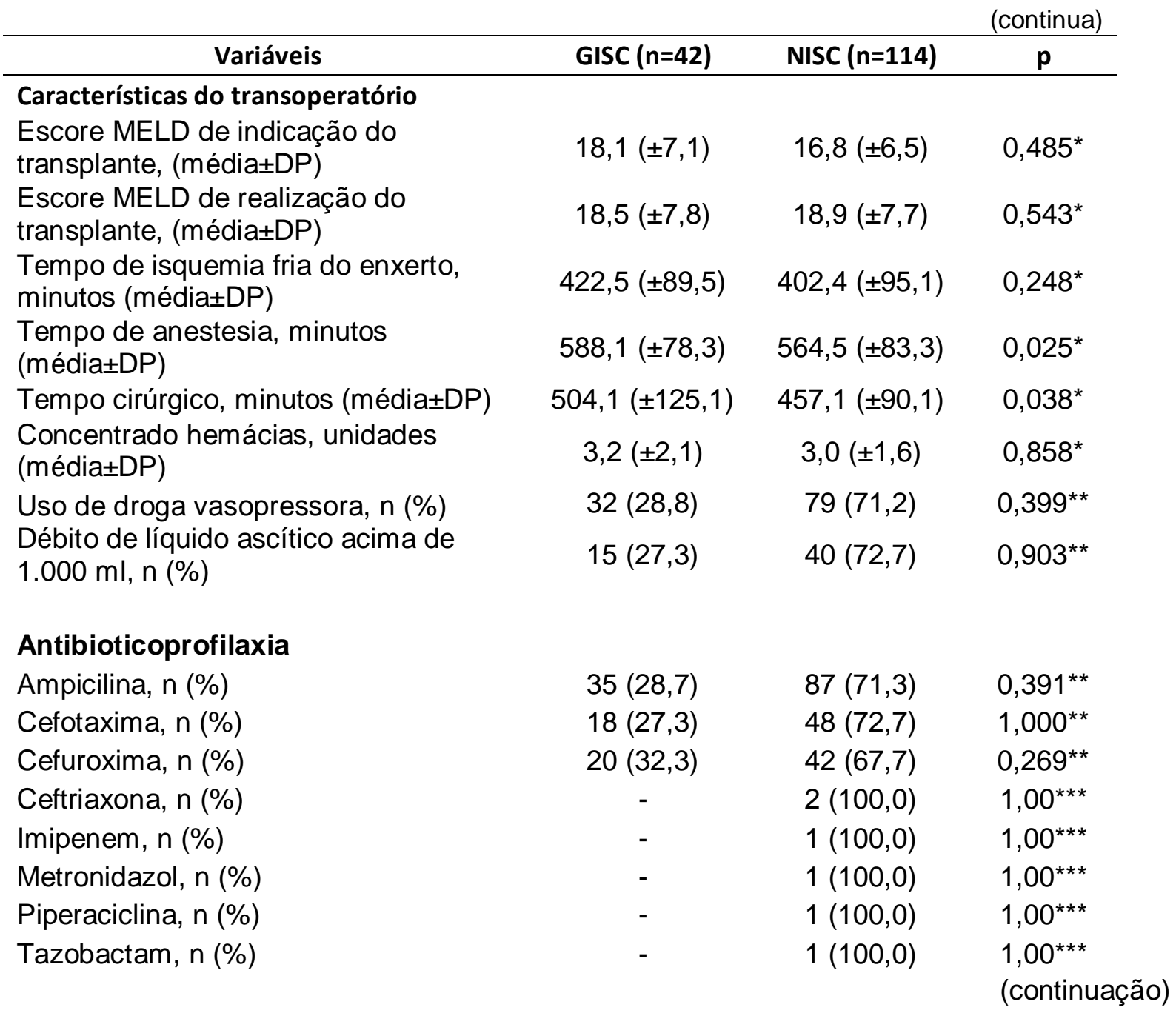




\begin{tabular}{|c|c|c|c|}
\hline Variáveis & GISC (n=42) & NISC $(n=114)$ & $\mathbf{p}$ \\
\hline Teicoplanina, $\mathrm{n}(\%)$ & $1(16,7)$ & $5(83,3)$ & $1,00^{\star * \star}$ \\
\hline Vancomicina, $\mathrm{n}(\%)$ & - & $1(100,0)$ & $1,00^{\star \star *}$ \\
\hline Tienam, n (\%) & - & $2(100,0)$ & $1,00^{\star * *}$ \\
\hline Tazocin, n (\%) & $3(23,1)$ & $10(76,9)$ & $1,00^{* * *}$ \\
\hline Fluconazol, n (\%) & - & $1(100,0)$ & $1,00^{\star * *}$ \\
\hline Levofloxacino, n (\%) & - & $1(100,0)$ & $1,00^{\star \star *}$ \\
\hline Cefazolina, n (\%) & - & $2(100,0)$ & $1,00^{\star * *}$ \\
\hline \multicolumn{4}{|c|}{ Dispositivos invasivos instalados no transoperatório } \\
\hline CVP, n (\%) & $42(27,6)$ & $110(72,4)$ & $0,575^{\star \star *}$ \\
\hline CVC jugular interna, n (\%) & $40(26,8)$ & $109(73,2)$ & $1,000^{\star * \star}$ \\
\hline CVC subclávia, n (\%) & $2(50,0)$ & $2(50,0)$ & $0,293^{\star * \star}$ \\
\hline SVD, n (\%) & $42(28,0)$ & $108(72,0)$ & $0,192^{\star * *}$ \\
\hline Cateter PAI em artéria radial, $\mathrm{n}(\%)$ & $41(26,8)$ & $112(73,2)$ & $1,000^{\star * *}$ \\
\hline SNG, n (\%) & $42(27,5)$ & $111(72,5)$ & $0,564^{\star \star \star}$ \\
\hline
\end{tabular}

No pós-operatório, a maioria dos pacientes GISC utilizou o medicamento tacrolimo (41; 97,6\%), seguido pelo ácido micofenólico (40; 95,2\%), metilprednisolona $(37 ; 88,1 \%)$ e prednisona $(35 ; 83,3 \%)$. Proporções semelhantes foram observadas entre os pacientes do grupo NISC, pois o fármaco ácido micofenólico foi utilizado por $102(70,8 \%)$ pacientes, seguido pelo tacrolimo em 103 (71,5\%); metilprednisolona foi administrada a $107(74,3 \%)$ pacientes e prednisona a $81(56,2 \%)$. Não pode ser inferida associação estatística entre os medicamentos imunossupressores e a ocorrência de ISC (Tabela 5).

No pós-operatório, a média de dias de internação em unidade de terapia intensiva foi de $10,9( \pm 1,1)$ dias entre participantes GISC e de $9,3( \pm 0,7)$ dias para os NISC. Não foi observada diferença estatística significante entre os grupos $(p=0,085)$; entretanto, ao se investigar o tempo de internação pós-operatória, obteve-se média de $21,6( \pm 1,2)$ dias para os pacientes GISC e de $16,1( \pm 0,9)$ dias para os NISC, o que resultou em diferença estatística significante ( $p=0,001)$ (Tabela 5$)$.

A reinternação em unidade de terapia intensiva foi uma variável associada à ocorrência de ISC $(p=0,05)$ e ocorreu entre quatro pacientes; destes, três $(75 \%)$ 
pertenciam ao grupo GISC e apenas um (25\%) ao grupo NISC ( $p=0,05)$. Quatorze pacientes foram submetidos a reabordagem cirúrgica, dos quais quatro $(28,6 \%)$ desenvolveram ISC (Tabela 5).

Com base nos valores glicêmicos mínimos e máximos diários, foram elaboradas médias das primeiras 96 horas de pós-operatório, de acordo com 0 acometimento ou não por ISC. Posteriormente, foi elaborada uma tabela de confusão na qual se obteve como ponto de corte o valor de $175 \mathrm{mg} / \mathrm{dl}$, com sensibilidade de $54,7 \%$ e especificidade de $71,1 \%$. Além disso, pacientes com média de glicemia capilar superior a $175 \mathrm{mg} / \mathrm{dl}$ nas primeiras 96 horas após o transplante apresentaram chance aproximadamente três vezes maior de serem acometidos por ISC quando comparados aos participantes cuja média manteve-se abaixo desse valor (OR 2,97; IC 95\% 1,43-6,17; p=0,002) (Tabela 5).

Tabela 5- Distribuição de pacientes submetidos ao transplante de fígado de acordo com características clínicas e assistenciais do pós-operatório e ocorrência de ISC. São Paulo, 2009-2015.

\begin{tabular}{|c|c|c|c|}
\hline Variáveis & $\begin{array}{c}\text { GISC } \\
(n=42)\end{array}$ & $\begin{array}{c}\text { NISC } \\
(n=114)\end{array}$ & $\mathbf{p}$ \\
\hline \multicolumn{4}{|l|}{ Imunossupressor recebido } \\
\hline Prednisona, n (\%) & $35(30,2)$ & $81(69,8)$ & $0,119^{*}$ \\
\hline Ácido mecofenólico, n (\%) & $40(28,2)$ & $102(71,8)$ & $0,355^{\star *}$ \\
\hline Tacrolimo, $\mathrm{n}(\%)$ & $41(28,5)$ & $103(71,5)$ & $0,183^{* *}$ \\
\hline Metilprednisolona, $\mathrm{n}(\%)$ & $37(25,7)$ & $107(74,3)$ & $0,307^{\star \star}$ \\
\hline \multicolumn{4}{|l|}{$\begin{array}{l}\text { Glicemia capilar nas primeiras } 96 \text { horas após o } \\
\text { transplante }\end{array}$} \\
\hline Glicemia capilar maior que 175 mg/dl, n (\%) & $23(41,1)$ & $33(58,9)$ & $0,002^{*}$ \\
\hline \multicolumn{4}{|l|}{ Efeitos da ISC } \\
\hline Tempo de internação em UTI, dias (médiatDP) & $10,9( \pm 1,1)$ & $9,3( \pm 0,7)$ & $0,085^{\star \star *}$ \\
\hline $\begin{array}{l}\text { Tempo total de internação pós-operatória, dias } \\
\text { (média } \pm D P)\end{array}$ & $21,6( \pm 1,2)$ & $16,1( \pm 0,9)$ & $0,001^{* * *}$ \\
\hline Reinternação em UTI, n (\%) & $3(75,0)$ & $1(25,0)$ & $0,05^{\star *}$ \\
\hline Reabordagem cirúrgica, n (\%) & $4(28,6)$ & $10(71,4)$ & $1,000^{* *}$ \\
\hline
\end{tabular}

${ }^{*} \mathrm{x} 2$ de Pearson; ${ }^{* *}$ Teste exato de Fisher; ${ }^{* * *}$ Log Rank (Mantel Cox)

Notou-se que, de modo geral, as médias de glicemia capilar entre os pacientes NISC apresentaram-se menores que os GISC em todo o período analisado (Gráfico 1). 


\section{Ramon Antônio Oliveira}

Observa-se que, nos dias iniciais após o transplante, a glicemia em ambos os grupos apresentou médias entre 181,2 e 191,5 mg/dl para os grupos NISC e GISC, respectivamente, com redução das médias até o quarto dia para os pacientes NISC, enquanto os pacientes GISC apresentam elevação das médias no quarto dia (Gráfico 1).

Gráfico 1 - Média dos valores de glicemia capilar entre receptores de transplante de fígado em 14 dias de pós-operatório. São Paulo, 2009-2014.

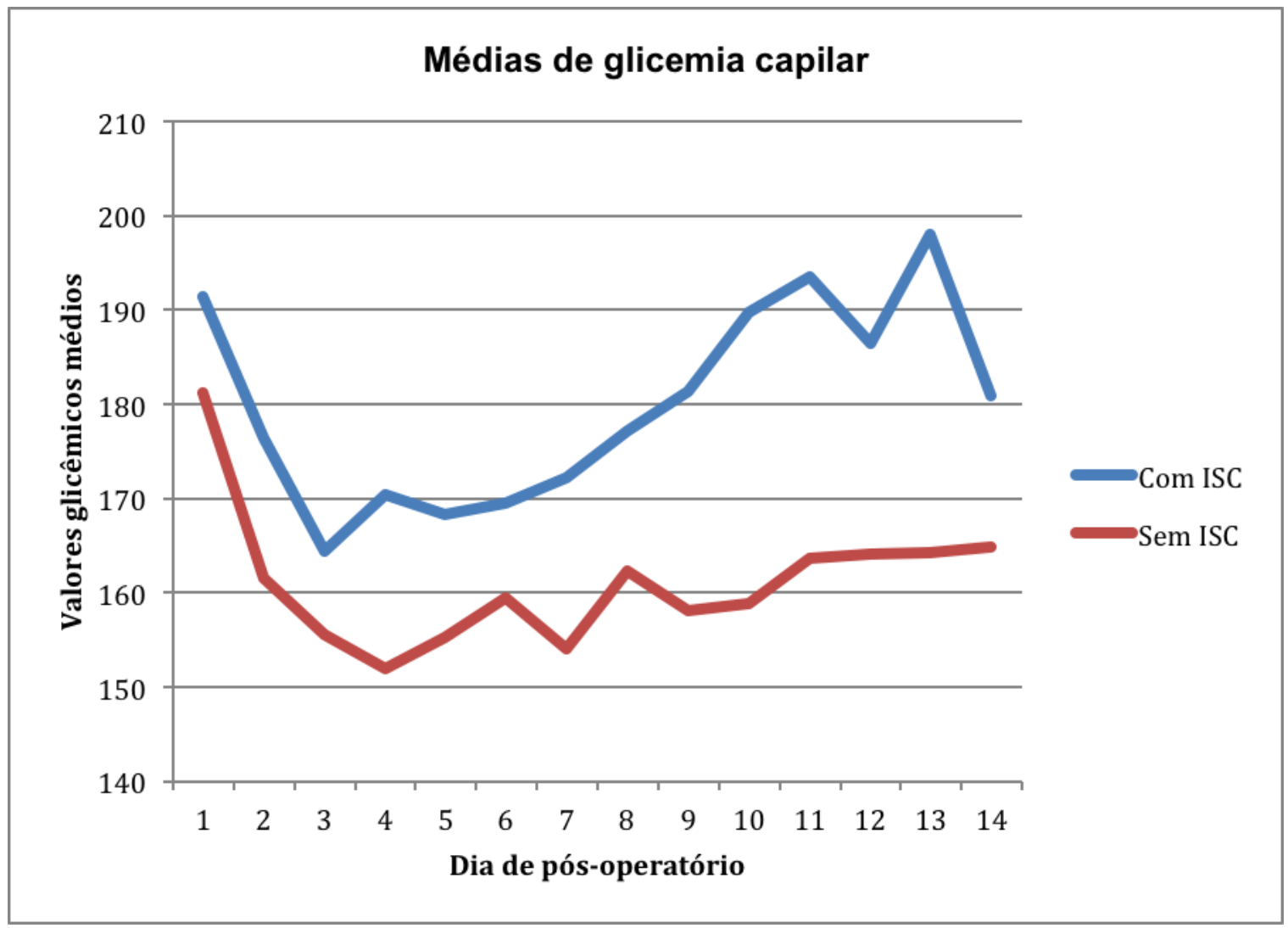

Entre os 156 (100\%) pacientes submetidos ao transplante de fígado avaliados, $22(14,1 \%)$ faleceram entre o quarto e o 29. dia após o procedimento cirúrgico, com média de $9,9( \pm 6,6)$ dias e mediana de 8 dias. Não foram observadas diferenças estatísticas significativas entre os grupos na comparação entre mortalidade e ocorrência de ISC $(p=0,462)$. 


\subsection{CARACTERÍSTICAS RELACIONADAS ÀS INFECÇÕES DO SíTIO CIRÚRGICO}

Como mencionado previamente, a taxa de ISC no período foi de $26,9 \%$. A classificação de ISC ocorreu por meio da busca de informações no prontuário dos pacientes ante os critérios diagnósticos para ISC estabelecidos pelo $\mathrm{CDC}^{(2)}$.

Observou-se que os sinais e sintomas diagnósticos de ISC passaram a manifestarse em média em 7,8 $( \pm 2,9)$ dias, mediana 8 dias. Além disso, observou-se que a maioria dos casos $(33 ; 78,6 \%)$ foram detectados entre o quinto e o décimo primeiro dia de pós-operatório.

Quanto à classificação topográfica das ISC, a de maior destaque foi a ISC incisional profunda, com $23(54,8 \%)$ casos. Analisadas em conjunto, a ISC superficial e a ISC em órgão ou cavidade foram responsáveis por 19 (45,2\%) casos. Além disso, observou-se que 23 (54,8\%) pacientes não tiveram o diagnóstico de ISC registrado no prontuário por um profissional médico (Tabela 6).

Todos os pacientes que desenvolveram ISC superficial (10; 100\%) apresentaram drenagem purulenta da incisão superficial, nove $(90 \%)$ relataram dor e em seis (60\%) notou-se hiperemia na região da ferida operatória (Tabela 6).

No grupo dos 23 (100\%) pacientes que manifestaram ISC incisional profunda, em todos $(100 \%)$ foi aferida temperatura axilar maior que $38^{\circ} \mathrm{C}$, em $20(87 \%)$ pacientes foi observada drenagem purulenta da incisão profunda e seis $(26,1 \%)$ pacientes referiram dor ou sensibilidade local (Tabela 6).

Quanto aos casos de ISC em órgão ou cavidade, oito $(88,9 \%)$ pacientes tiveram drenagem purulenta proveniente de um dreno situado dentro da cavidade. Em três $(33,3 \%)$ casos, a ISC foi identificada por meio da coleta e cultura de fluidos obtidos de forma asséptica (Tabela 6 ). 
Tabela 6- Distribuição de pacientes submetidos ao transplante de fígado que desenvolveram ISC de acordo com critérios diagnósticos, presença de registro do diagnóstico médico e sítios de coleta de material para cultura. São Paulo, 2009-2015.

\begin{tabular}{cc}
\hline Variáveis & $\mathbf{n}(\%)$ \\
Diagnóstico médico de ISC & $19(45,2)$
\end{tabular}

ISC superficial $(\mathrm{n}=\mathbf{1 0})$

Drenagem purulenta da incisão superficial

$10(100,0)$

Edema

$1(10,0)$

Hiperemia

$6(60,0)$

Dor

$9(90,0)$

ISC incisional profunda $(n=23)$

Drenagem purulenta de incisão profunda

$20(87,0)$

Deiscência

Temperatura axilar $>38^{\circ} \mathrm{C}$

$23(100,0)$

Dor ou sensibilidade local

$6(26,1)$

Abscesso nos planos profundos da ferida

$1(4,3)$

ISC órgão ou cavidade ( $\mathrm{n}=\mathbf{9})$

Drenagem purulenta de um dreno situado na cavidade

$8(88,9)$

Cultura positiva de fluidos obtidos de forma asséptica

$3(33,3)$

Abscesso em órgão ou cavidade

Realização de cultura $(n=42)$

$28(66,7)$

Sítio de coleta $(n=28)$

Sangue por meio de cateter vascular central

$7(25,0)$

Ponta de cateter vascular central

$6(21,4)$

Secreção da ferida operatória

Secreção de dreno localizado na cavidade

$4(14,3)$

Urina

$3(10,7)$

Líquido ascítico

$2(7,1)$

Material proveniente de reoperação

$1(3,6)$

Nota-se que todos os pacientes receberam antimicrobianos no pós-operatório. Entre os GISC, destaca-se o uso dos medicamentos das classes das penicilinas, glicopeptídeos, antifúngicos e carbapenêmicos (Tabela 7). 
Tabela 7- Distribuição de pacientes submetidos ao transplante de fígado de acordo com medicamentos antimicrobianos administrados no pós-operatório e ocorrência de ISC. São Paulo, 2009-2015.

\begin{tabular}{lccc}
\hline \multicolumn{1}{c}{ Variáveis } & GISC (n=42) & NISC (n=114) & p \\
\hline Ampicilina, n (\%) & $29(28,7)$ & $72(71,3)$ & $0,573^{*}$ \\
Teicoplanina, n (\%) & $26(45,6)$ & $31(54,4)$ & $<0,010^{*}$ \\
Fluconazol, n (\%) & $23(46,0)$ & $27(54,0)$ & $<0,010^{*}$ \\
Meropenem, n (\%) & $19(37,3)$ & $32(62,7)$ & $0,054^{*}$ \\
Cefotaxima, n (\%) & $19(31,1)$ & $42(68,9)$ & $0,360^{*}$ \\
Piperaciclina+tazobactam, n (\%) & $18(40,9)$ & $26(59,1)$ & $0,017^{*}$ \\
Cefuroxima, n (\%) & $14(32,6)$ & $29(67,4)$ & $0,419^{*}$ \\
Metronidazol, n (\%) & $6(46,2)$ & $7(53,8)$ & $0,113^{* *}$ \\
Vancomicina, n (\%) & $5(55,6)$ & $4(44,4)$ & $0,060^{* *}$ \\
Ciprofloxacino, n (\%) & $5(35,7)$ & $9(64,3)$ & $0,528^{* *}$ \\
Ampicilina + sulbactam, n (\%) & $4(36,4)$ & $7(63,6)$ & $0,488^{* *}$ \\
Imipenem + cilastatina, n (\%) & $2(100,0)$ & - & $0,071^{* *}$ \\
Cefepima, n (\%) & - & $5(100,0)$ & $0,325^{* *}$ \\
Clindamicina, n (\%) & - & $1(100,0)$ & $1,000^{* *}$ \\
Polimixina B, n (\%) & - & $2(100,0)$ & $1,000^{* *}$ \\
\hline
\end{tabular}

${ }^{*} \mathrm{x} 2$ de Pearson; ${ }^{* *}$ Teste exato de Fisher

Dentre os 42 (100\%) pacientes GISC, foram colhidas amostras para realização de exames de cultura e antibiograma de $28(66,7 \%)$ sujeitos.

Em seis $(21,4 \%)$ participantes foram coletados materiais para mais de um tipo de análise, como hemocultura e cultura de secreção do dreno abdominal. Assim, foram consideradas para essa análise 36 exames de cultura e antibiograma, das quais oito eram negativas. Portanto, foram analisados os resultados de 28 culturas e antibiogramas.

Destaca-se que $12(42,8 \%)$ amostras envolveram diretamente a detecção de micro-organismos para o diagnóstico de ISC, pois foram coletados secreção da ferida operatória, dreno, líquido ascítico ou material de reoperação (Tabela 8).

Entre as culturas positivas, verificou-se o crescimento de nove $(32,1 \%)$ bactérias Gram-positivas, 18 (64,2\%) Gram-negativas e um (3,6\%) fungo.

Dentre os 11 agentes detectados pelos exames de cultura nas topografias secreção da ferida operatória, secreção de dreno localizado na cavidade, líquido ascítico e material de reoperação, os de maior frequência foram Staphylococcus sp., Pseudomonas aeruginosa, Klebsiella sp. e Acinetobacter baumanii. Cabe destacar a 


\section{Ramon Antônio Oliveira}

ISC causada pelo fungo Candida albicans, o qual foi detectado em uma amostra de secreção de dreno localizado na cavidade (Tabela 8).

Tabela 8- Distribuição de pacientes submetidos ao transplante de fígado que desenvolveram ISC de acordo os micro-organismos isolados, coloração de Gram, espécie e sítio de coleta. São Paulo, 2009-2015.

\begin{tabular}{|c|c|c|c|c|c|c|}
\hline 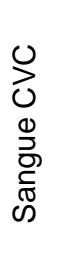 & 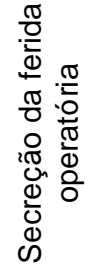 & 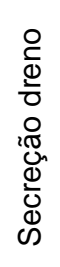 & 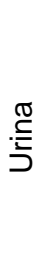 & 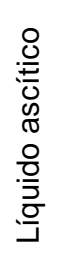 & 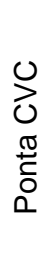 & 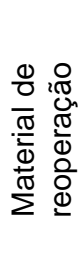 \\
\hline
\end{tabular}

\section{Gram-positivos}

Enterococcus sp. n (\%)

$1(3,5) \quad 1(3,5) \quad 1(3,5)$

$5(17,5)$

$8(28,0)$

Gram-negativos

$P$. aeruginosa, $\mathrm{n}(\%)$

Proteus sp., n (\%)

$1(3,5)$

$2(7,0)$

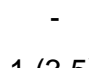

$2(7,0) \quad 1(3,5)$

$1(3,5)$

Klebsiella sp., n (\%)

$2(7,0)$

$1(3,5)$

Escherichia coli, $\mathrm{n}(\%)$

$1(3,0)$

-

$\begin{array}{cccc}- & - & - & - \\ - & - & - & - \\ 1(3,5) & 1(3,5) & - & - \\ - & - & & \\ 1(3,0) & 1(3,0) & 1(3,0) & 1(3,0) \\ 1(3,5) & - & - & -\end{array}$

$2(7,0)$

E. cloacae, n (\%)

\section{Fungo}

C. albicans, $\mathrm{n}(\%)$

Total $7(24,5) \quad 5(17,5)$

O perfil de resistência bacteriana foi investigado de acordo com o sítio de coleta. A partir do número de exemplares de micro-organismos isolados nas amostras, pode-se inferir que, entre os encontrados no sangue coletado por meio de CVC, foram testadas em média 7,8 classes de antimicrobianos, com resistência a antimicrobianos em $61,7 \%$ dos testes realizados.

Para o sítio de coleta ponta de CVC, foi isolado apenas um micro-organismo, o A. baumanii, que apresentou resistência a cinco classes de antibióticos entre oito testadas.

No sítio de coleta líquido ascítico, foram isolados dois micro-organismos: $A$. baumanii e K. pneumoniae. O primeiro apresentou perfil de resistência diferente 
daquele verificado no sangue coletado de CVC, pois foi resistente a monobactâmico, ureidopenicilinas, aminoglicosídeos, cloranfenicol e quinolonas.

Nas coletas de urina foram encontrados três micro-organismos. Um exemplar de E. cloacae foi isolado somente nessa amostra e apresentou resistência à maioria dos betalactâmicos testados, aminoglicosídeos, tetraciclinas e quinolonas.

$\mathrm{Na}$ secreção coletada a partir de dreno situado em cavidade, foram isolados um fungo ( $C$. albicans) e três bactérias, das quais $E$. coli e $P$. vulgaris apresentaram resistência à maioria dos betalactâmicos testados, tetraciclinas e cloranfenicol. O S. aureus apresentou resistência às cefalosporinas e às quinolonas; no entanto, mostrou-se sensível às tetraciclinas, cloranfenicol, glicopeptídeos e oxazolididonas.

$\mathrm{Na}$ secreção coletada da ferida operatória, encontrou-se um exemplar dos micro-organismos E. faecalis, K. oxytoca, S. epidermidis e dois de $P$. aeruginosa. Parece comum a eles a resistência à maioria dos betalactâmicos e aminoglicosídeos.

Com relação ao material de reoperação, foi isolado $A$. baumanii resistente a três classes de betalactâmicos e sensível às tetraciclinas e quinolonas (Tabela 9). 
Tabela 9 - Perfil de sensibilidade e resistência de micro-organismos isolados entre pacientes submetidos ao transplante de fígado que apresentaram ISC, por sítio de coleta e grupos de antimicrobianos. São Paulo, 2009-2015.

(continua)

\begin{tabular}{|c|c|c|c|c|c|c|c|c|c|c|c|c|c|c|c|c|c|c|c|c|c|c|}
\hline \multirow[b]{3}{*}{$\begin{array}{l}\text { Grupos/ } \\
\text { subgrupos }\end{array}$} & \multirow[b]{3}{*}{$\bar{E}$} & \multicolumn{21}{|c|}{ Sítio de coleta, agente isolado (n) } \\
\hline & & \multicolumn{5}{|c|}{ Sangue } & \multicolumn{2}{|c|}{ Ponta CVC } & \multicolumn{2}{|c|}{$\begin{array}{l}\text { Líquido } \\
\text { ascítico }\end{array}$} & \multicolumn{3}{|c|}{ Urina } & \multicolumn{4}{|c|}{ Secreção do dreno* } & \multicolumn{4}{|c|}{ Secreção FO** } & $\begin{array}{l}\text { Material } \\
\text { Reop*** }\end{array}$ \\
\hline & & 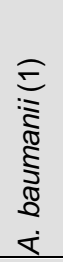 & $\begin{array}{l}\text { న్ } \\
\bar{\delta} \\
\text { 山े }\end{array}$ & 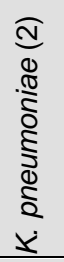 & 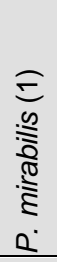 & 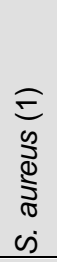 & 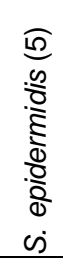 & 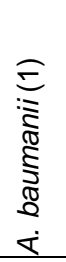 & 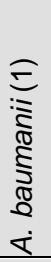 & 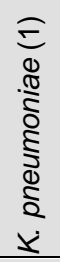 & 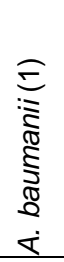 & $\begin{array}{l}\widehat{E} \\
\mathbb{\Xi} \\
\mathbb{J} \\
\mathbb{0} \\
0 \\
\text { u }\end{array}$ & 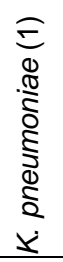 & 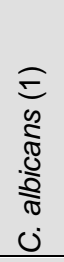 & $\begin{array}{c}\widehat{E} \\
\overline{0} \\
\text { 山i }\end{array}$ & 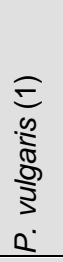 & 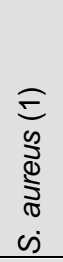 & 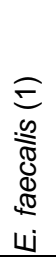 & $\begin{array}{l}\text { E } \\
\mathbb{8} \\
\delta \\
\frac{0}{x} \\
0 \\
\dot{x} \\
\dot{x}\end{array}$ & 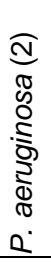 & 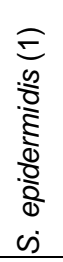 & 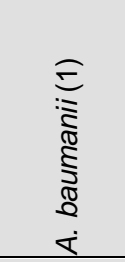 \\
\hline \multicolumn{23}{|l|}{$\beta$-lactâmicos } \\
\hline \multirow[t]{2}{*}{ Aminopenicilinas } & $S$ & 1 & 1 & - & - & - & - & 1 & 1 & - & 1 & - & - & - & - & - & - & 1 & - & - & - & - \\
\hline & $\mathrm{R}$ & - & 1 & 2 & 1 & - & - & - & - & 1 & - & 1 & 1 & - & 1 & 1 & - & - & 1 & - & - & - \\
\hline \multirow[t]{2}{*}{ Monobactâmico } & $S$ & - & 1 & - & - & - & - & - & - & 1 & - & - & - & - & - & - & - & - & - & 1 & - & - \\
\hline & $\mathrm{R}$ & - & 1 & 2 & 1 & - & - & - & 1 & - & - & 1 & 1 & - & 1 & 1 & - & - & 1 & 1 & - & - \\
\hline \multirow[t]{2}{*}{ Cefalosporinas } & $S$ & 1 & 1 & - & - & - & - & - & - & - & - & - & - & - & - & - & - & - & - & 1 & - & - \\
\hline & $\mathrm{R}$ & - & 1 & 2 & 1 & - & - & 1 & - & 1 & 1 & 1 & 1 & - & 1 & 1 & 1 & - & 1 & 1 & - & 1 \\
\hline \multirow[t]{2}{*}{ Isoxalilpenicilinas } & $S$ & - & - & - & - & - & - & - & - & - & - & - & - & - & - & - & 1 & - & - & - & - & - \\
\hline & $\mathrm{R}$ & - & - & - & - & 1 & 5 & - & - & - & - & - & - & - & - & - & - & - & - & - & - & - \\
\hline \multirow{2}{*}{ Ureidopenicilinas } & $S$ & 1 & 2 & 2 & 1 & - & - & - & - & 1 & - & 1 & 1 & - & 1 & 1 & - & - & - & 1 & - & - \\
\hline & $\mathrm{R}$ & - & - & - & - & - & - & 1 & 1 & - & 1 & - & - & - & - & - & - & - & 1 & 1 & - & 1 \\
\hline \multirow{2}{*}{ Carbapenêmicos } & $S$ & 1 & 2 & 2 & 1 & - & - & - & 1 & 1 & - & 1 & 1 & - & 1 & 1 & - & - & 1 & 1 & - & - \\
\hline & $\mathrm{R}$ & - & - & - & - & - & - & 1 & - & - & 1 & - & - & - & - & - & - & - & - & 1 & - & 1 \\
\hline \multirow[t]{2}{*}{ Aminoglicosídeos } & $S$ & 1 & 1 & 1 & 1 & - & 2 & - & - & - & - & - & - & - & 1 & - & 1 & - & - & 1 & - & 1 \\
\hline & $\mathrm{R}$ & - & 1 & 1 & - & 1 & 3 & 1 & 1 & 1 & 1 & 1 & 1 & - & - & 1 & - & 1 & 1 & 1 & 1 & - \\
\hline
\end{tabular}




\begin{tabular}{|c|c|c|c|c|c|c|c|c|c|c|c|c|c|c|c|c|c|c|c|c|c|c|}
\hline \multirow[b]{3}{*}{ Grupos/subgrupos } & \multirow[b]{3}{*}{ 产 } & \multicolumn{21}{|c|}{ Sítio de coleta, agente isolado ( $\mathrm{n}$ ) } \\
\hline & & \multicolumn{5}{|c|}{ Sangue } & \multicolumn{2}{|c|}{ Ponta CVC } & \multicolumn{2}{|c|}{$\begin{array}{l}\text { Líquido } \\
\text { ascítico }\end{array}$} & \multicolumn{3}{|c|}{ Urina } & \multicolumn{4}{|c|}{ Secreção do dreno* } & \multicolumn{4}{|c|}{ Secreção FO** } & \multirow[t]{2}{*}{$\begin{array}{l}\text { Material } \\
\text { Reop*** }\end{array}$} \\
\hline & & 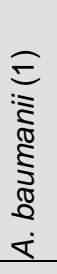 & $\begin{array}{l}\text { త্ } \\
\text { ठิ } \\
\text { wi }\end{array}$ & 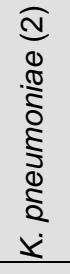 & 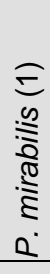 & 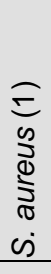 & 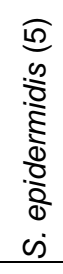 & 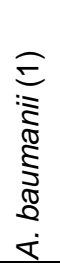 & 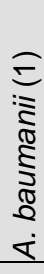 & 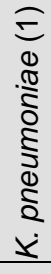 & 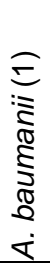 & $\begin{array}{l}\text { E } \\
0 \\
\mathbb{0} \\
0 \\
0 \\
0 \\
0 \\
\text { U }\end{array}$ & 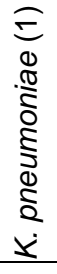 & 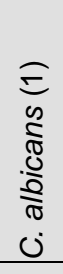 & $\begin{array}{l}\text { E } \\
\text { ¿े } \\
\text { ن }\end{array}$ & $\begin{array}{l}\text { E } \\
.0 \\
\frac{0}{\pi} \\
\frac{0}{3} \\
3 \\
2 \\
0\end{array}$ & 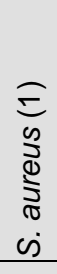 & 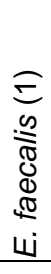 & 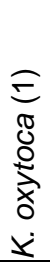 & 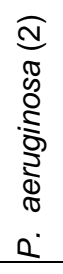 & 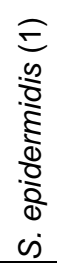 & \\
\hline \multirow{2}{*}{ Tetraciclinas } & $S$ & 1 & - & 1 & - & - & 3 & 1 & - & - & 1 & - & - & - & - & - & 1 & - & - & - & 1 & 1 \\
\hline & $\mathrm{R}$ & - & - & - & 1 & - & 2 & - & - & - & - & 1 & 1 & - & 1 & 1 & - & - & 1 & - & - & - \\
\hline \multirow{2}{*}{ Cloranfenicol } & $S$ & - & 1 & 2 & - & 1 & 1 & - & - & 1 & - & - & - & - & - & - & 1 & - & - & - & - & - \\
\hline & $\mathrm{R}$ & - & 1 & - & 1 & - & 4 & - & 1 & - & - & - & - & - & 1 & 1 & - & - & - & 2 & - & - \\
\hline \multirow{2}{*}{ Macrolídeos } & $S$ & - & - & - & - & - & - & 1 & - & - & - & - & - & - & - & - & - & - & - & - & - & - \\
\hline & $\mathrm{R}$ & - & - & - & - & 1 & 5 & - & - & - & - & - & - & - & - & - & 1 & 1 & - & - & 1 & - \\
\hline \multirow{2}{*}{ Quinolonas } & $S$ & 1 & 1 & 1 & - & - & - & - & - & 1 & - & - & - & - & - & 1 & - & - & - & 2 & - & 1 \\
\hline & $\mathrm{R}$ & - & 1 & 1 & 1 & 1 & 5 & 1 & 1 & - & 1 & 1 & 1 & - & 1 & - & 1 & 1 & 1 & - & 1 & - \\
\hline \multirow{2}{*}{ Glicopeptídeos } & $S$ & - & - & - & - & 1 & 5 & - & - & - & - & - & - & - & - & - & 1 & 1 & - & - & 1 & - \\
\hline & $\mathrm{R}$ & - & - & - & - & - & - & - & - & - & - & - & - & - & - & - & - & - & - & - & - & - \\
\hline \multirow{2}{*}{ Oxazolididonas } & $S$ & - & 1 & - & - & 1 & 5 & - & - & - & - & - & - & - & - & - & 1 & 1 & - & - & 1 & - \\
\hline & $\mathrm{R}$ & - & - & - & - & - & - & - & - & - & - & - & - & - & - & - & - & - & - & - & - & - \\
\hline \multirow{2}{*}{ Polimixinas } & $S$ & - & - & - & - & - & - & - & - & - & - & - & - & - & - & - & - & - & - & 2 & - & - \\
\hline & $\mathrm{R}$ & - & - & - & - & - & - & - & - & - & - & - & - & - & - & - & - & - & - & - & - & - \\
\hline
\end{tabular}

S: Sensível R: Resistente * Secreção do dreno situado na cavidade abdominal ${ }^{* * F e r i d a ~ O p e r a t o ́ r i a ~}{ }^{* * *}$ Material proveniente de reoperação. 
Para determinação dos fatores preditores para o desenvolvimento de ISC, as variáveis foram eleitas a partir dos resultados de uma revisão integrativa da literatura desenvolvida pelo autor. Realizou-se, posteriormente, um modelo de regressão do tipo árvore, Classification and Regression Tree (CART), que mostra a inter-relação entre as variáveis.

O modelo indicou como variável que divide o grupo entre os que desenvolveram ou não ISC o tempo cirúrgico, como maior e menor ou igual a 487 minutos. No próximo nível, a variável eleita como fator de risco foi a diferença entre IMC de receptores e doadores, menor e maior ou igual a $1,3 \mathrm{~kg} / \mathrm{m}^{2}$. Assim, os pacientes que foram submetidos ao transplante de fígado cujo tempo cirúrgico foi menor que 487 minutos tiveram menor chance de desenvolver ISC. Entre aqueles cujo tempo cirúrgico foi maior/igual a 487 minutos e a diferença entre o IMC de doador e receptor foi maior ou igual a $1,3 \mathrm{~kg} / \mathrm{m}^{2}$, a possibilidade de desenvolvimento de ISC foi maior.

O modelo classificou corretamente os casos de ocorrência ou não de ISC em 73,7\%, com especificidade de 79,8\%.

A interação entre os fatores de risco tempo cirúrgico maior que 487 minutos e diferenças entre as médias de IMC de doadores e receptores maiores que $1,3 \mathrm{~kg} / \mathrm{m}^{2}$ predispõe os pacientes a possibilidade cinco vezes e meia maior de desenvolverem ISC em comparação com aqueles não expostos a essas variáveis (OR 5,5 - IC 95\% $2,5-11,8)$. Os valores de Odds Ratio de cada fator de risco serão apresentados a seguir (Figura 1). 


\section{Ramon Antônio Oliveira}

Figura 1 - Árvore de classificação e regressão, identificação dos participantes que desenvolveram ISC de acordo com a inter-relação entre tempo cirúrgico e diferença de médias de IMC. São Paulo, 2009-2015.

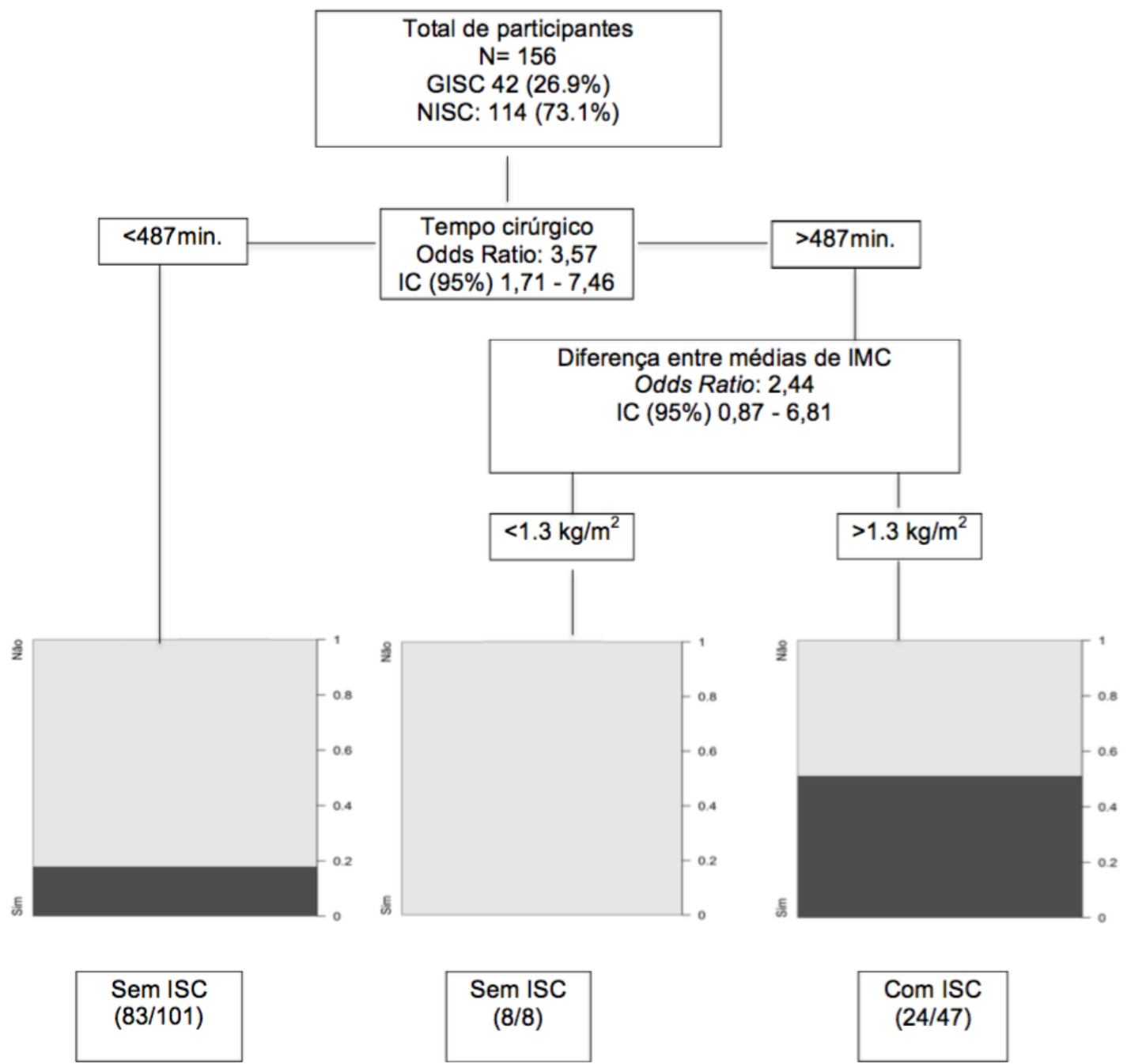


5. Discussão 


\section{DISCUSSÃO}

Os resultados apontaram elevada incidência de ISC para os transplantados de fígado avaliados. Destacaram-se os elevados níveis glicêmicos no pósoperatório, as diferenças entre as médias de IMC doador/receptor e tempo cirúrgico como fatores de risco para essa categoria de pacientes.

Nesta pesquisa, a maioria dos receptores de transplante de fígado eram do sexo masculino e não houve associação entre o sexo e a ocorrência de ISC. Parece haver um consenso na literatura científica de que a maioria dos sujeitos submetidos a esse procedimento seja do sexo masculino e de que essa característica não é um fator de risco para $\mathrm{ISC}^{(4,5)}$. No entanto, coorte histórica que avaliou os resultados de mais de 300 pacientes submetidos ao transplante de fígado por 20 anos mostrou correlação estatística significativa de que o tempo de sobrevida de pacientes do sexo masculino é menor comparado ao do sexo feminino e que as infecções foram responsáveis por $20,6 \%$ das causas de óbito ${ }^{(59)}$.

Os extremos de idade são fatores de risco clássicos para ISC ${ }^{(33)}$. No entanto, os pacientes incluídos nessa investigação eram predominantemente adultos, com discreta diferença entre as médias de idades dos sujeitos que desenvolveram infecção (54,9 anos) e daqueles que não apresentaram (54,6 anos). Resultados semelhantes foram obtidos em investigações americanas, que acompanharam 1.036 pacientes adultos receptores de transplante de fígado entre os anos de 2003 e 2008, obtendo idade média de 56 anos e taxa de ISC de $16 \%^{(5)}$. Outra pesquisa incluiu 367 participantes e observou média de idade de 46,8 $( \pm 10,9)$ anos e taxa de ISC de $20,2 \%{ }^{(60)}$. Em ambos os estudos ${ }^{(5,65)}$, os resultados mostraram sujeitos adultos com médias de idades semelhantes e a idade não foi identificada como variável preditora de ISC.

A obesidade é um fator de risco para ISC amplamente estudado( ${ }^{(33,61,62)}$. $\mathrm{Na}$ presente pesquisa, a média de IMC entre pacientes GISC foi de $28,2 \mathrm{~kg} / \mathrm{m}^{2}$ e verificou-se que a maioria da população deste estudo $(66,7 \%)$ foi classificada como em sobrepeso ou obesa. 


\section{Ramon Antônio Oliveira}

Outra investigação apontou média de IMC de $28 \mathrm{~kg} / \mathrm{m}^{2}$ e correlação entre IMC e ISC em 370 pacientes submetidos ao transplante de fígado ${ }^{(4)}$. Nesse mesmo sentido, outro estudo, que incluiu 586 pacientes submetidos ao transplante de pulmão nos EUA, apontou que valores de IMC $>30 \mathrm{~kg} / \mathrm{m}^{2}$ comportaram-se como fator de risco para $\mathrm{ISC}^{(63)}$. O mesmo ocorreu em pesquisa conduzida entre 7.388 pacientes submetidos à hepatectomia, em que a obesidade também foi fator de risco para ISC ${ }^{(64)}$.

A obesidade pode aumentar o risco de desenvolvimento de ISC por meio de vários mecanismos, como o aumento de dificuldades técnicas no intraoperatório, maior trauma tecidual e aumento da tensão na área suturada; e ferida operatória com menor circulação sanguínea e consequente redução da perfusão de oxigênio ${ }^{(65)}$. Além desses aspectos, menor resposta imunológica pode ser observada entre pacientes obesos em virtude da exposição crônica a estados inflamatórios que podem dessensibilizar as células imunológicas e suprimir a ação delas perante infecções ${ }^{(66)}$.

Concorrem para ISC comorbidades como a DM; nesta população, entre os pacientes GISC, 40,5\% eram portadores da doença. A DM é um fator de risco independente para a ocorrência de ISC em pacientes submetidos a cirurgias abdominais, cardiotorácicas, neurológicas, ortopédicas e de mama; verifica-se que participantes diabéticos apresentaram chance até 4,71 vezes maior de apresentar ISC, quando comparados aos não diabéticos ${ }^{(67,68)}$.

Sabe-se que, em modelos animais, elevados níveis de glicose podem causar redução na atividade imunológica por meio da inibição da quimiotaxia, fagocitose e mecanismos microbicidas desempenhados por neutrófilos ${ }^{(69,70)}$.

No presente estudo, $40,5 \%$ dos pacientes que apresentaram ISC eram extabagistas e observou-se ausência de associação estatística. Destaca-se que não foi possível quantificar o tempo de abstinência devido à ausência da informação no prontuário.

De modo geral, os efeitos deletérios do tabagismo em longo prazo ainda não estão estabelecidos. Estudo de coorte que acompanhou 136 pacientes submetidos ao transplante de fígado mostrou que o tabagismo ativo pode aumentar o risco de 


\section{Ramon Antônio Oliveira}

sepse em aproximadamente quatro vezes e meia e o risco de rejeição aguda do enxerto em até oito vezes, em comparação com sujeitos que nunca fumaram ${ }^{(71)}$.

Além disso, resultados de revisões sistemáticas e metanálises de estudos cujos pacientes incluídos foram submetidos a procedimentos cirúrgicos de várias especialidades, inclusive transplantes, mostrou que participantes em uso ativo de tabaco e ex-tabagistas apresentam risco até duas vezes e meia maior de complicações na ferida operatória, quando comparados a participantes não tabagistas $^{(72,73)}$.

Além dos efeitos nocivos do uso do tabaco para o sistema respiratório, há evidências de respostas imunológicas sistêmicas prejudicadas em razão de menores níveis de imunoglobulina, proporções entre células CD4 e CD8 alteradas e atividade fagocitária reduzida ${ }^{(74)}$. Deste modo, a inter-relação entre tabagismo e infecções no pós-operatório ainda merece novas investigações.

A incompatibilidade entre o sexo de doadores e receptores é amplamente investigada a fim de avaliar os eventos de rejeição e sobrevida, especialmente entre pacientes submetidos ao transplante de coração ${ }^{(75-77)}$, fígado ${ }^{(78-80)}$, pâncreas ${ }^{(81)}$ e rim $^{(82)}$. Entretanto, parecem escassas as evidências que avaliaram a incompatibilidade de sexo como preditor de ISC.

Nesta investigação, a incompatibilidade de sexo estabelecida como doadores do sexo masculino e receptores do sexo feminino não foi apontada como fator de risco para ISC. Apoia o resultado obtido outra pesquisa que não evidenciou a incompatibilidade de sexo como fator de risco para ISC ${ }^{(4)}$. Todavia, há que se considerar uma investigação em que essa variável apresentou correlação estatisticamente significante e aumentou em 1,42 vez o risco de ISC entre pacientes submetidos ao transplante de fígado ${ }^{(5)}$. Além disso, coorte retrospectiva, que avaliou 2.144 adultos submetidos ao transplante de fígado, mostrou entre doadores do sexo masculino e receptores do sexo feminino que as infecções apresentaram-se como a principal causa de complicações no pós-operatório, correspondendo a 17,2\% $\operatorname{delas}^{(80)}$.

Investigação envolvendo portadores de cirrose biliar primária revelou que, entre pacientes do sexo feminino receptores de órgãos provenientes de doadores falecidos do sexo masculino, os efeitos da transfusão de mais de quatro unidades de 


\section{Ramon Antônio Oliveira}

concentrados de hemácias e do tempo de isquemia fria do enxerto maior que oito horas podem ser agravados quando comparados a receptores do sexo feminino cujos doadores eram mulheres ${ }^{(78)}$.

O mecanismo subjacente ao fenômeno da rejeição de órgãos sólidos entre doadores do sexo masculino e receptores femininos relaciona-se à resposta autoimune desenvolvida pelos linfócitos do receptor contra os antígenos $\mathrm{H}-\mathrm{Y}$ presentes no enxerto( ${ }^{(83)}$. No entanto, ainda não há clareza dos processos fisiopatológicos que implicam maiores taxas de infecções entre pacientes submetidos ao transplante de fígado cujos doadores eram do sexo masculino e receptores do feminino ${ }^{(83,84)}$. Supõe-se que pacientes que desenvolvem fenômenos de rejeição com maior frequência são expostos a elevado período de internação e aumento da imunossupressão no pós-operatório, fatos que podem impactar na ocorrência de ISC.

Ainda com relação a fatores resultantes da interação entre características biológicas de doador e receptor, adicionam-se as diferenças entre as idades maiores que 10 anos. No presente estudo, $71,4 \%$ dos pacientes GISC tiveram como doadores pacientes cujas diferenças entre as idades foram iguais ou superiores a 10 anos; no entanto, não foi observada significância estatística entre as variáveis. Entretanto, resultado de uma investigação envolvendo 1.036 pacientes adultos submetidos ao transplante de fígado mostrou que pacientes que receberam enxerto de doadores cuja idade era 10 ou mais anos maior apresentaram incremento em $10 \%$ no risco de desenvolver ISC e de $11 \%$ no risco de desenvolver ISC em órgão ou espaço quando comparados aos receptores cuja diferença entre idades era menor $^{(5)}$.

Pesquisa que envolveu 221 pacientes adultos submetidos ao transplante de fígado mostrou taxa de infecção superior entre receptores que não tiveram as idades pareadas com seus doadores. Além disso, os tempos de sobrevida do enxerto e dos receptores foram maiores entre os que tiveram as idades pareadas com seus doadores $^{(85)}$.

Observando-se que a média das idades de receptores de fígado varia entre 43 e $56 \operatorname{anos}^{(4,5,42,86-88)}$, diferenças de idades entre doador e receptor maiores que 10 anos traduzem doadores com idades próximas ou superiores a 55 anos. Essa 


\section{Ramon Antônio Oliveira}

faixa etária corresponde ao período no qual se observa a elevação da taxa de óbitos relacionados a doenças hepáticas na população em geral ${ }^{(89)}$.

Assim, sugere-se que os efeitos do envelhecimento sobre o fígado, como alterações morfofuncionais; redução da circulação sanguínea; redução da capacidade de proteção contra danos oxidativos e mudanças nas atividades dos mastócitos podem exercer efeitos negativos sobre as células imunológicas ao influenciar o recrutamento, desenvolvimento e função das células e, com isso, suprimir a amplitude e duração das respostas imunológicas ${ }^{(90)}$. Esses aspectos podem ser uma explicação para piores resultados no transplante. No entanto, até este momento, poucas investigações ocuparam-se em estudar essa variável como preditora de ISC.

Nesse sentido, investigação que envolveu 2.476 candidatos e 1.371 pacientes submetidos ao transplante de fígado defende que a correspondência da idade entre doador e receptor seja incorporada aos critérios de alocação dos enxertos no transplante de fígado, pois isso reduziria em até $14 \%$ os anos de vida perdidos e, portanto, aumentaria a expectativa de vida entre receptores jovens e idosos ${ }^{(91)}$.

No pré-operatório, uma atividade de enfermagem que busca prevenir ISC é a realização de banho com solução antisséptica ${ }^{(92)}$. Nesta investigação, observou-se que esse procedimento foi relatado no prontuário de $35(83,3 \%)$ pacientes GISC; portanto, não foi realizado em sete $(16,7 \%)$ pacientes. Todavia, não se constatou associação com a ocorrência de ISC; ademais, notou-se que a solução antisséptica não foi relatada no prontuário de 41 (26,2\%) pacientes submetidos ao transplante.

A realização de banho com solução antisséptica foi amplamente recomendada pelo CDC, uma vez que objetiva redução da contagem de colônias bacterianas da pele e, consequentemente, colabora para a redução das taxas de $\mathrm{ISC}^{(33)}$.

Revisão sistemática recente, que reuniu dados de mais de 10 mil pacientes, cujos estudos compararam banho com gluconato de clorexidina e banho com solução placebo, sabonete sem adição de antissépticos e a não realização de banho pré-operatório, demonstrou não haver evidências de que a realização de banho com clorexidina reduza a ocorrência de ISC ${ }^{(93)}$. 


\section{Ramon Antônio Oliveira}

Além disso, estudo recente envolvendo sujeitos saudáveis demonstrou a necessidade de padronizar o procedimento do banho; assim, sugere-se que seja realizado um banho na noite anterior à realização da cirurgia e outro na manhã do dia em que será realizado o procedimento. Recomenda-se utilizar $118 \mathrm{ml}$ de solução de gluconato de clorexidina na concentração de $4 \%$ e, após a aplicação na pele, fazer pausa de um minuto previamente ao enxágue. O cumprimento dessa técnica parece manter concentrações suficientes do antisséptico na pele com a finalidade de reduzir a microbiota transitória e residente ${ }^{(94)}$. Os resultados desta investigação parecem ser de difícil aplicação no cenário dos transplantes, uma vez que não há agendamento prévio para a realização do procedimento.

No entanto, a ausência do relato da solução antisséptica utilizada no banho pré-operatório dos pacientes analisados é preocupante, pois, para além da questão da prevenção de ISC, o uso de antissépticos não infrequentemente pode causar efeitos nocivos na pele do paciente e a ausência da anotação implicaria dificuldade de associação ${ }^{(94)}$; além do mais, os registros de enfermagem compõem a rede de informações em saúde e devem proporcionar informações sobre o estado do paciente, favorecer a comunicação entre a equipe de enfermagem e a multiprofissional, garantir a continuidade da assistência, retratar o cuidado prestado e servir como fonte para pesquisas científicas ${ }^{(95)}$.

Outro cuidado de enfermagem é a remoção dos pelos do campo operatório, conhecida como tricotomia. Observou-se que esse procedimento foi relatado no prontuário de $71,4 \%$ dos pacientes que desenvolveram infecção; além disso, verificou-se elevado intervalo médio entre a realização da tricotomia e a incisão da pele entre esses pacientes (317,2 minutos).

Tradicionalmente, durante o preparo de pacientes para a cirurgia, a tricotomia da região operatória é realizada buscando evitar que os pelos dificultem a exposição da incisão e/ou interferiram na realização da sutura e na fixação de curativos, quando da finalização do procedimento. Ademais, uma região sem pelos pode proporcionar a sensação de limpeza ${ }^{(96)}$. No entanto, evidências científicas apontam que a tricotomia deve ser evitada, pois associa-se à elevação das taxas de ISC ${ }^{(33)}$.

Contudo, uma menor quantidade de pelos na região em que será realizada a operação contribui para a redução do risco de ISC, já que eles são uma fonte de 


\section{Ramon Antônio Oliveira}

micro-organismos e sua ausência facilita a realização de antissepsia da pele. No entanto, o procedimento de remoção dos pelos pode causar microlesões, com consequente infecção primária do tecido ${ }^{(97)}$. Assim, recente revisão sistemática da literatura demonstrou que, entre pacientes submetidos a cirurgias abdominais e tricotomia com lâmina, a taxa de ISC foi de $9,6 \%$, enquanto entre os que não foram submetidos a nenhum procedimento para retirada dos pelos a taxa foi de $6 \%$. Em pacientes submetidos a cirurgias limpas, comparando-se as taxas de ISC entre aqueles que foram submetidos ao uso de lâminas e tricotomizadores elétricos, observou-se taxa de ISC no primeiro grupo de $2,8 \%$ e, no segundo, de $1,4 \%$. Atualmente, novos mecanismos precisam ser mais estudados como opção para a realização da remoção dos pelos e para determinar seus efeitos sobre a prevenção de ISC, dentre os quais o uso de cremes depilatórios, que parecem apresentar menor risco para lesões de pele ${ }^{(97)}$.

Quanto ao momento para a realização da tricotomia, o $\mathrm{CDC}^{(33)}$ sugere que ela deve ser realizada imediatamente antes do início do procedimento cirúrgico. No entanto, os sujeitos desta investigação apresentaram intervalos médios elevados (317,2 minutos entre o GISC e 297,1 minutos entre o grupo NISC).

Apesar da recomendação do $\mathrm{CDC}^{(38)}$, o aspecto relativo ao momento ideal para a realização da tricotomia permanece controverso, com indicativos da Hospital Infection Society do Reino Unido, que recomenda a realização da tricotomia da pele no dia anterior à realização da cirurgia $^{(98)}$, e revisão sistemática da literatura que afirma ausência de evidências científicas que amparem a tomada de decisão quanto ao melhor momento para a tricotomia da pele ${ }^{(97)}$.

No transoperatório, na presente pesquisa, a média do escore MELD foi de 18,5 pontos entre os pacientes que desenvolveram ISC.

O escore MELD é amplamente utilizado para predizer o risco de morte de pacientes portadores de doença hepática terminal em um período de três meses, e busca reduzir a mortalidade entre pacientes na fila de espera por transplantes direcionando a alocação dos enxertos ${ }^{(99-101)}$. Além disso, investigação recente aponta outra aplicação: predição de uso de unidades de concentrados de hemácias no transoperatório em virtude de sua correlação positiva com o escore MELD ${ }^{(102)}$. Ademais, uma investigação prévia apontou correlação estatística significativa entre 


\section{Ramon Antônio Oliveira}

escores MELD maiores que 35 pontos como importante fator de risco para ISC, aumentando o risco em $1,81 \mathrm{vez}^{(5)}$, aspecto não evidenciado por esta pesquisa. Outra investigação que envolveu 680 pacientes submetidos ao transplante de fígado demonstrou que, entre os pacientes que não desenvolveram ISC, a média do escore MELD foi de 28,1 pontos e, entre os que apresentaram ISC, 32,6 pontos ${ }^{(86)}$. Verificase correlação positiva entre escores MELD elevados e maior taxa de mortalidade, inclusive por causas infecciosas após o transplante de fígado; esse fenômeno talvez ocorra porque pacientes em pior estado geral apresentam maior pontuação MELD previamente ao transplante ${ }^{(103)}$.

Observou-se neste estudo que, entre os pacientes acometidos por ISC, $35,7 \%$ apresentaram débito de líquido ascítico maior que $1.000 \mathrm{ml}$; contudo, não se observou associação estatística significativa com ISC. Resultado semelhante foi encontrado em uma investigação em que o débito de líquido ascítico no transoperatório não apresentou diferença estatística significante entre os grupos com e sem ISC ${ }^{(86)}$.

A ascite é uma das principais complicações entre portadores de cirrose hepática e acomete até $50 \%$ dos pacientes. Essa complicação relaciona-se à ocorrência de hérnia abdominal, hidrotórax hepático, desnutrição e comprometimento da função renal ${ }^{(104,}{ }^{105)}$. Além disso, pesquisa envolvendo portadores de cirrose hepática que necessitaram de internação hospitalar para o tratamento de patologias infecciosas observou que 29,1\% deles apresentaram peritonite bacteriana espontânea ${ }^{(106)}$. A patogênese da peritonite bacteriana espontânea resulta de vários fatores que se relacionam à redução da motilidade intestinal, alterações no sistema imunológico de pacientes cirróticos e especialmente na translocação bacteriana devido à ruptura de membranas intestinais ${ }^{(107)}$. Deste modo, parece-nos oportuno que sejam empreendidas novas investigações a fim de elucidar o impacto clínico do volume de líquido ascítico nas ISC.

Quanto à transfusão de unidades de concentrados de hemácias no transoperatório, nesta pesquisa, foram observadas discretas diferenças entre os grupos com e sem infecção (3,2; GISC e 3,0; NISC); no entanto, deve-se considerar que outras investigações envolvendo pacientes submetidos ao transplante de fígado apresentaram médias acentuadamente superiores de transfusão de unidades de 


\section{Ramon Antônio Oliveira}

concentrado de hemácias no transoperatório, com médias variando entre sete e 18,7 unidades de concentrado de hemácias transfundidas ${ }^{(4,42,86,87)}$.

Ausência de significância estatística entre o número de unidades de concentrado de hemácias e a ocorrência de ISC foi observada em um estudo envolvendo 370 pacientes submetidos ao transplante de fígado, cuja média foi de sete unidades por procedimento ${ }^{(4)}$. Contudo, várias pesquisas envolvendo pacientes submetidos ao transplante de fígado mostraram correlação entre o número de unidades de concentrado de hemácias transfundidas e a ocorrência de $\operatorname{ISC}^{(5,42,86}$, 87).

Pesquisa que envolveu 1.036 pacientes submetidos ao transplante de fígado apresentou correlação positiva entre o número de unidades de concentrado de hemácias administradas e a ocorrência de ISC incisional profunda ${ }^{(5)}$. Outra investigação que acompanhou 1.222 pacientes submetidos ao transplante de fígado concluiu que pacientes que receberam quatro ou mais unidades de concentrado de hemácias apresentaram chances aproximadamente duas vezes superiores de desenvolver ISC, quando comparados aos que receberam menos de quatro unidades de concentrado de hemácias ${ }^{(42)}$.

A transfusão de unidades de concentrado de hemácias alogênicas constitui uma terapia necessária em situações críticas no transoperatório; entretanto, relaciona-se a vários efeitos deletérios no receptor, como aumento da morbimortalidade, prolongamento do período de internação hospitalar no pósoperatório, elevação do risco de infecções relacionadas à assistência à saúde e aumento do consumo de antibióticos ${ }^{(108)}$. Esses efeitos devem-se ao fenômeno da imunomodulação associada à transfusão, ou seja, alterações na resposta imunológica celular do receptor ocasionando perturbações nas atividades das células T e limitação das funções das células natural killer ${ }^{(109)}$.

Além disso, a investigação conduzida entre pacientes submetidos a neurocirurgias comparou amostras de sangue entre grupos que não receberam hemotransfusão, que receberam transfusão alogênica e os que receberam transfusão autóloga. Evidenciaram-se alterações nos padrões de citocinas de pacientes que receberam hemotransfusão alogênica, as quais relacionaram-se com a elevação das taxas de morbidade no período pós-operatório ${ }^{(110)}$. 


\section{Ramon Antônio Oliveira}

Embora a administração de medicamentos vasopressores no transoperatório não esteja relacionada classicamente como fator de risco para ISC $^{(33)}$, observou-se nesta investigação que, apesar de não associada a ISC, $76,2 \%$ dos pacientes que desenvolveram ISC receberam essa classe de medicamentos. Neste sentido, investigação envolvendo 680 participantes submetidos ao transplante de fígado verificou associação estatística significante entre os pacientes diagnosticados com ISC e a utilização de drogas vasopressoras ${ }^{(86)}$.

Os processos que envolvem a administração de agentes vasopressores e o desenvolvimento de ISC ainda não estão claros. Contudo, sugere-se que, nos estados de choque hemorrágico ou cardiogênico, ocorra progressiva redução do diâmetro das arteríolas, podendo provocar a redução ou ausência de perfusão nos capilares, com impacto direto na diapedese de leucócitos. Além disso, em estados de baixo débito cardíaco, uma das respostas fisiológicas é a vasoconstrição da microcirculação da pele, provocando redução na perfusão de oxigênio, que pode causar prejuízo das respostas do sistema imunológico na ferida operatória, por exemplo. Sugere-se ainda que, mesmo com o uso de agentes vasopressores, a perfusão tecidual não ocorra de maneira homogênea, pois células próximas a capilares perfundidos recebem oxigênio suficiente, o que pode não ocorrer entre células distantes desses capilares ${ }^{(86,111)}$.

O tempo médio de isquemia fria do enxerto foi de 422,5 minutos entre os pacientes que desenvolveram ISC e de 402,4 minutos entre os participantes que não foram acometidos. Embora não tenha sido observada correlação estatística significante no presente estudo, a literatura científica sugere que essa variável se comporte como preditor de resultados desfavoráveis para o transplante de fígado, inclusive como fator de risco para ISC ${ }^{(45)}$.

Estudo que incluiu 543 pacientes submetidos ao transplante e retransplante de fígado apontou, por meio de análise multivariada, que os pacientes que receberam enxertos com tempo de isquemia fria igual ou superior a 400 minutos apresentaram chance aproximadamente duas vezes e meia maior de ISC quando comparados aos que receberam enxertos com duração de isquemia fria menor que 400 minutos $^{(45)}$. 


\section{Ramon Antônio Oliveira}

Investigação recente aponta deficiências no manejo atual dos enxertos, pois são armazenados de forma estática, em ambientes frios, expostos a estresse físico, ambiental e molecular. Há mudanças na temperatura, na perfusão sanguínea e na oferta de oxigênio e nutrientes que levam a uma impossibilidade de manutenção da homeostase. Observa-se também a produção de citocinas pró-inflamatórias que podem afetar negativamente a atividade do enxerto; além disso, o tempo de isquemia fria impacta no retorno das atividades celulares do enxerto após a reperfusão ${ }^{(112)}$.

Pouco tem sido estudado sobre os danos causados durante a isquemiareperfusão do fígado. Sabe-se, no entanto, que, nas primeiras duas horas após esse procedimento, alterações no enxerto, como a recuperação da temperatura, do suplemento de sangue, do oxigênio e nutrientes, formam um novo ambiente molecular. Observa-se elevado número de citocinas induzidas pelo estresse, que podem prejudicar a resposta do sistema imunológico ${ }^{(112)}$.

Além dos efeitos negativos sobre a ISC, recente investigação envolvendo 391 pacientes submetidos ao transplante de fígado cujo diagnóstico de indicação era carcinoma hepatocelular mostrou que elevado tempo de isquemia fria é fator de risco para a recorrência do diagnóstico que levou ao transplante ${ }^{(113)}$.

Estudo de validação de escore para estratificação do risco de morte após o transplante de fígado, envolvendo 21.949 pacientes, mostrou que o tempo de isquemia fria menor que 360 minutos comporta-se como fator de proteção para mortalidade pós-operatória(114).

Efeitos negativos foram observados em uma investigação que avaliou os danos causados pelo processo de isquemia-reperfusão por meio da realização de biópsias imediatamente após a reperfusão do fígado de 476 pacientes submetidos ao transplante. Evidenciou-se correlação positiva entre o tempo de isquemia fria e os níveis de danos causados ao tecido hepático. Além disso, observou-se entre pacientes classificados como receptores de enxertos com danos severos maiores taxas de retransplante nos primeiros 90 dias de pós-operatório e falência do enxerto no primeiro ano após o transplante ${ }^{(115)}$. Entretanto, ainda são escassas as investigações que abordam o tempo de isquemia fria e a ocorrência de ISC. 


\section{Ramon Antônio Oliveira}

Ainda no transoperatório, diferenças estatisticamente significantes foram encontradas com relação ao tempo anestésico-cirúrgico. Os tempos de duração da anestesia e da cirurgia foram superiores e estatisticamente significantes entre pacientes que desenvolveram ISC. Investigações envolvendo pacientes submetidos a cirurgias gastrointestinais e colorretais demonstram que o tempo de exposição e o tipo de anestésico utilizado podem interferir na atividade imunológica e na incidência de ISC; entretanto, torna-se de difícil controle a variável tempo de duração da anestesia, já que ela decorre do tempo cirúrgico ${ }^{(116-118)}$.

Ademais, no modelo de regressão CART, observou-se que a interação entre os fatores de risco tempo cirúrgico maior que 487 minutos e diferenças entre médias de IMC entre doadores e receptores maiores que $1,3 \mathrm{~kg} / \mathrm{m}^{2}$ apresentaram-se como fatores de risco para ISC. Assim, a chance de ISC entre pacientes em que houve exposição simultânea às duas variáveis é aproximadamente cinco vezes e meia maior quando comparados aos participantes que não foram expostos simultaneamente a esses fatores de risco.

Os efeitos do tempo cirúrgico têm sido motivo de preocupação entre pesquisadores. Verifica-se que, em estudo envolvendo 1.036 pacientes submetidos ao transplante de fígado, a cada 60 minutos transcorridos no tempo cirúrgico, há um aumento de $14 \%$ no risco de ISC $^{(5)}$.

Nesse mesmo sentido aponta a pesquisa que acompanhou 370 pacientes que realizaram o transplante de fígado: observou-se que o tempo cirúrgico aumentou o risco de ISC em aproximadamente $19 \%{ }^{(4)}$.

Outra investigação incluindo 777 pacientes submetidos ao transplante de fígado mostrou diferenças entre pacientes sem ISC (média de 6,3 horas) e aqueles que apresentaram ISC (média de 6,9 horas), resultando em aumento das chances de desenvolver ISC em 19\%(87).

A correlação entre elevado tempo cirúrgico e ISC tem motivado investigadores em diversas especialidades, como demonstra estudo retrospectivo envolvendo 42.187 pacientes que realizaram artroplastia de joelho. Esse estudo mostrou que, entre os pacientes expostos a menores tempos cirúrgicos, abaixo de 106 minutos, essa variável comportou-se como fator de proteção. Observou-se 


\section{Ramon Antônio Oliveira}

redução de $60 \%$ das chances de ISC em comparação com os pacientes cujo tempo cirúrgico foi maior ${ }^{(119)}$.

Corrobora com os resultados apresentados a investigação retrospectiva que analisou o prontuário de 547 pacientes submetidos a cirurgias hepatobiliares e colorretais e observou que, a cada 60 minutos de procedimento cirúrgico, aumentase a chance de ISC em aproximadamente $21 \%{ }^{(120)}$.

Os resultados da análise multivariada de uma pesquisa analisando 359 pacientes submetidos à hepatectomia, cujo diagnóstico primário era carcinoma hepatocelular, mostraram que pacientes cujo tempo cirúrgico foi maior que 280 minutos apresentaram chance aproximadamente duas vezes maior de desenvolver ISC quando comparados com aqueles em que a duração da cirurgia foi menor que 280 minutos $^{(121)}$

No presente estudo, as diferenças entre médias de IMC entre doadores e receptores maiores que $1,3 \mathrm{~kg} / \mathrm{m}^{2}$ comportaram-se como fator de risco para ISC associado ao elevado tempo cirúrgico.

Investigação prévia que envolveu 24.509 pacientes submetidos ao transplante de fígado, composto por três grupos - os que receberam enxertos "pequeno para o tamanho", "normal para o tamanho" e "grande para o tamanho" -, objetivou avaliar os efeitos nos receptores de enxertos do grupo "grande para o tamanho". Verificouse que os receptores apresentaram maior frequência de complicações no pósoperatório, como insuficiência primária do enxerto, rejeição aguda e infecções ${ }^{(122)}$.

É consistente com o resultado encontrado neste estudo investigação que envolveu 30 modelos animais submetidos ao transplante de fígado. Esses animais foram divididos em dois grupos: o primeiro consistiu no grupo controle, que recebeu enxertos de doadores com o mesmo peso; e o segundo foi composto por receptores de enxertos de doadores com peso até duas vezes maiores que o próprio. Foram realizadas análises histológicas do enxerto uma hora após o término do transplante em ambos os grupos, tendo-se observado que, no segundo grupo, houve maior necrose, piores parâmetros hemodinâmicos, menor fluxo portal e maior expressão de genes relacionados à lesão causada pelo processo de isquemia-reperfusão(123)

Realizou-se uma investigação entre pacientes submetidos ao transplante de fígado que foram divididos em dois grupos, o primeiro composto por 25 pacientes 


\section{Ramon Antônio Oliveira}

em que o peso do enxerto era maior que $2,5 \%$ do peso do receptor e o segundo composto por 137 pacientes cuja relação entre o peso do enxerto e o do doador era menor que 2,5\%. Observou-se, entre os pacientes do primeiro grupo, frequência de insuficiência respiratória aguda superior (32\%) em comparação ao segundo grupo (14\%). Notou-se também maior tempo de uso de ventilação mecânica, com consequente prologamento da estadia em $\mathrm{UTI}^{(124)}$.

Pouco se tem estudado sobre a associação entre o enxerto "grande para o tamanho" e ISC entre pacientes submetidos ao transplante de fígado cujo doador era falecido. Observa-se a temática entre trabalhos envolvendo o transplante de fígado intervivos e pacientes pediátricos ${ }^{(125-127)}$.

Sugere-se que a relação entre enxertos "grande para o tamanho" tenha efeitos nocivos locais e sistêmicos. Entre os efeitos locais, citam-se os contratempos técnicos no transoperatório, como dificuldades para realização da anastomose, menor perfusão de oxigênio no enxerto, obstáculos na fase de síntese, compressão do enxerto e necrose. Os efeitos na microcirculação causam hipoperfusão tecidual e resultam em um processo semelhante ao prolongamento da isquemia morna, levando ao atraso na recuperação das funções hepáticas e necrose ${ }^{(128)}$. Observa-se menor fluxo sanguíneo portal que resulta em aumento da frequência de complicações vasculares. Entre os efeitos sistêmicos, pode-se inferir maior frequência de hipotensão após a reperfusão, o que se deve a alterações hemodinâmicas causadas não só pelo sequestro de maior volume de sangue sistêmico para a circulação portal, mas pela grande produção de fatores inflamatórios que causam a vasodilatação. Além disso, há efeitos deletérios sobre o sistema respiratório, em decorrência do aumento da pressão na cavidade abdominal, que pode causar atelectasias na base dos pulmões e decréscimo no volume residual $^{(129)}$.

Observou-se, nas primeiras 96 horas de pós-operatório, correlação estatística significante entre as médias de valores glicêmicos maiores que $175 \mathrm{mg} / \mathrm{dl}$ e a ocorrência de ISC, aspecto presente em 54,7\% dos pacientes GISC. Além disso, entre os pacientes em que a média de glicemia capilar esteve maior que $175 \mathrm{mg} / \mathrm{dl}$ nas primeiras 96 horas de pós-operatório, observou-se aumento da chance de ISC 


\section{Ramon Antônio Oliveira}

de aproximadamente três vezes, quando comparados aos pacientes em que a média permaneceu menor que $175 \mathrm{mg} / \mathrm{dl}$.

Evidências sugerem a correlação entre elevado valor glicêmico e ISC, sendo recomendada pelo guideline do CDC a manutenção da glicemia abaixo de 200 $\mathrm{mg} / \mathrm{dl}^{(33)}$.

Para a mesma direção aponta a pesquisa que envolveu 680 pacientes submetidos ao transplante de fígado e evidenciou que a chance de ISC é aproximadamente duas vezes maior entre o grupo que apresentou média de glicemia capilar maior que 200 mg/dl no transoperatório, em comparação com os pacientes em que a média foi menor ${ }^{(86)}$.

No entanto, um estudo objetivou avaliar o efeito do controle glicêmico, mantendo glicemia capilar $\leq 150 \mathrm{mg} / \mathrm{dl}$ no trans e pós-operatório de 184 pacientes submetidos ao transplante de fígado. Foram observadas, entre os pacientes submetidos a estrito controle glicêmico, médias de glicemia capilar de 137 mg/dl; aqueles em que o controle foi menos rigoroso apresentaram médias de $184 \mathrm{mg} / \mathrm{dl}$, além da ocorrência mais frequente de infecções como ISC, pneumonia, infecção do trato urinário, infecção da corrente sanguínea e peritonite ${ }^{(130)}$.

Estudo quase experimental, que analisou os efeitos do controle glicêmico nas primeiras 24 horas de pós-operatório de cirurgia cardíaca entre pacientes submetidos a controle flexível, com meta de manutenção da glicemia entre 161 e $200 \mathrm{mg} / \mathrm{dl}$, e grupo tratado com intervenções e meta de manutenção da glicemia de 120 a 160 mg/dl, obteve médias de glicemia iguais a 173,9 mg/dl e 153,9 mg/dl, respectivamente. Os resultados apontam menor frequência de mortalidade nos 30 primeiros dias de pós-operatório entre os pacientes submetidos ao controle rigoroso de glicemia. Embora não se tenha observado significância estatística, há considerável diferença em relação à ocorrência de infecções entre os grupos: 8,6\% entre o grupo com controle rigoroso de glicemia e 11,2\% para o grupo de controle flexível $^{(131)}$.

Uma pesquisa que envolveu 109 pacientes submetidos à esofagectomia subtotal buscou determinar se os níveis de glicemia capilar dos primeiros três dias de pós-operatório relacionam-se com a ocorrência de infecções. O estudo foi composto por três grupos: os que mantiveram média de glicemia entre 120 e 159 


\section{Ramon Antônio Oliveira}

$\mathrm{mg} / \mathrm{dl}$, o segundo com média de 160 a $189 \mathrm{mg} / \mathrm{dl}$ e o terceiro com média igual ou superior a $190 \mathrm{mg} / \mathrm{dl}$. Observou-se que, entre os três grupos, 9,2\% dos pacientes apresentaram ISC. Os valores de glicemia compreendidos no primeiro grupo não foram considerados fatores de risco para infecções; entretanto, os sujeitos cujas médias de glicemia estiveram entre 160 e 189 mg/dl apresentaram chance aproximadamente três vezes e meia maior de infecções quando comparados com os pacientes do grupo com níveis glicêmicos inferiores. Pior cenário foi observado para os pacientes com médias de glicemia $\geq 190 \mathrm{mg} / \mathrm{dl}$, já que estão expostos a chance aproximadamente seis vezes e meia maior para o desenvolvimento de infecções, quando comparados aos sujeitos que compuseram o primeiro grupo ${ }^{(132)}$.

Concorda com os resultados evidenciados nesta investigação o Guideline Consensus Statement on Inpatient Glycemic Control, proposto pela American Association of Clinical Endocrinologists e pela American Diabetes Association, pois sugere que, entre pacientes críticos, internados em UTI, a meta de manutenção da glicemia esteja entre 140 e $180 \mathrm{mg} / \mathrm{dl}^{(133)}$. Entretanto, Park ${ }^{(134)}$ sugere a realização de novos estudos, a fim de estabelecer o valor glicêmico que atuaria como fator de proteção para ISC entre pacientes submetidos ao transplante de fígado no perioperatório.

Pacientes portadores de doença hepática terminal submetidos ao transplante de fígado estão expostos a maiores variações nos níveis glicêmicos no perioperatório. Isso talvez se deva ao comprometimento do metabolismo da glicose, exposição a elevado estresse cirúrgico, uso de corticosteroides, administração de soluções glicosadas, maciça transfusão sanguínea e uso de catecolaminas ${ }^{(130,134)}$.

Quanto à ISC, neste estudo observou-se taxa no período investigado de 26,9\%. O tempo de pós-operatório decorrido para a detecção de ISC foi de 7,8 dias.

As taxas de ISC obtidas por esta investigação são superiores às usualmente encontradas na literatura, embora se apresentem demasiadamente variáveis, segundo o tipo de procedimento ou o centro que o realiza, oscilando de $10,4 \%{ }^{(42)}$ a valores de $11,2 \%{ }^{(86,88)}, 16 \%{ }^{(5)}, 18 \%{ }^{(4)}$ e chegando a $20,5 \%{ }^{(87)}$.

Estudo brasileiro que incluiu 543 pacientes submetidos ao transplante primário de fígado, retransplante de fígado ou transplante de fígado e rim simultaneamente encontrou taxa de ISC de $23,6 \%{ }^{(45)}$. 


\section{Ramon Antônio Oliveira}

Entre pacientes submetidos à hepatectomia parcial em decorrência de carcinoma hepatocelular, verificou-se que a frequência de ISC variou entre $12,8 \%{ }^{(135)}$ e $14,5 \%{ }^{(136)}$. Quando estudados pacientes submetidos ao transplante de rim, a frequência de ISC variou entre $7,2 \%{ }^{(137)}, 15 \%{ }^{(138)}$ e $20,9 \%{ }^{(139)}$, a depender do centro analisado. Menores frequências foram observadas entre pacientes submetidos ao transplante de pulmão, nos quais a ocorrência de ISC é de $5,3 \%{ }^{(63)}$. Quanto ao período para detecção de ISC, corrobora com os resultados encontrados nesta investigação que a detecção de ISC entre pacientes submetidos ao transplante de fígado ocorre, em média, no sétimo dia e até a segunda semana de pós-operatório, com declínio pronunciado após esse período ${ }^{(41,42,45)}$.

Observou-se neste estudo, com relação à distribuição topográfica, que a maioria dos casos foi classificada como ISC incisional profunda $(54,8 \%)$, ISC superficial $(23,8 \%)$ e, finalmente, ISC em órgão ou cavidade (21,4\%). Destaca-se que, entre os pacientes que apresentaram ISC incisional profunda, todos apresentaram temperatura axilar maior que $38^{\circ} \mathrm{C}$ e, na maioria deles $(87,0 \%)$, observou-se drenagem purulenta da incisão profunda.

Resultados distintos foram encontrados em uma investigação envolvendo 166 pacientes submetidos ao transplante de fígado acometidos por ISC, pois a maioria desenvolveu ISC em órgão ou cavidade (65,7\%), ISC superficial $(24,7 \%)$ e, por fim, ISC incisional profunda $(9,6 \%)^{(5)}$.

Estudo que analisou 307 participantes, dos quais 66 desenvolveram ISC após o transplante de fígado, apontou que a maioria dos pacientes foram acometidos por ISC em órgão ou cavidade $(65,1 \%)^{(4)}$. Entretanto, pesquisa que envolveu 127 casos de ISC indicou como mais frequente a ISC incisional profunda $(42,0 \%)^{(42)}$.

Quanto ao registro do diagnóstico médico de ISC, observou-se que, na maioria dos casos $(54,8 \%)$, essa informação não foi descrita no prontuário do paciente.

Entre os métodos passíveis de vigilância de ISC cita-se o direto, que consiste na observação direta da ferida operatória por um cirurgião, enfermeiro ou pela equipe do serviço de controle de infecção hospitalar. Há ainda o método indireto, em que a detecção se dá por meio da consulta a resultados de exames laboratoriais e de imagem, coleta de dados oriundos dos profissionais envolvidos na assistência 


\section{Ramon Antônio Oliveira}

direta ao paciente, consulta aos registros referentes presentes no prontuário do paciente, prescrição de antimicrobianos, resultados de exames microbiológicos e acompanhamento de reinternação ${ }^{(33,140)}$.

A vigilância de ISC tem considerável repercussão nas taxas; falhas nesse processo podem subestimar os casos em 10 a 20\% e impactar negativamente na adoção de medidas para a redução da incidência desse problema ${ }^{(141)}$. Assim, a melhoria dos registros de ISC permitirá coletar dados fidedignos, no acompanhamento e avaliação da evolução das taxas de ISC entre as diversas topografias infecciosas, no planejamento e execução de ações capazes de minimizar o número de casos e os efeitos deletérios causados pela ISC ${ }^{(140)}$.

Quanto aos micro-organismos presentes nos sítios de coleta diretamente relacionados à ISC, observaram-se Staphylococcus sp., Pseudomonas aeruginosa, Klebsiella sp. e Acinetobacter baumanii e Candida albicans.

Observou-se que os micro-organismos encontrados entre os participantes desta investigação também foram descritos previamente por Mangram e cols. ${ }^{(33)}$ como frequentes causadores de ISC.

Estudo que investigou os fatores de risco para ISC entre 1.036 pacientes submetidos ao transplante de fígado encontrou os micro-organismos $S$. aureus, Enterococcus sp. e $P$. aeruginosa entre os que foram acometidos por ISC ${ }^{(5)}$. Outra investigação com 109 pacientes transplantados de fígado evidenciou que os microorganismos mais frequentes entre os pacientes que apresentaram ISC foram E. coli, Enterococcus sp. e A. baumanii ${ }^{(44)}$.

Entre os efeitos deletérios da ISC, verificou-se neste estudo o maior consumo de medicamentos antimicrobianos como fluconazol, piperaciclina+tazobactam e teicoplanina, além de aumento do tempo médio de internação no pós-operatório em aproximadamente cinco dias e readmissão em UTI.

Investigação que envolveu 777 pacientes adultos submetidos ao transplante primário de fígado, cuja frequência de ISC foi de $20,5 \%$, concluiu que, entre os pacientes que desenvolveram ISC, houve acréscimo de aproximadamente 24 dias no período de internação pós-operatório e elevação do consumo de recursos na ordem de 160 mil dólares, acrescido de maior uso de recursos do centro cirúrgico, medicamentos e exames laboratoriais ${ }^{(87)}$. 


\section{Ramon Antônio Oliveira}

Estudo que envolveu 370 pacientes, dos quais 17,8\% manifestaram ISC, demonstrou que o risco de óbito no primeiro ano após o transplante é aproximadamente duas vezes e meia maior e de falência do enxerto é quase quatro vezes maior, em comparação aos pacientes que não desenvolveram ISC ${ }^{(4)}$.

Uma coorte composta por 109 pacientes submetidos ao transplante e retransplante de fígado que buscou descrever as complicações infecciosas nos primeiros dois anos de pós-operatório evidenciou que a ISC foi a complicação infecciosa mais frequente (18\%). Observou-se que a sobrevida de pacientes que desenvolveram ISC ao término do período de acompanhamento foi de $75 \%$, enquanto, entre os participantes que não desenvolveram, foi de $80 \%{ }^{(44)}$.

A ISC pode causar deiscências, aumento da dor na vigência do problema, exposição a maior número de procedimentos invasivos, acometimento do bem-estar dos pacientes, internações em isolamentos, com consequente redução do contato familiar e social. Ao sistema de saúde impacta aumento dos custos pelo prolongamento da internação hospitalar, aumento do consumo de medicamentos antimicrobianos de maior valor, redução da produtividade hospitalar e realização de procedimentos adicionais ${ }^{(33,142)}$.

Deste modo, reconhecer quais são os fatores de risco para ISC entre pacientes transplantados que diferem daqueles amplamente levantados pela literatura científica permitirá implementar mudanças desde a alocação dos órgãos e redirecionar a assistência durante o perioperatório com vistas a atingir melhores resultados. Além disso, a prevenção das ISC poderá não somente poupar recursos financeiros das instituições e do sistema de saúde, mas promover abreviação do tempo de recuperação dos pacientes após o transplante, bem como minimizar o risco de óbito e perda do enxerto.

Assim, assume fundamental importância o conhecimento dos fatores de risco pelos profissionais envolvidos na assistência ao transplantado; destacam-se aqui os enfermeiros, que podem atuar na detecção dos fatores preditores e, mais tarde, implementar ações capazes de minimizá-los durante o perioperatório.

Este estudo teve como fonte de dados empíricos prontuários de pacientes; neste fato reside nossa principal limitação, pois a classificação de ISC dependeu da existência e da clareza dos registros referentes ao fenômeno nos prontuários 
consultados. Para o controle das limitações, o pesquisador utilizou-se de diversas fontes de informação disponíveis, como relatórios do Serviço de Controle de Infecção Hospitalar e verificação da existência de sinais e sintomas de ISC nos registros da equipe multiprofissional.

Sugere-se que posteriores investigações sejam realizadas no sentido de esclarecer a relação entre as variáveis: enxertos "grande para o tamanho", tempo de isquemia fria, manutenção de controles glicêmicos estritos e uso de hemocomponentes no perioperatório com a ocorrência de ISC. 


\section{Conclusão}




\section{CONCLUSÃO}

Entre os 156 pacientes adultos submetidos ao transplante de fígado incluídos nesta pesquisa, observou-se incidência de ISC igual a 26,9\%.

Os sinais e sintomas diagnósticos de ISC manifestaram-se, em média, no 7,8 dia de pós-operatório. A topografia de maior destaque foi a ISC incisional profunda (54,8\%), seguida por ISC superficial $(23,8 \%)$ e, por fim, em órgão/cavidade $(21,4 \%)$.

A maioria dos pacientes submetidos ao transplante de fígado que desenvolveram ISC eram do sexo masculino (83,3\%), com média de idade de 54,9 anos, não portadores de DM (59,5\%), IMC médio de $28,2 \mathrm{~kg} / \mathrm{m}^{2}$ e maioria $(59,5 \%)$ com histórico de uso de tabaco; além disso, não foram observadas, com relação a essas variáveis, diferenças estatísticas significantes entre os grupos acometidos ou não por ISC.

Não houve associação estatística significativa entre a ocorrência de ISC e as variáveis relacionadas à relação doador/receptor, como incompatibilidade de sexo entre (doador do sexo masculino e receptor do sexo feminino) e diferença de idade maior que 10 anos.

No transoperatório, as variáveis que não se comportaram como fatores de risco para ISC foram número de unidades de concentrado de hemácias transfundidas, administração de drogas vasopressoras, débito de líquido ascítico maior que $1.000 \mathrm{ml}$ e tempo de isquemia fria do enxerto.

Na regressão CART, a inter-relação entre elevado tempo cirúrgico (maior que 487 minutos) e diferenças de IMC entre doador/receptor maiores/iguais a $1,3 \mathrm{~kg} / \mathrm{m}^{2}$ comportaram-se como novo fator de risco, elevando a chance de ocorrência de ISC em até cinco vezes e meia em comparação aos pacientes não expostos à combinação das variáveis.

Nesta investigação, médias de glicemia capilar superiores a $175 \mathrm{mg} / \mathrm{dl}$ nas primeiras 96 horas de pós-operatório elevaram o risco de ISC em aproximadamente três vezes. 
Os micro-organismos identificados com maior frequência nas topografias diretamente relacionadas à ISC foram Staphylococcus sp., Pseudomonas aeruginosa, Klebsiella sp. e Acinetobacter baumanii; destaca-se a presença de um fungo, Candida albicans.

Quanto à mortalidade nos 30 primeiros dias de pós-operatório, verificou-se que $14,1 \%$ dos pacientes faleceram; entretanto, a análise bivariada não apontou diferenças estatisticamente significantes.

Por fim, nesta investigação, os efeitos deletérios da ISC relacionaram-se ao maior tempo de internação no pós-operatório (21,6 dias e 16,1 dias entre pacientes acometidos e não acometidos por ISC, respectivamente), maior frequência de reinternações em UTI $(75,0 \%$ e $25,0 \%$ entre pacientes GISC e NISC, respectivamente) e maior consumo de medicamentos antimicrobianos. 


\section{Referências}




\section{REFERÊNCIAS}

1. European Centre for Disease Control and Prevention - ECDC (União Européia). Surveillance of surgical site infections in European hospitals - HAISSI protocol. Version 1.02. Stockolm: ECDC; 2012. p. 47.

2. Centers for Disease Control and Prevention - CDC (EUA). Procedureassociated module: Surgical Site Infection. Atlanta-USA: CDC; 2016. p. 29.

3. Agencia Nacional de Vigilância Sanitária - ANVISA (Brasil). Critérios Diagnósticos de Infecções Relacionadas à Assistência à Saúde. 1st ed. Brasília-DF: ANVISA; 2013. p. 80.

4. Hellinger WC, Crook JE, Heckman MG, Diehl NN, Shalev JA, Zubair AC, et al. Surgical site infection after liver transplantation: risk factors and association with graft loss or death. Transplantation [Internet]. 2009 [cited 2015 May 15]; 87(9):[1387-93 pp.]. Available from: http://www.ncbi.nlm.nih.gov/pubmed/19424041.

5. Hellinger WC, Heckman MG, Crook JE, Taner CB, Willingham DL, Diehl NN, et al. Association of surgeon with surgical site infection after liver transplantation. Am J Transplant [Internet]. 2011 [cited 2015 Jul 25]; 11(9):[9 p.]. Available from: http://www.ncbi.nlm.nih.gov/pubmed/21827617.

6. Oliveira RA, Turrini RNT, Poveda VB. Risk factors for surgical site infection after liver transplantation. AORN Surgical Conference \& Expo. Anaheim - CA.2016.

7. Starzl TE, Iwatsuki S, Van Thiel DH, Gartner JC, Zitelli BJ, Malatack JJ, et al. Evolution of liver transplantation. Hepatology [Internet]. 1982 [cited 2015 Jun 20]; 2(5):[22 p.]. Available from: http://www.ncbi.nlm.nih.gov/pubmed/6749635.

8. Mies S. Transplante de fígado. Rev Assoc Med Bras [Internet]. 1998 [cited 2015 Jun 20]; 44(2):[8 $\quad$ p.]. Available from: http://www.scielo.br/scielo.php?script=sci abstract\&pid=S010442301998000200011\&lng=en\&nrm=iso\&tlng=pt.

9. Associação Brasileira de Transplante de Órgãos (ABTO). Diretrizes Básicas para Captação e retirada de Múltiplos Órgãos e Tecidos. 1st ed. São Paulo: ABTO; 2009. p. 144.

10. Neuberger J. Liver transplantation. Best Pract Res Clin Gastroenterol [Internet]. 2003 [cited 2015 Jun 10]; 17(2):[14 p.]. Available from: http://www.bpgastro.com/article/S1521-6918(02)00144-0/abstract.

11. Suddarth DS. Tratado de Enfermagem Médico-cirúrgica. 12th ed. Rio de Janeiro: Guanabara Koogan; 2011. 
12. Forman L, Lucey M. Predicting the prognosis of chronic liver disease: an evolution from child to MELD. Mayo End-stage Liver Disease. Hepatology [Internet]. 2001 [cited 2015 Jun 20]; 33(2):[4 p.]. Available from: http://www.ncbi.nlm.nih.gov/pubmed/11172352.

13. Kamath P, Wiesner R, Malinchoc M, Kremers W, Therneau T, Kosberg C, et al. A model to predict survival in patients with end-stage liver disease. Hepatology [Internet]. 2001 [cited 2015 Jun 20]; 33(2):[6 p.]. Available from: http://www.ncbi.nlm.nih.gov/pubmed/11172350.

14. Biggins S, Kim W, Terrault N, Saab S, Balan V, Schiano T, et al. Evidencebased incorporation of serum sodium concentration into MELD. Gastroenterology [Internet]. 2006 [cited 2015 Jul 20]; 130(6):[8 p.]. Available from: http://www.ncbi.nlm.nih.gov/pubmed/16697729.

15. Wiesner R, McDiarmid S, Kamath P, Edwards E, Malinchoc M, Kremers W, et al. MELD and PELD: application of survival models to liver allocation. Liver Transpl [Internet]. 2001 [cited 201520 Jul]; 7(7):[4 p.]. Available from: http://www.ncbi.nlm.nih.gov/pubmed/11460223.

16. Andrade Z. Regression of hepatic fibrosis. Rev Soc Bras Med Trop [Internet]. 2005 [cited 2015 Jun 22]; 38(6):[6 p.]. Available from: http://www.scielo.br/scielo.php?script=sci arttext\&pid=S0037-86822005000600013.

17. Massarollo MCKB, Kurcgant $P$. Nursing perceptions in the liver transplant program of a public hospital in Brazil. Rev Latino-Am Enfermagem [Internet]. 2000 [cited 2015 Jun 24]; 8(4):[7 $\quad$ p.]. Available from: http://www.scielo.br/scielo.php?script=sci abstract\&pid=S0104-

$11692000000400010 \& \operatorname{lng}=p t \& n r m=i s o \& t \operatorname{lng}=p t$.

18. Rodrigue JR, Nelson DR, Hanto DW, Reed AI, Curry MP. Patient-reported immunosuppression nonadherence 6 to 24 months after liver transplant: association with pretransplant psychosocial factors and perceptions of health status change. Prog Transplant [Internet]. 2013 [cited 201524 Jun]; 23(4):[9 p.]. Available from: http://www.ncbi.nlm.nih.gov/pubmed/24311395.

19. Associação Brasileira de Transplante de Órgãos (ABTO). Dimensionamento dos transplantes no Brasil e em cada estado (2006-2013). São Paulo: ABTO; 2013. p. 81.

20. Fernandes AT, Fernandes MOV, Ribeiro Filho N. A Infecção Hospitalar e suas interfaces na área da saúde. Atheneu, editor. Rio de Janeiro2000. 1956 p.

21. Miranda MC, Navarrete LT. Semmelweis y su aporte científico a la medicina: Un lavado de manos salva vidas. Rev Chil Infectol [Internet]. 2008 [cited 2015 Jun 24]; 25(1):[4 $\quad$ p.]. $\quad$ Available from: http://www.scielo.cl/scielo.php?script=sci abstract\&pid=S0716$10182008000100011 \& \mathrm{lng}=\mathrm{es} \& \mathrm{nrm}=\mathrm{iso} \& \operatorname{lng}=\mathrm{es}$. 
22. Pereira-Neto AF. Ser médico no Brasil: o presente no passado. 1st ed. Rio de Janeiro: Editora Fiocruz; 2001. 232 p.

23. Rodrigues EAC. Infecções Hospitalares: prevenção e controle. 1st ed. São Paulo: Sarvier; 1997. 669 p.

24. Gordon R. A assustadora história da medicina. 1st ed. Rio de Janeiro - RJ: Ediouro Publicações; 1997.

25. World Health Organization (WHO). Core components for infection prevention and control programmes. Geneva;2011. p. 37.

26. Cardo D, Dennehy PH, Halverson P, Fishman N, Kohn M, Murphy CL, et al. Moving toward elimination of healthcare-associated infections: a call to action. Infect Control Hosp Epidemiol [Internet]. 2010 [cited 2015 Jun 20]; 31(11):[5 p.]. Available from: http://www.ncbi.nlm.nih.gov/pubmed/20929300.

27. Padoveze MC, Fortaleza CMCB. Healthcare-associated infections: challenges to public health in Brazil. Rev Saúde Pública [Internet]. 2014 [cited 2015 Jun 25]; 48(6):[7 p.]. Available from: http://www.scielo.br/scielo.php?script=sci abstract\&pid=S0034-

89102014000600995\&lng=en\&nrm=iso\&tlng=en.

28. Prade SS, Oliveira ST, Rodrigues R, Aguiar F, Martins Neto E, Féliz JQ, et al. Estudo Brasileiro da Magnitude das Infecções Hospitalares em Hospitais Terciários. Rev Epidemiol Controle Infecç [Internet]. 1995; 2(2):[13 p.].

29. Fry DE. Fifty ways to cause surgical site infections. Surg Infect [Internet]. 2011 [cited 2015 Jun 25]; 12(6):[4 p.]. Available from: http://www.ncbi.nlm.nih.gov/pubmed/22142318.

30. Fry DE. Surgical site infections and the surgical care improvement project (SCIP): evolution of national quality measures. Surg Infect [Internet]. 2008 [cited 2015 Jun 25]; 9(6):[5 $\quad$ p.]. Available from: http://www.ncbi.nlm.nih.gov/pubmed/19216670.

31. May AK, Kauffmann RM, Collier BR. The place for glycemic control in the surgical patient. Surg Infect (Larchmt) [Internet]. 2011 [cited 2015 Jun 26]; 12(5):[13 p.]. Available from: http://www.ncbi.nlm.nih.gov/pubmed/22004441.

32. Young H, Bliss R, Carey JC, Price CS. Beyond core measures: identifying modifiable risk factors for prevention of surgical site infection after elective total abdominal hysterectomy. Surg Infect (Larchmt) [Internet]. 2011 [cited 2015 Jun 26]; 12(6):[491-6 pp.]. Available from: http://www.ncbi.nlm.nih.gov/pubmed/22142313.

33. Mangram AJ, Horan TC, Pearson ML, Silver LC, Jarvis WR. Guideline for prevention of surgical site infection, 1999. Hospital Infection Control Practices Advisory Committee. Infect Control Hosp Epidemiol [Internet]. 1999 [cited 2015 Jun 26]; 20(4):[30 p.]. Available from: http://www.ncbi.nlm.nih.gov/pubmed/10219875. 
34. Magill SS, Edwards JR, Bamberg W, Beldavs ZG, Dumyati G, Kainer MA, et al. Multistate Point-prevalence survey of health-care associated infections. N Engl J Med [Internet]. 2014 [cited 2015 Jun 26]; 370:[11 p.]. Available from: http://www.nejm.org/doi/full/10.1056/NEJMoa1306801 - t=article.

35. Awad SS. Adherence to surgical care improvement project measures and post-operative surgical site infections. Surg Infect (Larchmt) [Internet]. 2012 [cited 2015 Jun 26]; 13(4):[4 $\quad$ p.]. Available from: http://www.ncbi.nlm.nih.gov/pubmed/22913334.

36. Oliveira AC, Albuquerque CP, Rocha LCM, Fernandes AT. Infecções do sitio cirúrgico. In: Medsi, editor. Infecções hospitalares: abordagem, prevenção e controle. 1. Rio de Janeiro: Medsi; 2005. p. 93-123.

37. Nichols RL. Preventing surgical site infections: a surgeon's perspective. Emerg Infect Dis [Internet]. 2001 [cited 2015 Jun 16]; 7(2):[5 p.]. Available from: http://www.ncbi.nlm.nih.gov/pubmed/11294711.

38. Candel FJ, Grima E, Matesanz M, Cervera C, Soto G, Almela M, et al. Bacteremia and septic shock after solid-organ transplantation. Transplant Proc [Internet]. 2005 [cited 2015 Aug 2]; 37(9):[3 p.]. Available from: http://www.ncbi.nlm.nih.gov/pubmed/16386636.

39. Rubin $\mathrm{RH}$. The direct and indirect effects of infection in liver transplantation: pathogenesis, impact, and clinical management. Curr Clin Top Infect Dis [Internet]. 2002 [cited 2015 May 30]; 22:[29 p.]. Available from: http://www.ncbi.nlm.nih.gov/pubmed/12520651.

40. Xu L, Xu MQ, Yan LN, Li B, Wen TF, Wang WT. Causes of mortality after liver transplantation: a single center experience in mainland china. Hepatogastroenterology [Internet]. 2012 [cited 2015 May 30]; 59(114):[4 p.]. Available from: http://www.ncbi.nlm.nih.gov/pubmed/21940379.

41. Garcia-Prado ME, Matia EC, Ciuro FP, Diez-Canedo JS, Sousa Martin JM, Porras Lopez FM, et al. Surgical site infection in liver transplant recipients: impact of the type of perioperative prophylaxis. Transplantation [Internet]. 2008 [cited 2015 $\begin{array}{llll}\text { May } 17] ; & \text { 85(12):[6 } & \text { p. } & \text { Available }\end{array}$ http://www.ncbi.nlm.nih.gov/pubmed/18580480.

42. Asensio A, Ramos A, Cuervas-Mons V, Cordero E, Sanchez-Turrion V, Blanes $M$, et al. Effect of antibiotic prophylaxis on the risk of surgical site infection in orthotopic liver transplant. Liver Transpl [Internet]. 2008 [cited 2016 May 30]; 14(6):[6 p.]. Available from: http://www.ncbi.nlm.nih.gov/pubmed/18508358.

43. Karapanagiotou A, Kydona C, Papadopoulos S, Giasnetsova T, Sgourou K, Pasakiotou $\mathrm{M}$, et al. Infections after orthotopic liver transplantation in the intensive care unit. Transplant Proc [Internet]. 2012 [cited 2016 Jun 16]; 44(9):[3 p.]. Available from: http://www.ncbi.nlm.nih.gov/pubmed/23146512. 
44. Garcia-Prado H, Cordeiro E, Álamo JM, Gómes MÁ, Pascasio JM, Sánchez $\mathrm{M}$, et al. Estudio descriptivo de las complicaciones infecciosas en 109 receptores de transplantes hepáticos consecutivos. Enferm Infecc Microbiol Clín [Internet]. 2009 [cited 2015 Sep 09]; 27(4):[6 p.]. Available from: http://www.elsevier.es/en-revistaenfermedades-infecciosas-microbiologia-clinica-28-articulo-estudio-descriptivo-lascomplicaciones-infecciosas-S0213005X0800061X?redirectNew=true.

45. Freire MP, Soares ICO, Bonazzi PR, Guimarães T, Ramos Figueira ER, Bacchella T, et al. Surgical site infections in liver transplant recipients in the model for end-stage liver disease era: an analysis of the epidemiology, risk factors, and outcomes. Liver Transpl [Internet]. 2013 [cited 2015 May 30]; 19(9):[8 p.]. Available from: http://www.ncbi.nlm.nih.gov/pubmed/23744748.

46. Polit DF, Beck CT. Fundamentos de Pesquisa em Enfermagem. $7^{\mathfrak{a}}$ ed. Porto Alegre: Artmed; 2011. 669 p.

47. Fletcher RH, Fletcher SW, Fletcher GS. Epidemiologia clínica: elementos essenciais. Porto Alegre: Artmed; 2014. 280 p.

48. Vieira S, Hossne WS. Metodologia para a área da saúde. 192 ed. Rio de Janeiro: Campus, Elservier; 2001.

49. Lazcano-Ponce E, Fernandez E, Salazar-Martinez E, Hernandez-Avila M. Cohort studies. Methodology, biases, and application. Salud Publica Mex [Internet]. 2000 [cited 2016 Jun 08]; 42(3):[11 p.]. Available from: http://www.ncbi.nlm.nih.gov/pubmed/10929505.

50. Guyatt G, Rennie D, Meade MO, Cook DJ. Diretrizes para utilização da literatura médica. 2nd ed. Porto Alegre: Artmed; 2011.

51. Departamento de Informática do SUS - DATASUS (Brasil). Procedimentos hospitalares do SUS por local de internação 2015 [cited 2016 Jun 30]. Available from: http://tabnet.datasus.gov.br/cgi/tabcgi.exe?sih/cnv/qisp.def

52. Dutkowski P, Schlegel A, Oliveira M, Müllhaupt B, Neff F, Clavien P. HOPE for human liver grafts obtained from donors after cardiac death. $\mathrm{J}$ Hepatol [Internet]. 2014 [cited 2016 Aug 21]; 60(4):[8 p.]. Available from: http://www.ncbi.nlm.nih.gov/pubmed/24295869.

53. Manner H, Enderle MD, Pech O, May A, Plum N, Riemann JF, et al. Secondgeneration argon plasma coagulation: two-center experience with 600 patients. J Gastroenterol Hepatol [Internet]. 2008 [cited 2016 Aug 10]; 23(6):[7 p.]. Available from: http://www.ncbi.nlm.nih.gov/pubmed/18565020.

54. Kawecki D, Chmura A, Pacholczyk M, Lagiewska B, Adadynski L, Wasiak D, et al. Bacterial infections in the early period after liver transplantation: etiological agents and their susceptibility. Med Sci Monit [Internet]. 2009 [cited 2016 Aug 25]; 15(12):[10 p.]. Available from: http://www.ncbi.nlm.nih.gov/pubmed/19946234. 
55. Ribeiro JC. Análise da ocorrência e dos fatores de predisponentes de infecção de sítio cirúrgico em pacientes submetidos a cirurgias ortopédicas. Ribeirão Preto: Escola de Enfermagem de Ribeirão Preto da Universidade de São Paulo; 2012.

56. Poveda VB. Análise dos fatores predisponentes à infecção do sítio cirúrgico em gastrectomia. Ribeirão Preto: Escola de Enfermagem de Ribeirão Preto da Universidade de São Paulo; 2004.

57. Conselho Nacional de Saúde (Brasil). Resolução 466 de 12 de dezembro de 2012. In: CNS, editor. Brasília-DF: Diário Oficial da União; 2012. p. 12.

58. Noleto-Rosa T, Garrafa V. Bioética e Confidencialidade do Doador Cadáver em Transplantes Renais no Brasil. Rev Latino-Am Bioética [Internet]. 2011 [cited 2016 Jun 06]; 11(2):[7 p.]. Available from: http://www.scielo.org.co/scielo.php?script=sci arttext\&pid=S1657$\underline{47022011000200010 .}$

59. Schoening WN, Buescher N, Rademacher S, Andreou A, Kuehn S, Neuhaus $\mathrm{R}$, et al. Twenty-year longitudinal follow-up after orthotopic liver transplantation: a single-center experience of 313 consecutive cases. Am J Transplant [Internet]. 2013 [cited 2016 Jul 27]; 13(9):[10 p.]. Available from: http://www.ncbi.nlm.nih.gov/pubmed/23915357.

60. Avkan-Oguz V, Ozkardesler S, Unek T, Ozbilgin M, Akan M, Firuzan E, et al. Risk Factors for Early Bacterial Infections in Liver Transplantation. Transplant Proc [Internet]. 2013 [cited 2015 May 30]; 45:[5 p.]. Available from: http://www.sciencedirect.com/science/article/pii/S004113451300256X.

61. Kwaan M, Sirany A, Rothenberger D, Madoff R. Abdominal wall thickness: is it associated with superficial and deep incisional surgical site infection after colorectal surgery? Surg Infect (Larchmt) [Internet]. 2013 [cited 2016 Aug 22]; 14(4):[6 p.]. Available from: http://www.ncbi.nlm.nih.gov/pubmed/23676120.

62. Wiseman J, Fernandes-Taylor S, Barnes M, Saunders R, Saha S, Havlena J, et al. Predictors of surgical site infection after hospital discharge in patients undergoing major vascular surgery. J Vasc Surg [Internet]. 2015 [cited 2016 Aug 21]; 62(4):[9 p.]. Available from: http://www.ncbi.nlm.nih.gov/pubmed/26143662.

63. Shields RK, Clancy CJ, Minces LR, Shigemura N, Kwak EJ, Silveira FP, et al. Epidemiology and outcomes of deep surgical site infections following lung transplantation. Am J Transplant [Internet]. 2013 [cited 2016 Jul 28]; 13(8):[9 p.]. Available from: http://www.ncbi.nlm.nih.gov/pubmed/23710593.

64. Yang T, Tu PA, Zhang H, Lu JH, Shen YN, Yuan SX, et al. Risk factors of surgical site infection after hepatic resection. Infect Control Hosp Epidemiol [Internet]. 2014 [cited 2016 Jul 28]; 35(3):[4 p.]. Available from: http://www.ncbi.nlm.nih.gov/pubmed/24521601. 
65. Govinda R, Kasuya Y, Bala E, Mahboobi R, Devarajan J, Sessler DI, et al. Early postoperative subcutaneous tissue oxygen predicts surgical site infection. Anesth Analg [Internet]. 2010 [cited 2016 Jul 28]; 111(4):[7 p.]. Available from: http://www.ncbi.nlm.nih.gov/pubmed/20601453.

66. Milner JJ, Beck MA. The impact of obesity on the immune response to infection. Proc Nutr Soc [Internet]. 2012 [cited 2016 Jul 29]; 71(2):[8 p.]. Available from: http://www.ncbi.nlm.nih.gov/pubmed/22414338.

67. Aga E, Keinan-Boker L, Eithan A, Mais T, Rabinovich A, Nassar F. Surgical site infections after abdominal surgery: incidence and risk factors. A prospective cohort study. Infect Dis (Lond) [Internet]. 2015 [cited 2016 Aug 09]; 47(11):[7 p.]. Available from: http://www.ncbi.nlm.nih.gov/pubmed/26114986.

68. Martin ET, Kaye KS, Knott C, Nguyen H, Santarossa M, Evans R, et al. Diabetes and Risk of Surgical Site Infection: A Systematic Review and Metaanalysis. Infect Control Hosp Epidemiol [Internet]. 2016 [cited 2016 Aug 09]; 37(1):[13 p.]. Available from: http://www.ncbi.nlm.nih.gov/pubmed/26503187.

69. Mauriello CT, Hair PS, Rohn RD, Rister NS, Krishna NK, Cunnion KM. Hyperglycemia inhibits complement-mediated immunological control of $\mathrm{S}$. aureus in a rat model of peritonitis. J Diabetes Res [Internet]. 2014 [cited 2016 Aug 09]; 2014:[12 p.]. Available from: http://www.ncbi.nlm.nih.gov/pubmed/25610878.

70. Alba-Loureiro TC, Munhoz CD, Martins JO, Cerchiaro GA, Scavone C, Curi R, et al. Neutrophil function and metabolism in individuals with diabetes mellitus. Braz $\mathrm{J}$ Med Biol Res [Internet]. 2007 [cited 2016 Aug 09]; 40(8):[8 p.]. Available from: http://www.ncbi.nlm.nih.gov/pubmed/17665039.

71. Leithead JA, Ferguson JW, Hayes PC. Smoking-related morbidity and mortality following liver transplantation. Liver Transpl [Internet]. 2008 [cited 2016 Aug 09]; 14(8):[5 p.]. Available from: http://www.ncbi.nlm.nih.gov/pubmed/18668649.

72. Gronkjaer M, Eliasen M, Skov-Ettrup LS, Tolstrup JS, Christiansen AH, Mikkelsen SS, et al. Preoperative smoking status and postoperative complications: a systematic review and meta-analysis. Ann Surg [Internet]. 2014 [cited 2016 Aug 09]; 259(1):[19 p.]. Available from: http://www.ncbi.nlm.nih.gov/pubmed/23799418.

73. Sorensen LT. Wound healing and infection in surgery. The clinical impact of smoking and smoking cessation: a systematic review and meta-analysis. Arch Surg [Internet]. 2012 [cited 2016 Aug 09]; 147(4):[10 p.]. Available from: http://www.ncbi.nlm.nih.gov/pubmed/22508785.

74. Arcavi L, Benowitz NL. Cigarette smoking and infection. Arch Intern Med [Internet]. 2004 [cited 201604 Aug]; 164(20):[10 p.]. Available from: http://www.ncbi.nlm.nih.gov/pubmed/15534156. 
75. Candinas D, Gunson B, Nightingale P, Hubscher S, McMaster P, Neuberger J. Sex mismatch as a risk factor for chronic rejection of liver allografts. Lancet [Internet]. 1995 [cited 2016 Aug 09]; 346(8983):[5 p.]. Available from: http://www.ncbi.nlm.nih.gov/pubmed/7475600.

76. Kilic A, Weiss E, Allen J, Conte J, Shah A, Baumgartner W, et al. Simple score to assess the risk of rejection after orthotopic heart transplantation. Circulation [Internet]. 2012 [cited 2016 Aug 09]; 125(24):[9 p.]. Available from: http://www.ncbi.nlm.nih.gov/pubmed/22634267.

77. Martinez-Selles M, Almenar L, Paniagua-Martin M, Segovia J, Delgado J, Arizón J, et al. Donor/recipient sex mismatch and survival after heart transplantation: only an issue in male recipients? An analysis of the Spanish Heart Transplantation Registry. Transpl Int [Internet]. 2015 [cited 2016 Aug 09]; 28(3):[9 p.]. Available from: http://www.ncbi.nlm.nih.gov/pubmed/25399778.

78. Grat M, Lewandowski Z, Patkowski W, Wronka KM, Grat K, Krasnodebski M, et al. Relevance of male-to-female sex mismatch in liver transplantation for primary biliary cirrhosis. Ann Transplant [Internet]. 2015 [cited 2016 Aug 09]; 20:[8 p.]. Available from: http://www.ncbi.nlm.nih.gov/pubmed/25728977.

79. Brooks B, Levy M, Jennings L, Abbasoglu O, Vodapally M, Goldstein R, et al. Influence of donor and recipient gender on the outcome of liver transplantation. Transplantation [Internet]. 1996 [cited 2016 Aug 09]; 62(12):[4 p.]. Available from: http://www.ncbi.nlm.nih.gov/pubmed/8990363.

80. Schoening W, Helbig M, Buescher N, Andreou A, Bahra M, Schmitz V, et al. Gender Matches in Liver Transplant Allocation: Matched and Mismatched MaleFemale Donor-Recipient Combinations; Long-term Follow-up of More Than 2000 Patients at a Single Center. Exp Clin Transplant [Internet]. 2016 [cited 2016 May 19]; 14(2):[7 p.]. Available from: http://www.ncbi.nlm.nih.gov/pubmed/27015533.

81. Zhiwei L, Shengmin M, Jie X, Jie Z, Qijun Z, Sheng Y, et al. Influence of donor-recipient sex mismatch on long-term survival of pancreatic grafts. Sci Rep [Internet]. 2016 [cited 2016 Aug 09]; 6:[8 p.]. Available from: http://www.ncbi.nlm.nih.gov/pmc/articles/PMC4941418/.

82. Tan JC, Kim JP, Chertow GM, Grumet FC, Desai M. Donor-recipient sex mismatch in kidney transplantation. Gend Med [Internet]. 2012 [cited 2016 Aug 09]; 9(5):[13 p.]. Available from: http://www.ncbi.nlm.nih.gov/pubmed/22906727.

83. Popli R, Sahaf B, Nakasone H, Lee J, Miklos D. Clinical impact of $\mathrm{H}-\mathrm{Y}$ alloimmunity. Immunol Res [Internet]. 2014 [cited 2016 Aug 09]; 58(2-3):[10 p.]. Available from: http://www.ncbi.nlm.nih.gov/pubmed/24781195.

84. Reddy MS, Varghese J, Venkataraman J, Rela M. Matching donor to recipient in liver transplantation: Relevance in clinical practice. World $\mathrm{J}$ Hepatol [Internet]. 
2013 [cited 2016 Aug 09]; 5(11):[9 p.]. Available from: http://www.ncbi.nlm.nih.gov/pmc/articles/PMC3847943/.

85. Pagano D, Grosso G, Vizzini G, Spada M, Cintorino D, Malaguarnera M, et al. Recipient-donor age matching in liver transplantation: a single-center experience. Transplant Proc [Internet]. 2013 [cited 2016 May 19]; 45(7):[7 p.]. Available from: http://www.ncbi.nlm.nih.gov/pubmed/24034027.

86. Park C, Hsu C, Neelakanta G, Nourmand H, Braunfeld M, Wray C, et al. Severe intraoperative hyperglycemia is independently associated with surgical site infection after liver transplantation. Transplantation [Internet]. 2009 [cited 2016 May 19]; 87(7):[6 p.]. Available from: http://www.ncbi.nlm.nih.gov/pubmed/19352123.

87. Hollenbeak CS, Alfrey EJ, Souba WW. The effect of surgical site infections on outcomes and resource utilization after liver transplantation. Surgery [Internet]. 2001 [cited 2016 May 17]; 130(2):[8 p.]. Available from: http://www.ncbi.nlm.nih.gov/pubmed/11490376.

88. Schaeffer DF, Yoshida EM, Buczkowski AK, Chung SW, Steinbrecher UP, Erb $\mathrm{SE}$, et al. Surgical morbidity in severely obese liver transplant recipients - a single Canadian Centre Experience. Ann Hepatol [Internet]. 2009 [cited 2016 May 30]; 8(1):[3 p.]. Available from: http://www.ncbi.nlm.nih.gov/pubmed/19221532.

89. Schmucker D. Age-related changes in liver structure and function: Implications for disease? Exp Gerontol [Internet]. 2005 [cited 2016 Aug 10]; 40(8-9):[9 p.]. Available from: http://www.ncbi.nlm.nih.gov/pubmed/16102930.

90. Grizzi F, Di Caro G, Laghi L, Hermonat P, Mazzola P, Nguyen D, et al. Mast cells and the liver aging process. Immun Ageing [Internet]. 2013 [cited 2016 Aug 10]; 10(9):[10 p.]. Available from: http://www.ncbi.nlm.nih.gov/pmc/articles/PMC3599827/.

91. Cucchetti A, Ross L, Thistlethwaite J, Vitale A, Ravaioli M, Cescon M, et al. Age and equity in liver transplantation: An organ allocation model. Liver Transpl [Internet]. 2015 [cited 2016 Aug 10]; 21(10):[9 p.]. Available from: http://www.ncbi.nlm.nih.gov/pubmed/26174971.

92. Injean P, McKinnell J, Hsiue P, Vangala S, Miller L, Benharash P, et al. Survey of preoperative infection prevention for coronary artery bypass graft procedures. Infect Control Hosp Epidemiol [Internet]. 2014 [cited 2016 Aug 10]; 35(6):[2 p.]. Available from: http://www.ncbi.nlm.nih.gov/pubmed/24799654.

93. Webster J, Osborne S. Preoperative bathing or showering with skin antiseptics to prevent surgical site infection. Cochrane Database Syst Rev [Internet]. 2015 [cited 2016 Aug 10]; 2(CD004985):[51 p.]. Available from: http://www.ncbi.nlm.nih.gov/pubmed/25927093.

94. Edmiston Jr CE, Lee CJ, Krepel CJ, Spencer M, Leaper D, Brown KR, et al. Evidence for a Standardized Preadmission Showering Regimen to Achieve Maximal 
Antiseptic Skin Surface Concentrations of Chlorhexidine Gluconate, 4\%, in Surgical Patients. JAMA Surg [Internet]. 2015 [cited 2016 Aug 10]; 150(11):[7 p.]. Available from: http://www.ncbi.nlm.nih.gov/pubmed/26308490.

95. Carneiro SM, Dutra HS, Costa FM, Mendes SE, Arreguy-Sena C. Uso de abreviaturas nos registros de enfermagem em um hospital de ensino. Rev Rene [Internet]. 2016 [cited 2016 Aug 12]; 17(2):[9 p.]. Available from: http://www.periodicos.ufc.br/index.php/rene/article/view/3001.

96. Broekman ML, Beijnum J, Peul WC, Regli L. Neurosurgery and shaving: what's the evidence? J Neurosurg [Internet]. 2011 [cited 2016 Aug 10]; 115(4):[9 p.]. Available from: http://www.ncbi.nlm.nih.gov/pubmed/21721875.

97. Tanner J, Norrie P, Melen K. Preoperative hair removal to reduce surgical site infection. Cochrane Database Syst Rev [Internet]. 2011 [cited 2016 Aug 12]; 11(CD004122):[51 p.]. Available from: http://www.ncbi.nlm.nih.gov/pubmed/22071812.

98. Woodhead K, Taylor E, Bannister G, Chesworth T, Hoffman P, Humphreys H. Behaviours and rituals in the operating theatre. A report from the Hospital Infection Society Working Party on Infection Control in Operating Theatres. J Hosp Infect [Internet]. 2002 [cited 2016 Aug 12]; 51(4):[15 p.]. Available from: http://www.ncbi.nlm.nih.gov/pubmed/12183138.

99. Bilal M, Satapathy SK, Ismail MK, Vanatta JM. Long-Term Outcomes of Liver Transplantation for Hepatic Sarcoidosis: A Single Center Experience. J Clin Exp Hepatol [Internet]. 2016 [cited 2016 Aug 13]; 6(2):[6 p.]. Available from: http://www.ncbi.nlm.nih.gov/pubmed/27493456.

100. Khandoga A, Iskandarov E, Angele M, Gerbes A, Frey L, Ağayev B, et al. Model for end-stage liver disease score in the first 3 weeks after liver transplantation as a predictor for long-term outcome. Eur J Gastroenterol Hepatol [Internet]. 2016 [cited 2016 Aug 10]; 28(2):[6 p.]. Available from: http://www.ncbi.nlm.nih.gov/pubmed/26545081.

101. Klein KB, Stafinski TD, Menon D. Correction: Predicting Survival after Liver Transplantation Based on Pre-Transplant MELD Score: a Systematic Review of the Literature. PLoS One [Internet]. 2013 [cited 2016 Aug 13]; 8(12):[5 p.]. Available from: http://journals.plos.org/plosone/article?id=10.1371/journal.pone.0080661.

102. Alonso IJ, Maestro OC, Gómez NF, Mateos RS, Quinto AM, Molero FC, et al. Mind the model for end-stage liver disease: model for end-stage liver disease score as an indicator of hemoderivate transfusion and survival in liver transplantation. Transplant Proc [Internet]. 2015 [cited 2016 Aug 13]; 47(1):[4 p.]. Available from: http://www.ncbi.nlm.nih.gov/pubmed/25645781.

103. Rostved AA, Lundgren JD, Hillingso J, Peters L, Mocroft A, Rasmussen A. MELD score measured day 10 after orthotopic liver transplantation predicts death 
and re-transplantation within the first year. Scand J Gastroenterol [Internet]. 2016 [cited 2016 Aug 13]; Epub ahead of print:[7 p.]. Available from: http://www.ncbi.nlm.nih.gov/pubmed/27319374.

104. Singhal S, Baikati KK, Jabbour II, Anand S. Management of refractory ascites. Am J Ther [Internet]. 2012 [cited 2016 May 30]; 19(2):[12 p.]. Available from: http://www.ncbi.nlm.nih.gov/pubmed/21192246.

105. Garcia N, Sanyal AJ. Ascites. Curr Treat Options Gastroenterol [Internet]. 2001 [cited 2016 May 18]; 4(6):[10 p.]. Available from: http://www.ncbi.nlm.nih.gov/pubmed/11696279.

106. Fernández J, Navasa M, Gómez J, Colmenero J, Vila J, Arroyo V, et al. Bacterial infections in cirrhosis: epidemiological changes with invasive procedures and norfloxacin prophylaxis. Hepatology [Internet]. 2002 [cited 2016 Aug 13]; 35(1):[9 p.]. Available from: http://www.ncbi.nlm.nih.gov/pubmed/11786970.

107. Koutsounas I, Kaltsa G, Siakavellas SI, Bamias G. Markers of bacterial translocation in end-stage liver disease. World J Hepatol [Internet]. 2015 [cited 2016 Aug 13]; 7(20):[10 $\quad$ p.]. $\quad$ Available [rom: http://www.ncbi.nlm.nih.gov/pmc/articles/PMC4568487/.

108. Rohde JM, Dimcheff DE, Blumberg N, Saint S, Langa KM, Kuhn L, et al. Health care-associated infection after red blood cell transfusion: a systematic review and meta-analysis. JAMA [Internet]. 2014 [cited 2016 Aug 14]; 311(13):[9 p.]. Available from: http://www.ncbi.nlm.nih.gov/pubmed/24691607.

109. Ghio M, Contini P, Mazzei C, Merlo A, Filaci G, Setti M, et al. In vitro immunosuppressive activity of soluble HLA class I and F as ligand molecules: do they play a role in autologous blood transfusion? Transfusion [Internet]. 2001 [cited $2016 \quad$ Aug 14]; 41(8):[8 $\quad$ p.]. Available from: http://www.ncbi.nlm.nih.gov/pubmed/11493729.

110. Pandey P, Chaudhary R, Aggarwal A, Kumar R, Khetan D, Verma A. Transfusion-associated immunomodulation: Quantitative changes in cytokines as a measure of immune responsiveness after one time blood transfusion in neurosurgery patients. Asian J Transfus Sci [Internet]. 2010 [cited 2016 Aug 14]; 4(2):[7 p.]. Available from: http://www.ncbi.nlm.nih.gov/pmc/articles/PMC2937301/.

111. De Backer D, Ospina-Tascon G, Salgado D, Favory R, Creteur J, Vincent JL. Monitoring the microcirculation in the critically ill patient: current methods and future approaches. Intensive Care Med [Internet]. 2010 [cited 2016 Aug 14]; 36(11):[12 p.]. Available from: http://www.ncbi.nlm.nih.gov/pubmed/20689916.

112. Henry SD, Nachber E, Tulipan J, Stone J, Bae C, Reznik L, et al. Hypothermic machine preservation reduces molecular markers of ischemia/reperfusion injury in human liver transplantation. Am J Transplant [Internet]. 2012 [cited 2016 Aug 14]; 12(9):[10 p.]. Available from: http://www.ncbi.nlm.nih.gov/pubmed/22594953. 
113. Nagai S, Yoshida A, Facciuto M, Moonka D, Abouljoud MS, Schwartz ME, et al. Ischemia time impacts recurrence of hepatocellular carcinoma after liver transplantation. Hepatology [Internet]. 2015 [cited 2016 Aug 14]; 61(3):[9 p.]. Available from: http://onlinelibrary.wiley.com/doi/10.1002/hep.27358/epdf.

114. Rana A, Jie T, Porubsky M, Habib S, Rilo H, Kaplan B, et al. The survival outcomes following liver transplantation (SOFT) score: validation with contemporaneous data and stratification of high-risk cohorts. Clin Transplant [Internet]. 2013 [cited 2016 Aug 14]; 27(4):[6 p.]. Available from: http://www.ncbi.nlm.nih.gov/pubmed/23808891.

115. Ali JM, Davies SE, Brais RJ, Randle LV, Klinck JR, Allison ME, et al. Analysis of ischemia/reperfusion injury in time-zero biopsies predicts liver allograft outcomes. Liver Transpl [Internet]. 2015 [cited 2016 Aug 14]; 21(4):[12 p.]. Available from: http://www.ncbi.nlm.nih.gov/pubmed/25545865.

116. Shimizu K, Hirose M, Mikami S, Takamura K, Goi T, Yamaguchi A, et al. Effect of anaesthesia maintained with sevoflurane and propofol on surgical site infection after elective open gastrointestinal surgery. J Hosp Infect [Internet]. 2010 [cited 2016 Aug 17]; 74(2):[7 p.]. Available from: http://www.ncbi.nlm.nih.gov/pubmed/20061057.

117. Koo BW, B. SJ, Shin HJ, Kim DW, Kang SB, Do SH, et al. Surgical site infection after colorectal surgery according to the main anesthetic agent: a retrospective comparison between volatile anesthetics and propofol. Korean $\mathrm{J}$ Anesthesiol [Internet]. 2016 [cited 2016 Aug 17]; 69(4):[9 p.]. Available from: http://www.ncbi.nlm.nih.gov/pubmed/27482309.

118. Chen WK, Ren L, Wei Y, Zhu DX, Miao CH, Xu JM. General anesthesia combined with epidural anesthesia ameliorates the effect of fast-track surgery by mitigating immunosuppression and facilitating intestinal functional recovery in colon cancer patients. Int J Colorectal Dis [Internet]. 2015 [cited 2016 Aug 17]; 30(4):[7 p.]. Available from: http://www.ncbi.nlm.nih.gov/pubmed/25579161.

119. Dicks KV, Baker AW, Durkin MJ, Anderson DJ, Moehring RW, Chen LF, et al. Short Operative Duration and Surgical Site Infection Risk in Hip and Knee Arthroplasty Procedures. Infect Control Hosp Epidemiol [Internet]. 2015 [cited 2016 Aug 18]; 36(12):[6 $\quad$ p.]. http://www.ncbi.nlm.nih.gov/pubmed/26391277.

120. Zhang Y, Mahar AL, Edgar B, Williams V, Wallace D, Vearncombe M, et al. Length of surgery and intra-operative best practices determine surgical site infection risk in operations of prolonged duration. Can J Infect Control [Internet]. 2015 [cited 2016 Aug 18]; 30(3):[7 p.]. Available from: http://www.ipaccanada.org/cjic/vol30no3.pdf.

121. Sadamori H, Yagi T, Shinoura S, Umeda Y, Yoshida R, Satoh D, et al. Risk factors for organ/space surgical site infection after hepatectomy for hepatocellular carcinoma in 359 recent cases. J Hepatobiliary Pancreat Sci [Internet]. 2013 [cited 
2016 Aug 18]; 20(2):[10 p.]. Available from: http://www.ncbi.nlm.nih.gov/pubmed/22273719.

122. Fukazawa K, Yamada Y, Nishida S, Hibi T, Arheart KL, Pretto Jr EA. Determination of the safe range of graft size mismatch using body surface area index in deceased liver transplantation. Transpl Int [Internet]. 2013 [cited 2016 Aug 19]; 26(7):[10 p.]. Available from: http://www.ncbi.nlm.nih.gov/pubmed/23647566.

123. Moreira DAR, Tannuri ACA, Belon AR, Coelho MCM, Gonçalves JO, Serafini $S$, et al. Large-for-size liver transplantation: a flowmetry study in pigs. J Surg Res [Internet]. 2014 [cited 2016 Aug 19]; 189(2):[8 p.]. Available from: http://www.ncbi.nlm.nih.gov/pubmed/24721605.

124. Levesque E, Duclos J, Ciacio O, Adam R, Castaing D, Vibert E. Influence of larger graft weight to recipient weight on the post-liver transplantation course. Clin Transplant [Internet]. 2013 [cited 2016 Aug 19]; 27(2):[9 p.]. Available from: http://www.ncbi.nlm.nih.gov/pubmed/23293941.

125. Vasavada B, Chen CL. Vascular complications in biliary atresia patients undergoing living donor liver transplantation: Analysis of 110 patients over 10 years. J Indian Assoc Pediatr Surg [Internet]. 2015 [cited 2016 Aug 19]; 20(3):[6 p.]. Available from: https://www.ncbi.nlm.nih.gov/pmc/articles/PMC4481622/.

126. Sakuma Y, Sasanuma H, Miki A, Shimizu A, Sata N, Yasuda Y, et al. LivingDonor Liver Transplantation Using Segment 2 Monosegment Graft: A Single-Center Experience. Transplant Proc [Internet]. 2016 [cited 2016 Aug 19]; 48(4):[4 p.]. Available from: http://www.ncbi.nlm.nih.gov/pubmed/27320568.

127. Akdur A, Kirnap M, Ozcay F, Sezgin A, Soy HEA, Yarbug FK, et al. Large-forsize liver transplant: a single-center experience. Exp Clin Transplant [Internet]. 2015 [cited 2016 Aug 19]; 13(Suppl 1):[3 p.]. Available from: http://www.ncbi.nlm.nih.gov/pubmed/25894137.

128. Brustia R, Perdigao F, Sepulveda A, Schielke A, Conti F, Scatton O. Negative wound therapy to manage large-for-size liver graft mismatch. Clin Res Hepatol Gastroenterol [Internet]. 2015 [cited 2016 Aug 19]; 39(5):[3 p.]. Available from: http://www.ncbi.nlm.nih.gov/pubmed/26099450.

129. Fukazawa K, Nishida S. Size mismatch in liver transplantation. J Hepatobiliary Pancreat Sci [Internet]. 2016 [cited 2016 Aug 19]; 23:[9 p.]. Available from: http://www.ncbi.nlm.nih.gov/pubmed/27474079.

130. Ammori JB, Sigakis M, Englesbe MJ, O'Reilly M, Pelletier SJ. Effect of intraoperative hyperglycemia during liver transplantation. J Surg Res [Internet]. 2007 [cited 2016 Aug 20]; 140(2):[7 p.]. Available from: http://www.ncbi.nlm.nih.gov/pubmed/17509267. 
131. Giakoumidakis K, Eltheni R, Patelarou E, Theologou S, Patris V, Michopanou $\mathrm{N}$, et al. Effects of intensive glycemic control on outcomes of cardiac surgery. Heart Lung [Internet]. 2013 [cited 2016 Aug 20]; 42(2):[6 p.]. Available from: http://www.ncbi.nlm.nih.gov/pubmed/23453011.

132. Ito N, Iwaya T, Ikeda K, Kimura Y, Akiyama $\mathrm{Y}$, Konosu M, et al. Hyperglycemia 3 days after esophageal cancer surgery is associated with an increased risk of postoperative infection. J Gastrointest Surg [Internet]. 2014 [cited 2016 Aug 21]; 18(9):[10 p.]. Available from: http://www.ncbi.nlm.nih.gov/pubmed/24992996.

133. Moghissi ES, Korytkowski MT, DiNardo M, Einhorn D, Hellman R, Hirsch IB, et al. American Association of Clinical Endocrinologists and American Diabetes Association consensus statement on inpatient glycemic control. Diabetes Care [Internet]. 2009 [cited 2016 Aug 20]; 32(6):[14 p.]. Available from: http://www.ncbi.nlm.nih.gov/pubmed/19429873.

134. Park CS. Predictive roles of intraoperative blood glucose for post-transplant outcomes in liver transplantation. World J Gastroenterol [Internet]. 2015 [cited 2016 Aug 20]; 21(22):[7 $\quad$ p.]. $\quad$ Available [rom: http://www.ncbi.nlm.nih.gov/pubmed/26078559.

135. Kokudo T, Uldry E, Demartines N, Halkic N. Risk factors for incisional and organ space surgical site infections after liver resection are different. World $\mathrm{J}$ Surg [Internet]. 2015 [cited 2016 Aug 20]; 39(5):[7 p.]. Available from: http://www.ncbi.nlm.nih.gov/pubmed/25561190.

136. Sadamori H, Yagi T, Shinoura S, Umeda Y, Yoshida R, Satoh D, et al. Risk factors for organ/space surgical site infection after hepatectomy for hepatocellular carcinoma in 359 recent cases. J Hepatobiliary Pancreat Sci [Internet]. 2013 [cited 2016 May 13]; 20(2):[10 $\quad$ p.]. Available from: http://www.ncbi.nlm.nih.gov/pubmed/22273719.

137. Wszola M, Kwiatkowski A, Ostaszewska A, Górski L, Kuthan R, SawickaGrzelak A, et al. Surgical site infections after kidney transplantation-where do we stand now? Transplantation [Internet]. 2013 [cited 2016 Aug 20]; 95(6):[5 p.]. Available from: http://www.ncbi.nlm.nih.gov/pubmed/23511213.

138. Harris AD, Fleming B, Bromberg JS, Rock $P$, Nkonge G, Emerick $M$, et al. Surgical site infection after renal transplantation. Infect Control Hosp Epidemiol [Internet]. 2015 [cited 2016 Aug 20]; 36(4):[7 p.]. Available from: http://www.ncbi.nlm.nih.gov/pubmed/25782896.

139. Sacristán PG, Marfil AP, Moratalla JMO, Guindo CG, Fuentes CR, Barbosa YAC, et al. Predictive factors of infection in the first year after kidney transplantation. Transplant Proc [Internet]. 2013 [cited 2016 Aug 20]; 45(10):[4 p.]. Available from: http://www.ncbi.nlm.nih.gov/pubmed/24314976. 
140. Anderson DJ, Podgorny K, Berrios-Torres SI, Bratzler DW, Dellinger EP, Greene L, et al. Strategies to prevent surgical site infections in acute care hospitals: 2014 update. Infect Control Hosp Epidemiol [Internet]. 2014 [cited 2016 Aug 14]; 35(6):[33 p.]. Available from: http://www.ncbi.nlm.nih.gov/pmc/articles/PMC4267723/.

141. Leaper DJ, Tanner J, Kiernan M, Assadian O, Edmiston Jr CE. Surgical site infection: poor compliance with guidelines and care bundles. Int Wound J [Internet]. 2015 [cited 2016 Aug 21]; 12(3):[6 p.]. Available from: http://www.ncbi.nlm.nih.gov/pubmed/24612792.

142. Leaper D, Ousey K. Evidence update on prevention of surgical site infection. Curr Opin Infect Dis [Internet]. 2015 [cited 2016 Aug 22]; 28(2):[6 p.]. Available from: http://www.ncbi.nlm.nih.gov/pubmed/25692267. 


\section{Apêndices}




\section{APÊNDICES}

Prontuário:

\section{APÊNDICE A - INSTRUMENTO DE COLETA DE DADOS}

\section{Dados de identificação}

\section{Data da Coleta:}

1. Número da Coleta:

2. Nome do Paciente:

3. Endereço:

4. Cidade:

5. CEP:

II. Dados sociodemográficos e histórico de saúde

6. Data de nascimento:

7. Sexo: 1. Feminino 2. Masculino

8. Tabagista?

1. Sim 2. Não 3.Ex-tabagista

9. Quantificação do uso de tabaco:

1. maço/dia 99. Não se aplica

10. Quantificação do tempo de uso de tabaco (expresso em anos):

1. anos 99. Não se aplica

11. Etilista antes da cirurgia?

1.Sim 2. Não

12. Frequência de uso de bebida alcoólica:
1. $1 \mathrm{vez} / \mathrm{sem}$
2. 2 vezes/sem
3. 3 vezes/sem
4. 4 vezes/sem
5.5 vezes/sem
6. 6 vezes/sem
7. Diariamente
99.Não se aplica

13. Tipo: 1 . Destilado 2.Fermentado

14. Durante quanto tempo (em anos):

15. Parou de beber? 1.Sim 2.Não

16. Há quanto tempo parou (expresso em meses):

17. Classificação da Doença Hepática (indicação do transplante)

1. Cirrose hepática alcoólica

2. Colangite esclerosante primária

3. Cirrose hepática por vírus $B$

4. Cirrose hepática por vírus $C$

5. Cirrose biliar primária

6. Cirrose hepática criptogênica

7. Paramiloidose familiar

8. Cirrose hepática por vírus $\mathrm{B}$ e $\mathrm{C}$

9. Colangite esclerosante primária

10. Cirrose hepática por hepatite autoimune

11. Carcinoma hepatocelular

12. Cirrose hepática NASH

13. Hepatite aguda fulminante

14. Cirrose hepática por vírus $D$

15. Metástase hepática de carcinoma neuroendócrino

16. Doença de Wilson

17. Síndrome de Budd-Chiari

18. Hemocromatose+cirrose hepática

18. Portador de doenças crônicas?

\begin{tabular}{|lllll}
\hline \multicolumn{3}{|c|}{ 1.Sim 2.Não } & & \\
\hline 13.1 & 1.Diabetes mellitus & 2.Hipertensão arterial sistêmica & 3. Cardiopatia & 4. Obesidade \\
\hline
\end{tabular}




\section{Ramon Antônio Oliveira}

\begin{tabular}{|c|}
\hline 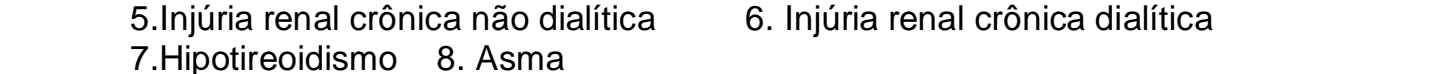 \\
\hline $\begin{array}{l}\text { 19. Medicamentos de uso domiciliar: } \\
\text { 1. Anti-hipertensivos cardiotônicos } \\
\text { 2. Anti-hipertensivos diuréticos } \\
\text { 3. Anticoagulantes } \\
\text { 4. Antidiabéticos injetáveis } \\
\text { 5. Antidiabéticos orais } \\
\text { 6. Barbitúricos } \\
\text { 7. Diuréticos de alça } \\
\text { 8. Diuréticos depletores de potássio } \\
\text { 9. Diuréticos poupadores de potássio } \\
\text { 10. Imunossupressores } \\
\text { 11. Laxantes } \\
\text { 12. Polivitamínicos }\end{array}$ \\
\hline $\begin{array}{l}\text { 20. Histórico de transplante de órgãos? } \\
\text { 1. Fígado } \\
\text { 2. Pâncreas } \\
\text { 3. Intestino } \\
\text { 4. Rim } \\
\text { 5. Pulmão } \\
\text { 6. Coração } \\
\text { 99. Não submetido a transplantes previamente }\end{array}$ \\
\hline 21. Data da inclusão na fila do transplante: \\
\hline 22. Escore MELD (sem correção) quando da indicação do transplante de fígado: \\
\hline $\begin{array}{l}\text { 23. Em tratamento hemodialítico em decorrência da doença hepática? } \\
\text { 1. Sim 2. Não }\end{array}$ \\
\hline III. Dados do pré-operatório \\
\hline 24. Data da Admissão Hospitalar: \\
\hline 25. Peso: $\mathrm{kg}$ \\
\hline 26. Altura: $\mathrm{cm}$ \\
\hline $\begin{array}{l}\text { 27. Realizado banho com solução antisséptica prévio ao transplante? } \\
\begin{array}{ll}\text { 1. Sim } & \text { 2. Não }\end{array}\end{array}$ \\
\hline $\begin{array}{l}\text { 28. Para os pacientes com resposta "sim" no item anterior. Qual foi a solução utilizada? } \\
\text { 1. Clorexidina degermante } 2 \text { 2. PVPI degermante } \quad 99 . \text { Não se aplica } 999 . \text { Não informado }\end{array}$ \\
\hline $\begin{array}{l}\text { 29. Realizado tricotomia? } \\
\begin{array}{ll}\text { 1. Sim } & \text { 2. Não } 999 . \text { Não informado } \\
\end{array}\end{array}$ \\
\hline $\begin{array}{l}\text { 30. Horário da realização da tricotomia: } \\
\begin{array}{llll}\text { 1. } & \text { h_ } \quad \min & \text { 2. Não realizado } & 999 . \text { Não informado }\end{array}\end{array}$ \\
\hline $\begin{array}{l}\text { 31. Utilizado tricotomizador elétrico? } \\
\begin{array}{ll}\text { 1.Sim } & \text { 2. Não } \\
\text { 3. Não informado } 99 . \text { Não se aplica }\end{array}\end{array}$ \\
\hline $\begin{array}{l}\text { 32. Admitido no centro cirúrgico proveniente: } \\
\begin{array}{ll}\text { 1. Unidade de internação } & \text { 2. Unidade de Terapia Intensiva }\end{array}\end{array}$ \\
\hline $\begin{array}{l}\text { 33. Dispositivos em que foi admitido da unidade de origem: } \\
\text { 1. Cateter venoso periférico } \\
\text { 2. Cateter venoso central - em veia jugular interna } \\
\text { 3. Cateter venoso central - em veia subclávia } \\
\text { 4. Cateter venoso central - em veia femoral } \\
\text { 5. Sonda vesical de demora } \\
\text { 6. Sonda nasogástrica } \\
\text { 7. Sonda nasoentérica }\end{array}$ \\
\hline
\end{tabular}




\section{Ramon Antônio Oliveira}

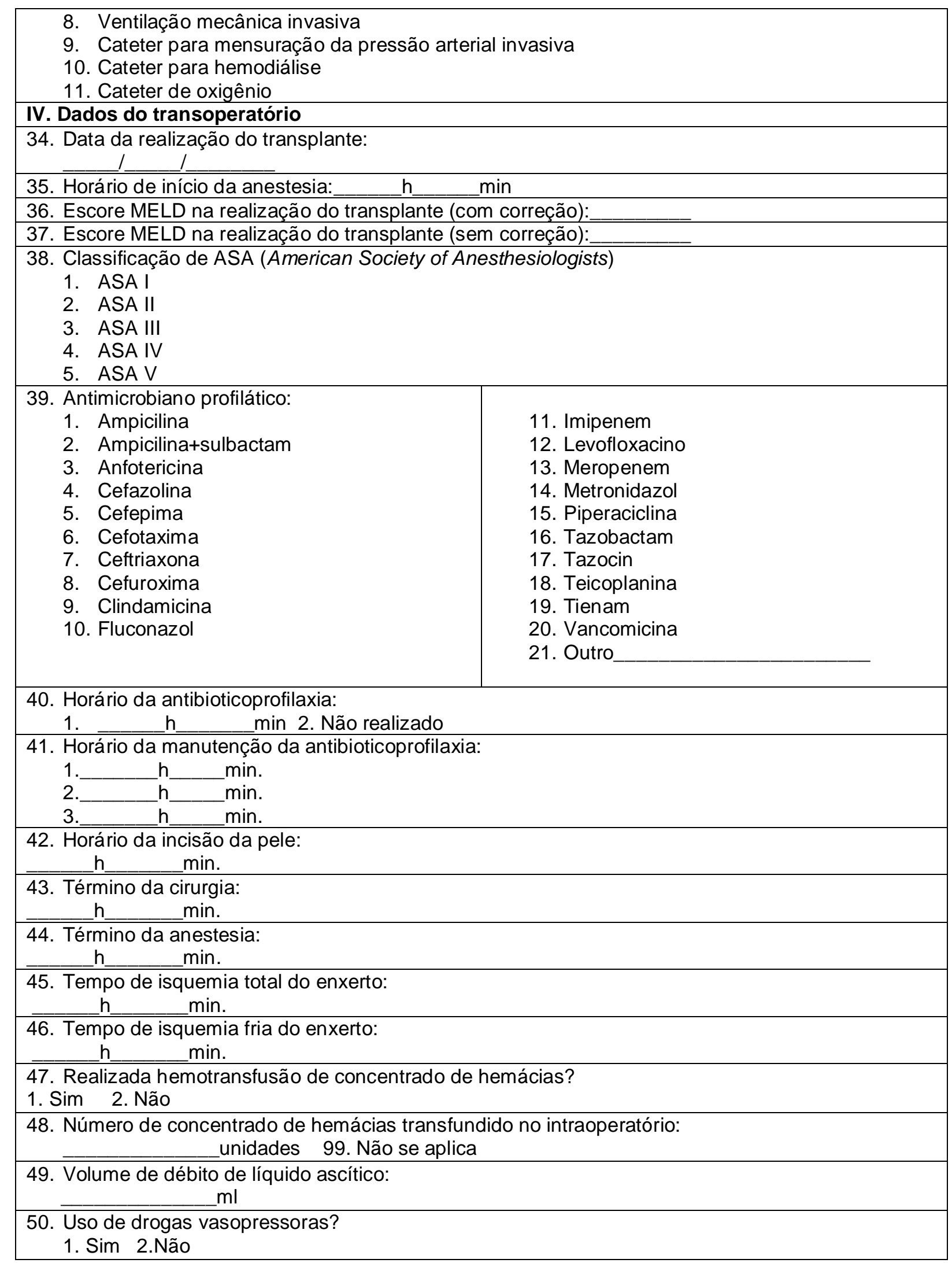




\section{Ramon Antônio Oliveira}

51. Técnica usada para anastomose biliar:

1. Anastomose término-terminal contínuo posterior e separado anterior

2. Anastomose biliodigestiva em Y de Roux

99. Não realizada anastomose

52. Drenos instalados:

1. Dreno de Blake em flanco direito

2. Dreno de Blake em flanco esquerdo

3. Dreno suctor em flanco direito

4. Dreno suctor em flanco esquerdo

53. Dispositivos instalados no CC:

1. Cateter venoso periférico

2. Cateter venoso central - em veia jugular interna

3. Cateter venoso central - em veia subclávia

4. Cateter venoso central - em veia femoral

5. Cateter de Swan-Ganz

6. Sonda nasogástrica

7. Cateter para monitorização de pressão arterial invasiva

8. Sonda vesical de demora

\section{Dados do pós-operatório}

54. Data de admissão na unidade de terapia intensiva:

Data de admissão na enfermaria cirúrgica:

$$
\text { I I I }
$$

55. Data de alta hospitalar:

1

56. Data de alta por transferência:

57. Ocorrência de reabordagem cirúrgica?

1. $\operatorname{Sim} 2$.Não

58. Ocorrência de reinternação em UTI?

1. Sim 2.Não

59. Medicamentos utilizados para a imunossupressão:

1. Prednisona

2. Hidrocortisona

3. Micofenolato de mofetila

4. Ciclosporina

5. Tacrolimo (Prograf)

6. Micofenolato (Mifortyc)

7. Metilprednisolona (Solu-medrol)

60. Valores glicêmicos máximos e mínimos diários:

\begin{tabular}{|c|l|l|l|l|l|}
\hline $\begin{array}{l}\text { Dia de pós- } \\
\text { operatório }\end{array}$ & $\begin{array}{l}\text { Valor glicêmico } \\
\text { mínimo (mg/dl) }\end{array}$ & $\begin{array}{l}\text { Valor } \\
\text { glicêmico } \\
\text { máximo } \\
(\mathrm{mg} / \mathrm{dl})\end{array}$ & $\begin{array}{l}\text { Dia de pós- } \\
\text { operatório }\end{array}$ & $\begin{array}{l}\text { Valor } \\
\text { glicêmico } \\
\text { mínimo } \\
(\mathrm{mg} / \mathrm{dl})\end{array}$ & $\begin{array}{l}\text { Valor } \\
\text { glicêmico } \\
\text { máximo } \\
(\mathrm{mg} / \mathrm{dl})\end{array}$ \\
\hline 1. & & & 16. & & \\
\hline 2. & & & 17. & & \\
\hline 3. & & & 18. & & \\
\hline 4. & & & 19. & & \\
\hline 5. & & & 20. & & \\
\hline 6. & & 21. & & \\
\hline
\end{tabular}


Ramon Antônio Oliveira

\begin{tabular}{|c|l|l|l|l|}
\hline 7. & & 22. & & \\
\hline 8. & & 23. & & \\
\hline 9. & & 24. & & \\
\hline 10. & & 25. & & \\
\hline 11. & & 26. & & \\
\hline 12. & 27. & & \\
\hline 13. & & 28. & & \\
\hline 14. & & 29. & & \\
\hline 15. & & 30. & & \\
\hline
\end{tabular}

\section{Informações sobre a incisão cirúrgica}

\section{Infecção \\ 62. ISC incisional profunda} superficial

1. Drenagem purulenta da incisão superficial

2. Dor

3. Edema

4. Hiperemia

5. Calor

6. Cultura asséptica

MO Isolado

99. Não apresentou sinais e sintomas para ISC.

64. Classificação da ISC:

1. Drenagem purulenta de incisão profunda

2. Deiscência parcial ou total da parede abdominal ou abertura ou aspiração da ferida pelo cirurgião

3. Febre (T.ax. $\left.>38^{\circ} \mathrm{C}\right)$

4. Dor ou sensibilidade local

5. Cultura asséptica

MO Isolado

6. Presença de abscesso que envolva os planos profundos da ferida, identificados em reoperação. Exame de imagem ou histocitopatológico.

99. Não apresentou sinais e sintomas para ISC.
63. ISC em órgão/cavidade

1. Drenagem purulenta de um dreno situado dentro de órgão/cavidade

2. Cultura positiva de secreção, fluido ou tecido obtido assepticamente

3. Abscesso ou evidência de infecção envolvendo os planos profundos da ferida, identificada em reoperação, exame de imagem ou histocitopatológico.

99. Não apresentou sinais e sintomas para ISC.

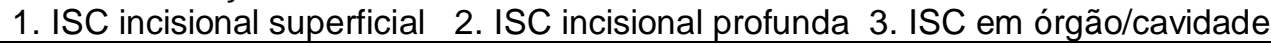

65. Classificação de ISC no __ dia de pós-operatório.

66. Houve registro de diagnóstico de ISC pelo profissional médico ?

1. Sim 2. Não

67. Colhido material para cultura e antibiograma?

1. Sim 2.Não

68. Qual material, se sim no item 67.

69. Análise do perfil de sensibilidade, caso exista sinais de ISC pesquisados nos itens 63, 64 e 65.

Assinalar 1 para susceptível, 2 para resistente, 88 para não pesquisado e 99 para não se aplica.

\begin{tabular}{|l|l|l|l|l|l|l|l|l|l|}
\hline & \multicolumn{7}{|c|}{ Antimicrobiano testado } \\
\hline $\begin{array}{l}\text { Micro-organismo } \\
\text { isolado }\end{array}$ & & & & & & & & & \\
\hline $\begin{array}{l}\text { 1. Staphylococcus } \\
\text { aureus }\end{array}$ & & & & & & & & & \\
\hline $\begin{array}{l}\text { Klebsiella } \\
\text { pneumoniae }\end{array}$ & & & & & & & & & \\
\hline
\end{tabular}




\section{Ramon Antônio Oliveira}

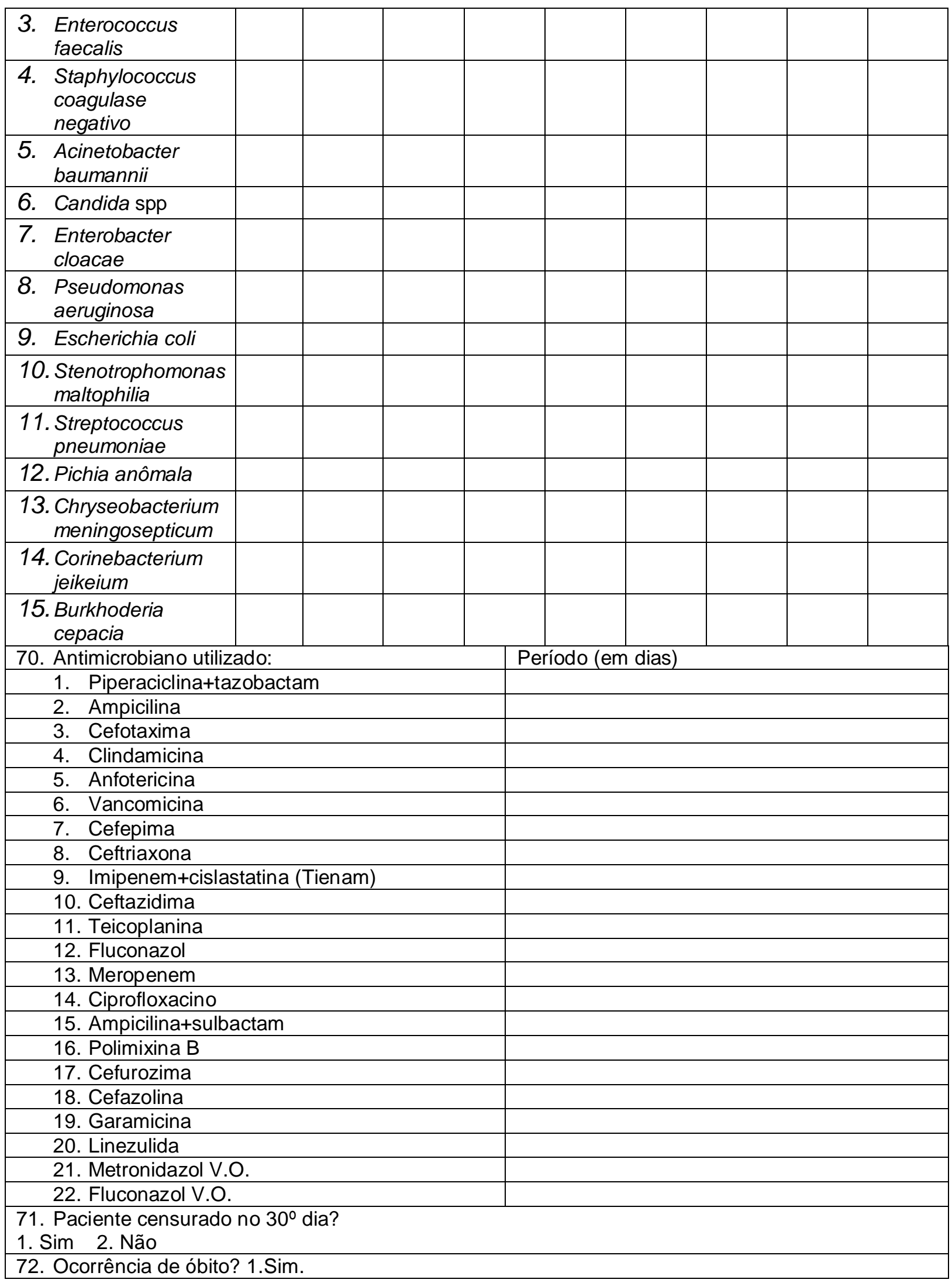


73. Data do óbito _ / / /

74. Diagnóstico principal atribuído ao óbito:

\section{Dados sobre o doador}

75. Data de Nascimento:

76. Sexo:

1. Feminino

2. Masculino

77. Peso:

$\mathrm{kg}$

78. Altura:

79. Diagnóstico prévio à morte encefálica

80. Comorbidades:

1. Hipertensão arterial sistêmica

2.Injúria renal crônica dialítica

3. Asma brônquica

4. TU cerebral 


\section{APÊNDICE B - TERMO DE CONSENTIMENTO LIVRE E ESCLARECIDO}

CAAE: 50960815.1 .0000 .5392

\section{Caro(a) Senhor(a),}

Meu nome é Ramon Antônio Oliveira, sou enfermeiro e estudante da Escola de Enfermagem da Universidade de São Paulo. Gostaria de convida-Io(a) como voluntário(a) a participar da pesquisa: "Fatores de risco para infecção do sítio cirúrgico em transplante de fígado: coorte histórica".

Justificativa, objetivos e procedimentos: A infecção do sítio cirúrgico é uma das principais complicações entre pacientes submetidos a cirurgias e este é o principal motivo que nos leva a estudá-la. O objetivo desse projeto é identificar a prevalência de infecção do sítio cirúrgico e os fatores de risco para o seu desenvolvimento entre pacientes adultos submetidos ao transplante de fígado. Para isso, haverá uma coleta de dados em que as informações serão obtidas a partir de seu prontuário, desde o momento do transplante até 30 dias após a cirurgia. Assim, sua participação se dará pela autorização de coleta de dados em seu prontuário.

Desconfortos, riscos e benefícios: A pesquisa será realizada por meio dos prontuários dos pacientes; os riscos poderão ser de desconforto por parte do paciente em relação ao pesquisador tomar conhecimento da situação clínica que gerou a internação do sujeito incluído na investigação. No entanto, o pesquisador garante manter o mais amplo e absoluto sigilo sobre a identidade dos indivíduos durante e após o término da pesquisa. Espera-se como benefícios a obtenção de dados que auxiliem os profissionais de saúde na tomada de decisões, com o objetivo de minimizar os casos de infecção do sítio cirúrgico e aumentar a sobrevida dos receptores de transplante de fígado.

Forma de acompanhamento e assistência: Informamos que, por tratar-se de uma pesquisa com dados relacionados à sua saúde que já ocorreram há algum tempo, caso seja identificada a infecção do sítio cirúrgico não será necessário realizar encaminhamentos pois espera-se que o(a) senhor(a) já tenha sido tratado.

Garantia de esclarecimento, liberdade de recusa e garantia de sigilo: $O(a)$ senhor(a) será esclarecido(a) sobre a pesquisa a respeito de qualquer aspecto que desejar. $\mathrm{O}(\mathrm{a})$ senhor(a) é livre para recusar-se a participar, retirar seu consentimento ou interromper a participação a qualquer momento. A sua participação é voluntária e a recusa em participar não acarretará qualquer penalidade, perda de benefícios ou descontinuidade de sua assistência.

Rubrica do participante/responsável legal:

Rubrica do pesquisador: 
O pesquisador tratará a sua identidade com padrões profissionais de sigilo. Seu nome ou o material que indique a sua participação não será utilizado sem a sua permissão. $\mathrm{O}$ (a) senhor(a) não será identificado(a) em nenhuma publicação que possa resultar deste estudo.

Assinaturas e garantia de recebimento de uma via do TCLE: Este Termo de Consentimento Livre e Esclarecido deverá ser rubricado pelo(a) senhor(a) e por mim, nas suas duas páginas e assinado nas duas vias. $O$ (a) senhor(a) receberá uma via do Termo de Consentimento Livre e Esclarecido assinada e rubricada por mim (pesquisador).

Custos da participação, ressarcimento e indenização por eventuais danos: A participação no estudo não acarretará custos para o(a) senhor(a) e caso haja, com as devidas comprovações legais, o pesquisador acionará recursos próprios à compensação financeira. Caso a pesquisa lhe cause algum dano explicitado nos riscos ou ocorridos em razão de sua participação, seu direito de indenização será garantido, mediante comprovação legal.

Acesso ao pesquisador responsável: Em qualquer etapa do estudo, o(a) senhor(a) terá acesso ao pesquisador responsável pela investigação para esclarecimento de dúvidas.

O principal pesquisador é Ramon Antônio Oliveira, que pode ser encontrado no endereço: Escola de Enfermagem da USP - Departamento de Enfermagem Médico-cirúrgica - Av. Dr. Enéas de Carvalho Aguiar, 419 - Cerqueira Cesar - São Paulo/SP CEP - 05403-000 Telefone: (11)3061-7544 ou 9041-11-98700-1434, email: ramon.oliveira@usp.br

Assinatura do participante/responsável legal:

Assinatura do pesquisador:

Acesso ao Comitê de Ética em Pesquisa da Escola de Enfermagem da USP: Caso o(a) senhor(a) tenha alguma consideração ou dúvida sobre a ética da pesquisa, entre em contato com o Comitê de Ética em Pesquisa (CEP) - Endereço Av. Dr. Enéas de Carvalho Aguiar, 419 - Cerqueira Cesar - São Paulo/SP CEP 05403-000 Telefone- (11) 30618858 e-mail - cepee@usp.br

Esta pesquisa atende todas as especificações da Resolução 466, de 12 de dezembro de 2012 que aprova as diretrizes e normas regulamentadoras de pesquisas envolvendo seres humanos.

Local e data de de 2016 
Anexos 
ANEXOS

\section{ANEXO A - PARECER DE APROVAÇÃO DO COMITÊ DE ÉTICA EM PESQUISA}

ESCOLA DE ENFERMAGEM DA
UNIVERSIDADE DE SÃO
PAULO - EEUSP

\section{PARECER CONSUBSTANCIADO DO CEP}

\section{DADOS DO PROJETO DE PESQUISA}

Título da Pesquisa: FATORES DE RISCO PARA INFECÇÃO DO SíTIO CIRÚRGICO EM TRANSPLANTE DE FÍGADO: COORTE HISTÓRICA

Pesquisador: Ramon Antônio Oliveira

Área Temática:

Versão: 2

CAAE: 50960815.1 .0000 .5392

Instituição Proponente: Escola de Enfermagem da Universidade de São Paulo - EEUSP

Patrocinador Principal: Financiamento Próprio

\section{DADOS DO PARECER}

Número do Parecer: 1.400 .112

\section{Apresentação do Projeto:}

Propõe-se uma investigação do tipo coorte histórica em um hospital geral, municipal, terciário, referência regional em transplantes, situado no interior do Estado de São Paulo. Serão coletados dados de prontuários de pacientes adultos, submetidos ao

transplante de fígado, cujos doadores eram falecidos, realizados entre janeiro de 2009 e dezembro de 2015 . Para tanto, utilizar-se-á um instrumento, construído pelo proponente e sua orientadora, que será submetido à validação aparente e de conteúdo por especialistas na área de enfermagem perioperatória e de transplantes. Esclarece-se que para a realização do transplante o paciente deve ser submetido a uma avaliação completa da reserva hepática e de seu estado de saúde; parte dessa avaliação inclui a classificação do grau de necessidade clínica, por meio do Model of End-stage Liver Disease (MELD), que estratifica o nível da doença dos que aguardam um transplante de fígado, constituindo-se num indicador de mortalidade a curto prazo para pacientes com doença hepática terminal. Os pesquisadores convidarão os pacientes a participar da pesquisa no momento do acompanhamento clínico (retorno ambulatorial), uma vez que esses pacientes comparecem regularmente ao serviço onde foi realizado o transplante. Para aqueles em que não for possível a abordagem no serviço de saúde, os pesquisadores

Endereço: Av. Dr Enéas de Carvalho Aguiar, 419

Bairro: Cerqueira Cesar

CEP: $05.403-000$

UF: SP

Município: SAO PAULO

Telefone: (11)3061-8858

E-mail: cepee@usp.br 


\section{Ramon Antônio Oliveira}

\begin{tabular}{cc}
\hline$\equiv$ & ESCOLA DE ENFERMAGEM DA \\
UNIVERSIDADE DE SÃO & Plotoforma \\
ENFERMAGEM & PAULO - EEUSP
\end{tabular}

Continuação do Parecer: 1.400 .112

comprometem-se em encaminhar o Termo de Consentimento Livre e Esclarecido - TCLE, em duas vias, e um envelope resposta previamente preenchido e selado para o endereço do paciente. Quanto a coleta de dados relacionados ao doador, serão obtidos a partir do prontuário do receptor.

Sabe-se que a identidade do doador, em virtude dos procedimentos de manutenção do sigilo e confidencialidade, não está disponível nos prontuários dos receptores. Para análise dos dados será construído um banco de dados no software Microsft Excel for Mac 2011®, posteriormente os dados serão exportados para o software Statistical Package for the Social Sciences (SPSS) for Mac OS X 11; os resultados serão analisados com auxílio de um profissional estatístico, segundo os objetivos e metodologia proposta.

\section{Objetivo da Pesquisa:}

Objetivo Primário:

- Analisar a incidência e os fatores de risco para o desenvolvimento de infecção do sítio cirúrgico entre pacientes adultos submetidos ao transplante de fígado.

Objetivos Secundários:

- Descrever as características sócio-demográficas, clínicas, cirúrgicas e de enfermagem de pacientes submetidos a transplante de fígado no local de estudo;

- Analisar a associação entre a ocorrência de infecção do sítio cirúrgico em pacientes submetidos ao transplante de fígado e as variáveis relacionadas ao paciente como idade, sexo, índice de massa corporal, diagnóstico de indicação do transplante, escore MELD, doenças pré-existentes, tabagismo e etilismo;

- Analisar as associações entre a ocorrência de infecção do sítio cirúrgico em pacientes submetidos ao transplante de fígado e as variáveis relacionadas ao doador como idade, sexo, índice de massa corporal, diagnóstico prévio à morte encefálica e afecções de

base;

-Descrever a frequência, tempo até o diagnóstico e as implicações da infecção de sítio cirúrgico relacionada ao transplante de fígado;

- Verificar associação entre as variáveis, tempo de espera na fila do transplante e mortalidade pós operatória;

- Verificar a associação entre a infecção do sítio cirúrgico e mortalidade em 30 dias após o transplante hepático e

- Descrever os principais diagnósticos de enfermagem no período perioperatório.

Endereço: Av. Dr Enéas de Carvalho Aguiar, 419

Bairro: Cerqueira Cesar

UF: SP Município: SAO PAULO

Telefone: (11)3061-8858

CEP: $05.403-000$

E-mail: cepee@usp.br 


\section{ED. TSSP ESCOLA DE ENFERMAGEM DA

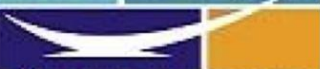 \\ UNIVERSIDADE DE SÃO PAULO - EEUSP \\ ENFERMAGEM}

Continuação do Parecer: 1.400 .112

\section{Avaliação dos Riscos e Benefícios:}

Riscos:

- Evidencia-se a possibilidade de desconforto por parte do paciente em relação ao

pesquisador tomar conhecimento da situação clínica que ocasionou a sua internação. Entretanto, assegurase a manutenção do mais amplo e absoluto sigilo sobre a identidade dos indivíduos durante e após o término da pesquisa.

Benefícios:

- Obtenção de dados que auxiliem os profissionais de saúde na tomada de decisões para minimizar os casos de infecção do sítio cirúrgico e aumentar a sobrevida dos receptores de transplante de fígado.

\section{Comentários e Considerações sobre a Pesquisa:}

De acordo com os proponentes a ocorrência de infecção do sítio cirúrgico entre pacientes submetidos ao transplante de fígado tem sido pouco explorada mundialmente e os fatores de risco para o seu desenvolvimento ainda não estão completamente compreendidos. A realização do presente estudo poderá contribuir com o avanço do conhecimento desta temática.

\section{Considerações sobre os Termos de apresentação obrigatória:}

Comentários e Considerações sobre a Pesquisa:

- O TCLE é claro, objetivo e conciso;

- Foi apresentado Termo de Consentimento assinado pelo representante legal do Hospital Campo de Estudo autorizando a realização da pesquisa;

- O cronograma de execução da pesquisa é adequado;

- Consta orçamento financeiro, do tipo custeio, totalizando $\mathrm{R} \$ 544,00$

Recomendações:

Não há.

Conclusões ou Pendências e Lista de Inadequações:

todas as solicitações acatadas.

Considerações Finais a critério do CEP:

- Este CEP informa a necessidade de registro dos resultados parciais e finais na Plataforma Brasil;

- Esta aprovação não substitui a autorização da instituição coparticipante, antes do início da coleta de dados.

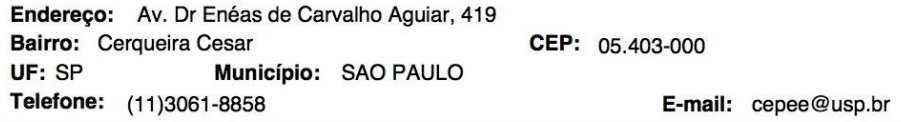




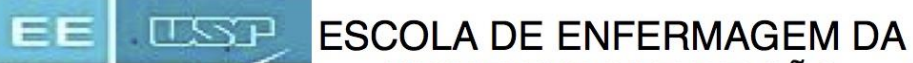 $>-1$ UNIVERSIDADE DE SÃO PAULO - EEUSP}

Continuação do Parecer: 1.400 .112

Este parecer foi elaborado baseado nos documentos abaixo relacionados:

\begin{tabular}{|c|c|c|c|c|}
\hline Tipo Documento & Arquivo & Postagem & Autor & Situação \\
\hline $\begin{array}{l}\text { Informações Básicas } \\
\text { do Projeto }\end{array}$ & $\begin{array}{l}\text { PB_INFORMAÇÕES_BÁSICAS_DO_P } \\
\text { ROJETO 620160.pdf }\end{array}$ & $\begin{array}{c}16 / 12 / 2015 \\
11: 05: 51\end{array}$ & & Aceito \\
\hline $\begin{array}{l}\text { TCLE / Termos de } \\
\text { Assentimento / } \\
\text { Justificativa de } \\
\text { Ausência }\end{array}$ & TCLE_16_12_15.docx & $\begin{array}{c}16 / 12 / 2015 \\
11: 05: 01\end{array}$ & $\begin{array}{l}\text { Ramon Antônio } \\
\text { Oliveira }\end{array}$ & Aceito \\
\hline $\begin{array}{l}\text { Projeto Detalhado / } \\
\text { Brochura } \\
\text { Investigador }\end{array}$ & Tx_Figado_16_12_15.docx & $\begin{array}{c}16 / 12 / 2015 \\
11: 04: 16\end{array}$ & $\begin{array}{l}\text { Ramon Antônio } \\
\text { Oliveira }\end{array}$ & Aceito \\
\hline Outros & ICD.docx & $\begin{array}{c}13 / 11 / 2015 \\
09: 40: 44\end{array}$ & $\begin{array}{l}\text { Ramon Antônio } \\
\text { Oliveira }\end{array}$ & Aceito \\
\hline $\begin{array}{l}\text { Declaração de } \\
\text { Instituição e } \\
\text { Infraestrutura }\end{array}$ & Autorizacao.pdf & $\begin{array}{c}07 / 11 / 2015 \\
20: 56: 03\end{array}$ & $\begin{array}{l}\text { Ramon Antônio } \\
\text { Oliveira }\end{array}$ & Aceito \\
\hline $\begin{array}{l}\text { Declaração de } \\
\text { Pesquisadores }\end{array}$ & TERMO_DE_COMPROMISSO.docx & $\begin{array}{c}07 / 11 / 2015 \\
20: 54: 30\end{array}$ & $\begin{array}{l}\text { Ramon Antônio } \\
\text { Oliveira }\end{array}$ & Aceito \\
\hline Folha de Rosto & FR.pdf & $\begin{array}{l}07 / 11 / 2015 \\
20: 49: 27\end{array}$ & $\begin{array}{l}\text { Ramon Antônio } \\
\text { Oliveira }\end{array}$ & Aceito \\
\hline
\end{tabular}

Situação do Parecer:

Aprovado

Necessita Apreciação da CONEP:

Não

SAO PAULO, 01 de Fevereiro de 2016

Assinado por:
Lisabelle Mariano Rossato
(Coordenador)

(Coordenador)

Endereço: Av. Dr Enéas de Carvalho Aguiar, 419

Bairro: Cerqueira Cesar

UF: SP Município: SAO PAULO

CEP: $05.403-000$

Telefone: (11)3061-8858 